\title{
Effect of feedrate, depth of cut, tool material, and toolpath on dimensional accuracy and surface roughness of milled CFRP
}

\author{
Assem Hesham Almadani \\ ahalmadani@mix.wvu.edu
}

Follow this and additional works at: https://researchrepository.wvu.edu/etd

Part of the Computer-Aided Engineering and Design Commons, Industrial Engineering Commons, and the Manufacturing Commons

\section{Recommended Citation}

Almadani, Assem Hesham, "Effect of feedrate, depth of cut, tool material, and toolpath on dimensional accuracy and surface roughness of milled CFRP" (2021). Graduate Theses, Dissertations, and Problem Reports. 8262.

https://researchrepository.wvu.edu/etd/8262

This Thesis is protected by copyright and/or related rights. It has been brought to you by the The Research Repository @ WVU with permission from the rights-holder(s). You are free to use this Thesis in any way that is permitted by the copyright and related rights legislation that applies to your use. For other uses you must obtain permission from the rights-holder(s) directly, unless additional rights are indicated by a Creative Commons license in the record and/ or on the work itself. This Thesis has been accepted for inclusion in WVU Graduate Theses, Dissertations, and Problem Reports collection by an authorized administrator of The Research Repository @ WVU. For more information, please contact researchrepository@mail.wvu.edu. 
Effect of feedrate, depth of cut, tool material, and toolpath on dimensional accuracy and surface roughness of milled CFRP

Assem Almadani

Thesis submitted

to the Benjamin M. Statler College of Engineering and Mineral Resources at West Virginia University

In partial fulfillment of the requirements for the degree of

Master of Science in

Industrial Engineering

\author{
Thorsten Wuest, Ph.D., Chair \\ Omar Al-Shebeeb, Ph.D. \\ Zhichao Liu, Ph.D.
}

Department of Industrial and Management Systems Engineering

\author{
Morgantown, West Virginia \\ 2021
}

Keywords: Milling, Carbon fiber reinforced, Polymer, Surface Roughness, Dimensional Accuracy

Copyright 2021 Assem Almadani 


\title{
Abstract \\ Effect of feedrate, depth of cut, tool material, and toolpath on dimensional accuracy and surface roughness of milled CFRP
}

\begin{abstract}
Assem Almadani
This thesis investigates the effect of different factors on Carbon Fiber Reinforced Polymers (CFRP) milling, like feedrate, tool material, and cutting speed. CFRP offers excellent material properties, which led to the increase of the material in today's manufacturing industry. CFRP offers up to 2.25 times steel's modulus of elasticity at about a fifth of the weight and excellent thermal properties, which allow the use of this material in applications with high heat like automobiles. Many industries have implemented the use of CFRP in their applications, like airplanes and automobiles, which lead to a decrease in weight and increase in strength. A literature review was conducted to determine the research gap, which resulted in 132 articles, of which 72 were relevant. The literature review results showed no specific machine settings were recommended, and neither was the type of material to use. Almost all reviewed articles used different tool materials and machine settings, with little work done in comparing various tools and settings regarding surface roughness and dimensional accuracy. A CNC mill was used to make slots in a CFRP workpiece using different combinations of the factors listed above. An initial experiment was conducted to determine the optimal toolpath, using Autodesk Fusion 360, that achieves the highest accuracy and lowest surface roughness. The slots were then analyzed using a profiler and a digital caliper to determine which toolpath to use for the experiment. After determining the toolpath, the factor level determination was conducted. Four different tool coatings were tested at three different levels of feedrate and depths of cut on a Tormach PCNC 1100. Multiple bits were used to reduce the effect of tool wear. Data was then collected on the slots' accuracy and surface roughness using a digital caliper and the Dektak XT Stylus profilometer, respectively. The data obtained were then analyzed in JMP to determine the optimal settings to mill CFRP. The analysis showed feedrate, tool coating, depth of cut, and their interaction effects have a significant effect on dimensional accuracy and surface roughness.
\end{abstract}




\section{Dedication}

To my parents, Hesham and Abeer, thank you for all the support and inspiration. You are my role models.

To my partner, Shereen, I would not have become what I am if it wasn't for you. I am eternally grateful.

To my family, thank you for always supporting me. 


\section{Acknowledgments}

I would like to express my deepest gratitude to my committee chair, Dr. Thorsten Wuest, for all his help and guidance.

I would like to express my deepest appreciation to my committee member, Dr. Omar AlShebeeb, for his help and support.

I would like to thank my committee member, Dr. Zhichao Liu, for his help during my master's

I am what I am because of Mr. Shanti Hamburg, I would like to thank him for taking a chance on me and help me achieve my dream. 


\section{Table of Contents}

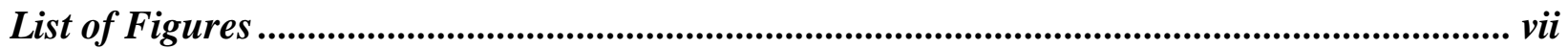

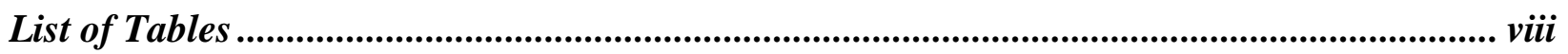

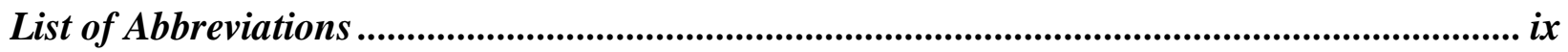

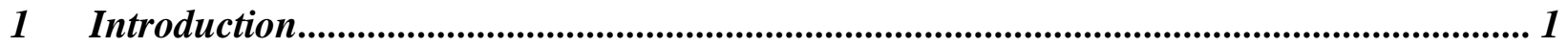

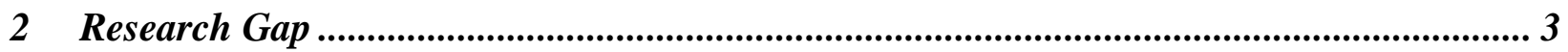

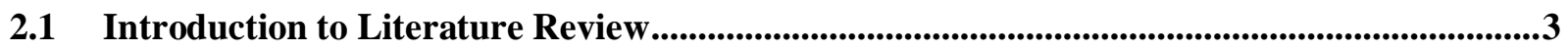

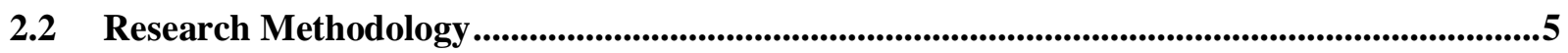

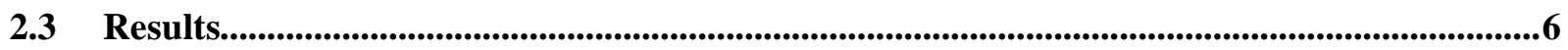

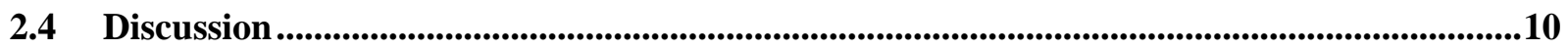

2.5 Identified Research Gap .............................................................................................................11

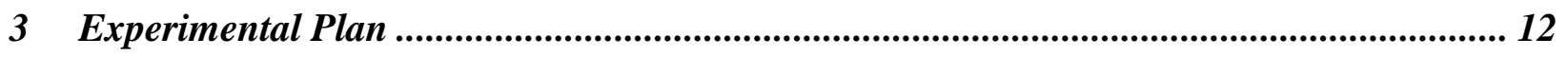

3.1 Research Objective..........................................................................................................................12

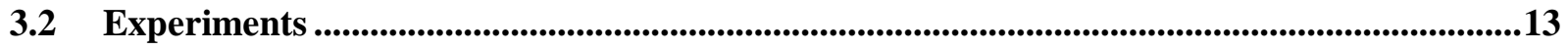

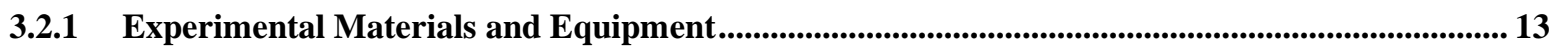

3.2.2 Toolpath Determination Setup (Pre-Experiment) ................................................................................ 17

3.2.3 Factor Level Determination Setup ................................................................................................ 18

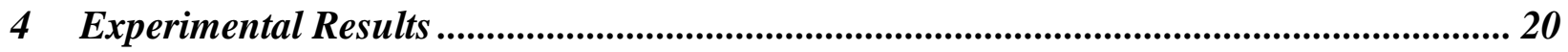

4.1 Toolpath Determination (Pre-Experiment) ......................................................................................20

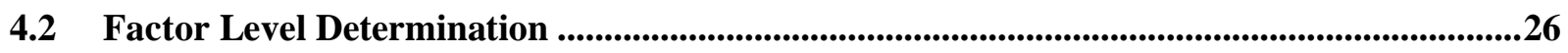

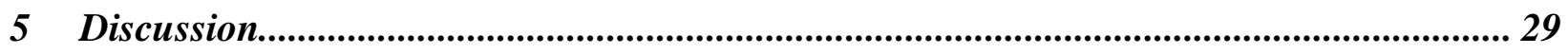

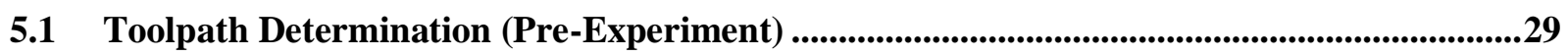

5.2 Factor Level Determination .........................................................................................................31

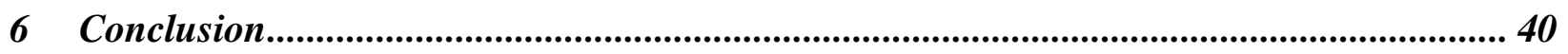

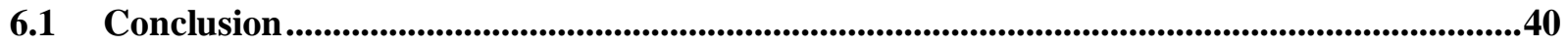

6.2 Limitations and Future Work ............................................................................................................41 
Work Cited .............................................................................................................................................. 42

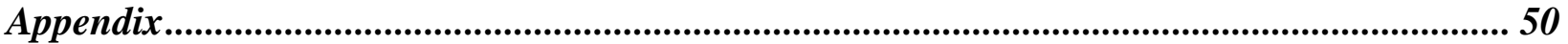

Appendix A: Tormach PCNC 1100 Software and Equipment ..............................................................50

Appendix B: Dektak XT Stylus Profilometer Software and Equipment ..............................................55

Appendix C: Data Tables......................................................................................................................58

Appendix D: Toolpath Determination JMP Output ................................................................................62

Appendix E: Factor Level Determination JMP Output ............................................................................71 


\section{List of Figures}

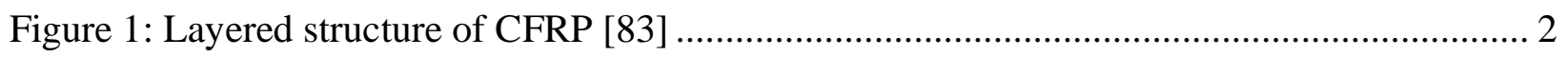

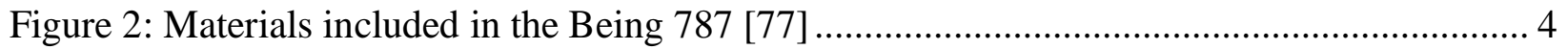

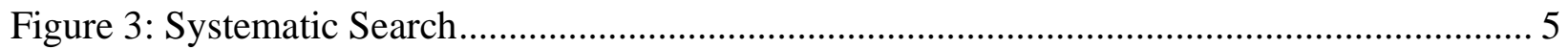

Figure 4: Tormach PCNC 1100 located in ESB G85 at WVU ............................................ 14

Figure 5: Dektak XT Stylus profilometer located in the cleanroom at WVU .......................... 15

Figure 6: Data output from Dektak profilometer................................................................. 16

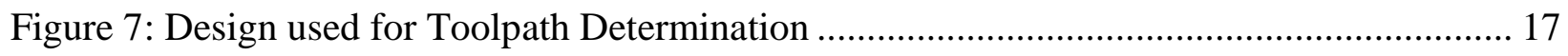

Figure 8: Design used for Factor Level Determination ........................................................ 19

Figure 9: Material removal pattern for each toolpath ...................................................... 21

Figure 10: (a) 2D Pocket. (b) 3D Pocket ............................................................................ 22

Figure 11: Example of a slot larger than two times the bit diameter ....................................... 23

Figure 12: Milled part used for toolpath determination................................................... 23

Figure 13: Surface roughness measurement location. (a) 2D Adaptive (b) 2D Contour (c) 2D

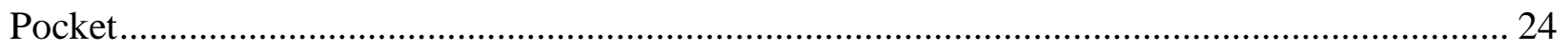

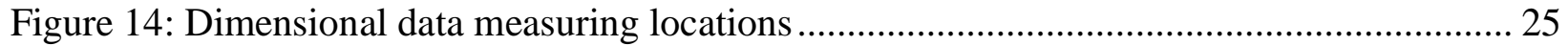

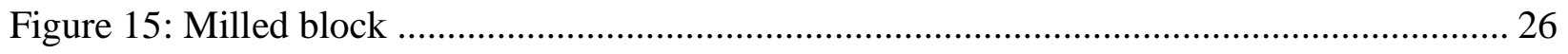

Figure 16: Surface roughness value and profile for slot 5 ............................................ 28

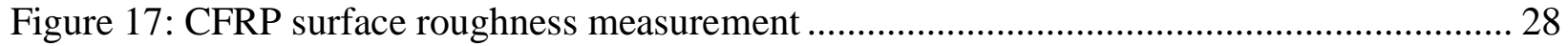

Figure 18: Peel up and push out delamination in CFRP. [84] ............................................. 31

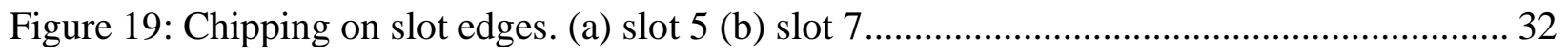

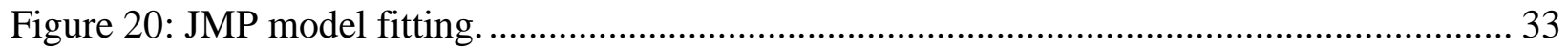

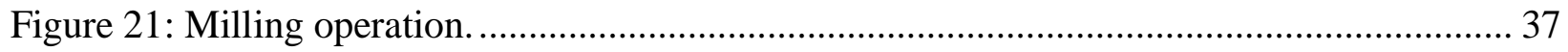

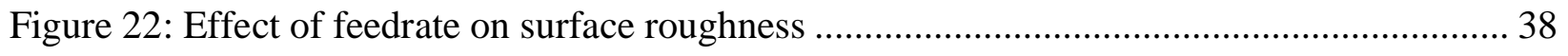

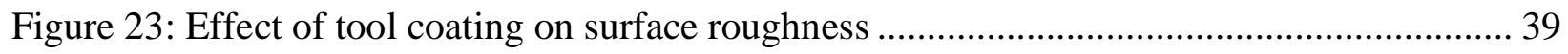

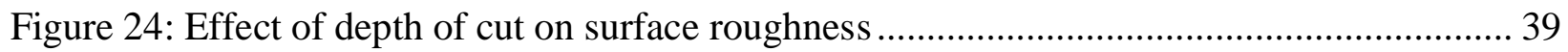




\section{List of Tables}

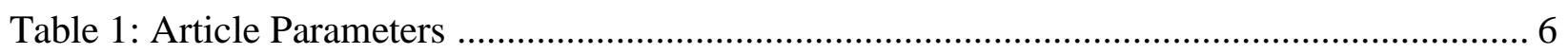

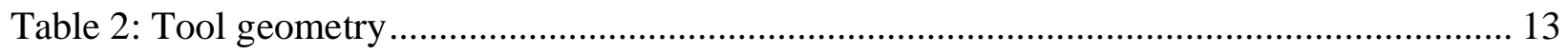

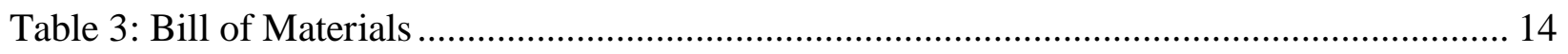

Table 4: Dektak profilometer measurement settings ............................................................ 16

Table 5: Machine Settings used for Toolpath Determination .............................................. 18

Table 6: Machine settings used for the experiment .......................................................... 19

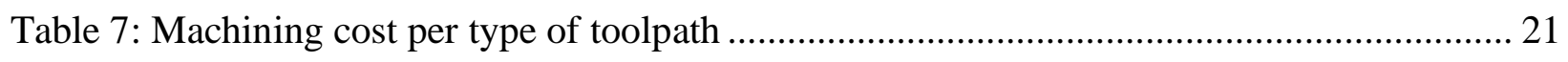

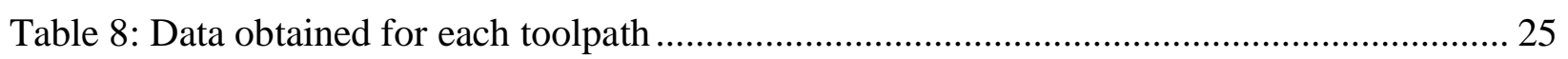

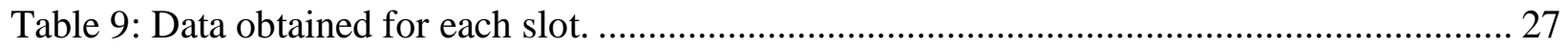

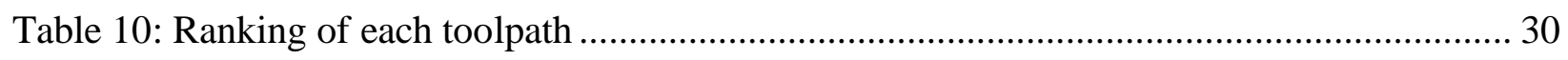

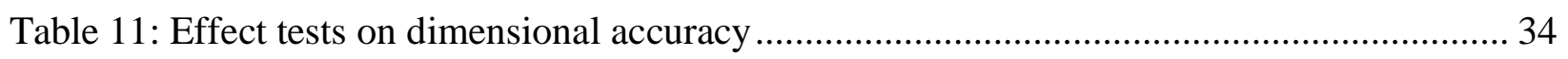

Table 12: Significant effects on dimensional accuracy ....................................................... 34

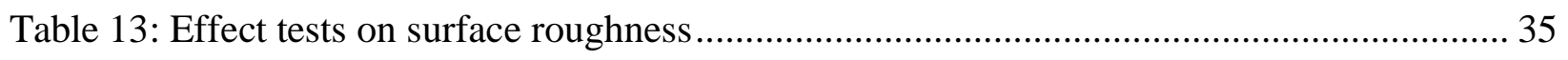

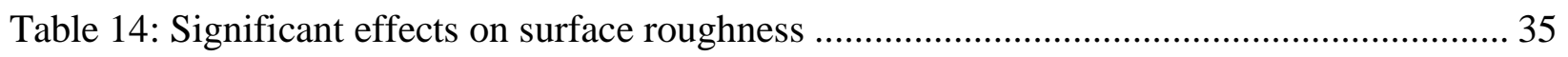




\section{List of Abbreviations}

\begin{tabular}{|l|l|}
\hline AlCrN & Aluminum Chromium Nitride \\
\hline AlTiBN & Aluminum Titanium Boron Nitride \\
\hline AlTiN & Aluminum Titanium Nitride \\
\hline Ar & Aramid \\
\hline CF & Carbon Fiber \\
\hline CFRP & Carbon Fiber Reinforced Polymer/Plastic \\
\hline CS & Case Study \\
\hline CVD & Chemical Vapor Deposition \\
\hline DIA-BNC & Diamond Coated \\
\hline DIA-HBC4 & Diamond Coated \\
\hline DLC & Diamondlike Carbon \\
\hline DoC & Depth of Cut \\
\hline EXP & Experiment \\
\hline Fr & Feedrate \\
\hline GF & Glass Fiber \\
\hline HSS & High Speed Steel \\
\hline IPM & Inches per Minute \\
\hline PCD & Polycrystalline Diamond \\
\hline RF & Reinforcement \\
\hline RMS & Root Mean Square \\
\hline RPM & Revolutions per Minute \\
\hline SiAlON & Silicon Aluminum Oxygen Nitrogen - Ceramic \\
\hline TC & Tool Coating \\
\hline Ti & Titanium \\
\hline TiAlN & Titanium Aluminum Nitride \\
\hline TiCN & Titanium Carbonitride \\
\hline TiN & Titanium Nitride \\
\hline UD & Unidirectional \\
\hline UN & UNS A97075 \\
\hline WC & Tungesten Carbide \\
\hline WoS & Web of Science \\
\hline YG6 & Tool Grade \\
\hline
\end{tabular}




\section{Introduction}

Manufacturing is an essential aspect of today's life. It plays a massive role in making our lives better by offering various products to improve it. It also has a significant effect on the economy. For every dollar spent on manufacturing, almost $\$ 1.89$ is increased in the country's economy.[82] Although there are various manufacturing processes, CNC machining allows low costs at low volumes, a good surface finish, and a tight tolerance.

Tolerance is a crucial aspect when making a product. The majority of manufactured parts are used as parts in other mechanisms or are interchangeable, requiring accurate dimensions to an extent. Therefore, ensuring that the manufacturing process leads to the lowest tolerance possible is vital in ensuring all parts fit correctly. Surface Roughness is another critical aspect of manufacturing. In some cases, surface roughness is vital to the use of a specific product. For example, in cars and airplanes, surface roughness can affect the vehicle's aerodynamics by increasing drag, requiring a smooth surface.

Carbon Fiber Reinforced Polymers (CFRP) are among the most known composites in the manufacturing industry for their high strength to weight ratio. CFRP is about a fifth the weight of steel and up to 2.5 times stronger. However, shown in the literature review, no settings and tool materials are recommended to be used. The articles found in the search show a large range of materials, feedrate, and cutting speeds used. The purpose of this thesis is to narrow down that range and show the most suitable settings and materials for successful machining. CFRP is made by adding carbon fiber laminates between layers of plastic and binding them together, as shown in Figure 1. It is being used in more and more machines around us like airplanes and Formula 1 race cars. Both Boeing and Airbus designed and built planes comprised of $50 \%$ composites, with carbon fiber being the most used.[73][77] CFRP is the addition of carbon fiber to plastic to increase its strength. The use of CFRP led to a huge reduction in airplanes' and vehicles' weight, which leads to a reduction in fuel costs. The use of composites will increase in the future as we understand more and more about how to manufacture them. 
CFRP offers superior material properties compared to other traditional materials used like aluminum and steel. CFRP is considerably stronger than steel while only being about a fifth of the weight. The literature review clearly shows a gap in how to mill CFRP successfully. This proposal examines the recommended settings and tool materials for the highest accuracy and the lowest surface roughness. An experimental plan is also shown below, showing how the data will be interpreted and how the recommendation will be decided upon.

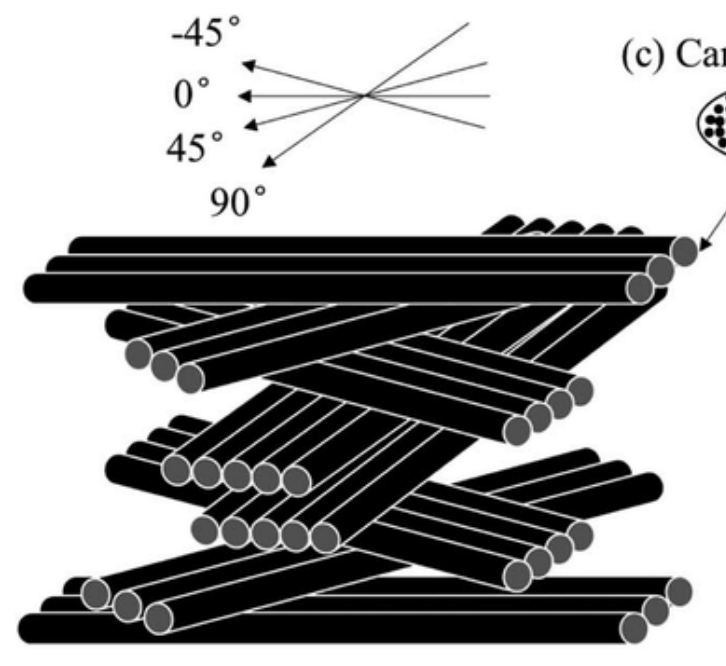

(a) E-CFRP (c) Carbon fiber bundle

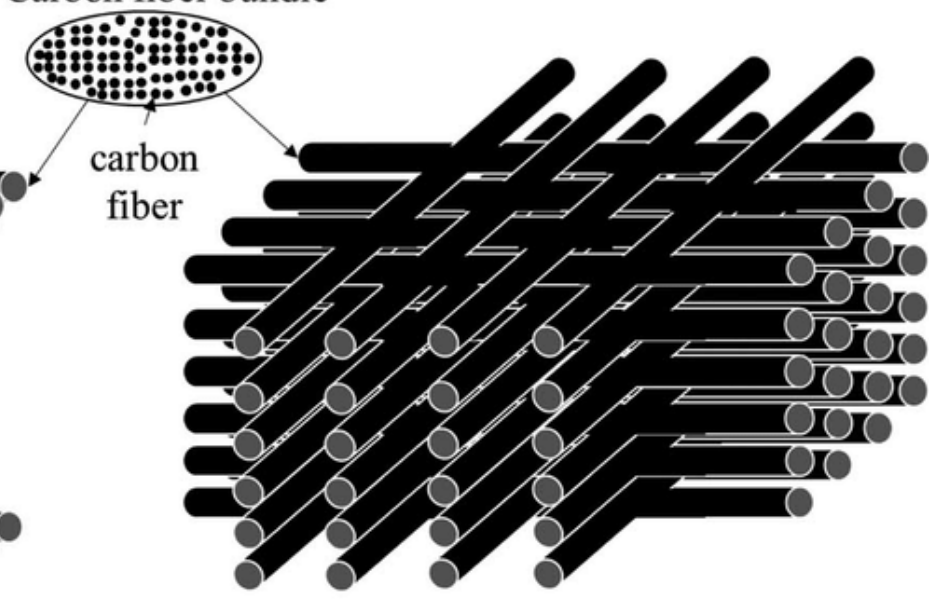

(b) T-CFRP

Figure 1: Layered structure of CFRP [83] 


\section{Research Gap}

\subsection{Introduction to Literature Review}

The manufacturing industry is moving rapidly towards more intelligent and more advanced processes. This includes smarter, more data-driven, and sensor-based insights on the one hand, and advances in both processing technologies, e.g., additive manufacturing, and advanced materials, such as composites. An area where these advances of processing technology and materials interject is the processing of carbon fiber reinforced polymers (CFRP). These materials offer distinct advantages over traditional materials.

Carbon fiber has a high strength-to-weight ratio, a 20 percent weight reduction compared to steel.[76] On the other hand, as a material that possesses unidirectional properties and is anisotropic, they also present distinct challenges for the design and manufacturing engineer, such as degradation of the matrix due to heat, the fibers fracturing instead of being cut, and increased tool wear.[74][75]

$\mathrm{CNC}$ milling is one of the most used subtractive manufacturing processes. CNC milling is generally more economical when it comes to low quantity production than injection molding and other high-throughput processes. One of the many advantages of CNC milling is the ability to process CFRP parts. As mentioned before, CFRP parts are comparably durable and have many uses in the aerospace and automotive industries, among many others. CFRP is generally more expensive to process; however, this is acceptable given its superior strength and lightweight properties. According to Airbus, more than 50\% of the A350 XWB model is CFRP.[73] CFRP is used for functional parts of the airplane, which allows it to carry more passengers and burn less fuel while being lighter, as shown in Figure 2. CFRP is also used in a lot of Formula 1's vehicles.[75] 


\section{$10 \%$ Steel (primarily landing gear)}

$15 \%$

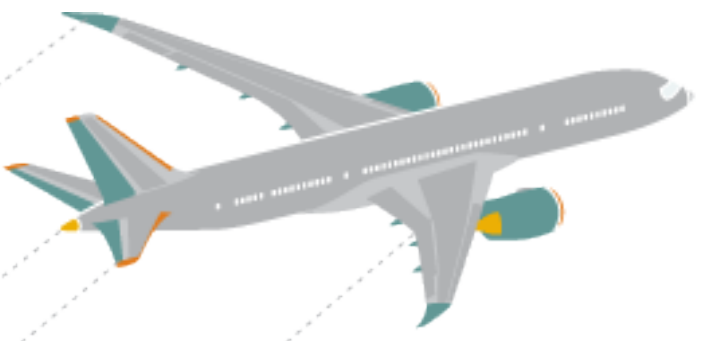

$20 \%$ Aluminum

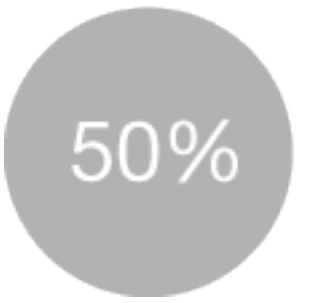

Advanced Composites

HOW COMPOSITE SOLUTIONS ARE APPLIED THROUGHOUT THE 787

Figure 2: Materials included in the Being 787 [77]

The same properties that make CFRP material the desired choice for selected applications, e.g., its increased strength, present a challenge for processing a $\mathrm{CNC}$ milling center. In addition, as an anisotropic material, the machining process must be carefully planned to avoid costly and dangerous quality problems during the manufacturing process. Therefore, setting the correct machine settings and parameters is crucial to successfully mill CFRP with minimal scrap and quality issues.

In this paper, we investigate the state of the art of CNC milling of CFRP to identify standard parameters and drivers that impact the process quality. Quality in this paper is defined as surface roughness and dimensional accuracy. Thus, this paper's overall research question is: What key parameters affect CFRP parts' quality during CNC machining?

The paper is structured as follows: Subsection 2.2 covers the research methodology, specifically the search string and the results. Followed by subsection 2.3 that shows the results obtained from the articles found in the search. subsection 2.4 discusses and compares the results of all reviewed articles. Finally, subsection 2.5 concludes the literature review by answering the research question and recommending future research areas. 


\subsection{Research Methodology}

At the core of our literature review, we conducted a systematic search in the most prominent databases, compendex and WoS. The search query used keywords relevant to the research question on June 3rd, 2020, and filters were applied to ensure the returned article's scope fits the manufacturing domain. The initial search yielded 132 records, from which only 72 were relevant and available. The search string was: (milling OR Machining) AND ("Carbon fiber reinforced" OR "carbon fibre reinforced" OR "carbon-fiber reinforced" OR "carbon-fibre reinforced") AND polymer AND quality. The following filters were used: i) limit articles to the years 2009-present (June 3rd, 2020), ii) English language, iii) journal articles. Furthermore, we removed duplicates using compendex as the preferred database since most articles were available through compendex.

All records found in the initial search were screened to ensure they used the correct manufacturing process and focused mainly on the effect of machining on quality. Fifty articles were excluded by reading through titles and abstracts due to using a different manufacturing process than CNC milling. After reading all 73 available articles, one was excluded due to using a different process than $\mathrm{CNC}$ milling that was not specified in the title and abstract. The search breakdown is shown in Figure 3.

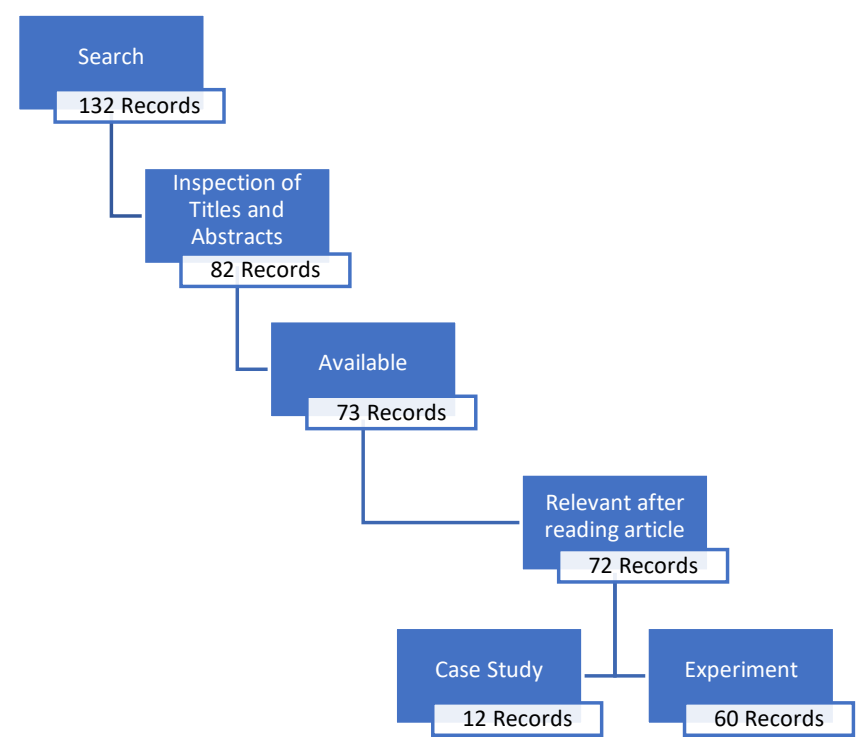

Figure 3: Systematic Search 


\subsection{Results}

The objective of the results is to determine the factors that affect the quality of machined CFRP. The results reached by the articles found in the search are shown in this section in Table 1, and then each of the factors that affect CFRP quality is shown with how many articles concluded the same result.

Table 1: Article Parameters

\begin{tabular}{|c|c|c|c|c|c|c|c|c|}
\hline$\#$ & RF & $\begin{array}{l}\text { Fiber } \\
\text { Wgt }\end{array}$ & Fiber Placement & \# Layers & $\begin{array}{l}\text { Workpiece } \\
\text { Thickness } \\
(\mathrm{mm})\end{array}$ & $\begin{array}{l}\text { Layer } \\
\text { Thickness } \\
(\mathrm{mm})\end{array}$ & $\begin{array}{l}\text { EXP or } \\
\text { CS }\end{array}$ & Tool \\
\hline 1 & $\mathrm{CF}$ & $70 \%$ & & & 10 & & EXP & $\begin{array}{l}\text { TiA1n coated solid carbide } \\
\text { drill }\end{array}$ \\
\hline 2 & $\mathrm{CF}$ & & $0 / 90$ & & 10 & & EXP & $\begin{array}{l}\text { TiA1n coated solid carbide } \\
\text { drill }\end{array}$ \\
\hline 3 & $\begin{array}{l}\text { CF } \\
\text { and } \\
\text { GF }\end{array}$ & & bidirectional & & & & EXP & multiple \\
\hline 4 & $\mathrm{CF}$ & & $\begin{array}{l}{[((0,90) /(+45,-45)) 3 /} \\
(0,90)]\end{array}$ & 14 & 3 & 0.2143 & EXP & $\begin{array}{l}\text { DIA-BNC (burr style) and } \\
\text { DIA-HBC4 (herringbone } \\
\text { style) diamond-coated } \\
\text { carbide tools }\end{array}$ \\
\hline 5 & $\mathrm{CF}$ & & $\begin{array}{l}\text { UD-(+-45,0, +-45,90, +- } \\
45,0,-45,90,45,90)\end{array}$ & 26 & 5 & 0.1923 & EXP & tungsten carbide \\
\hline 6 & $\mathrm{CF}$ & & $\begin{array}{l}\text { UD- varying from 0-180 } \\
\text { in } 15 \text { increments }\end{array}$ & & 5 & & EXP & carbide YG6 \\
\hline 7 & $\mathrm{CF}$ & & $\begin{array}{l}\text { UD-25\% each } 0,- \\
45,45,90 \text { and another } \\
\text { with 50\% } 0\end{array}$ & & 4 and 5 & & EXP & \\
\hline 8 & $\mathrm{CF}$ & $59 \%$ & UD-0/90/45/-45 & & 10 & 0.14 & EXP & SiA1ON ceramic drills \\
\hline 11 & $\mathrm{CF}$ & $55 \%$ & UD- $0 / 90$ & 12 & 3 & 0.25 & EXP & twist drill \\
\hline 12 & $\mathrm{CF}$ & $60 \%$ & {$[-45 / 45]$} & & 5 & & EXP & $\begin{array}{l}\text { TiAlN-coated cemented } \\
\text { carbide tool }\end{array}$ \\
\hline 13 & $\mathrm{CF}$ & $44.71 \%$ & & & & & $\mathrm{CS}$ & \\
\hline 14 & $\mathrm{CF}$ & & $\begin{array}{l}\text { woven at } 0 \text { and second } \\
\text { UD [45/45/0/90 }\end{array}$ & 10 and 24 & 2.2 and 3 & $\begin{array}{l}0.22 \text { and } \\
0.125 \\
\end{array}$ & EXP & \\
\hline 15 & $\mathrm{CF}$ & $44.71 \%$ & & 10 & 2.2 & 0.22 & EXP & Uncoated helicoidal carbide \\
\hline 16 & $\begin{array}{l}\text { CF } \\
\text { and } \\
\text { UN }\end{array}$ & $66 \%$ & UD-0/90/45/-45/45/-45 & & 4.5 and 4.86 & & EXP & \\
\hline 17 & $\mathrm{CF}$ & $\begin{array}{l}40 \% \\
\text { and } \\
17.5 \% \\
\end{array}$ & & & 5 & & EXP & \\
\hline 18 & & & UD- 0,90 & 32 & 4.224 & 0.132 & $\mathrm{CS}$ & \\
\hline 19 & $\mathrm{CF}$ & & UD-0/45/90/-45 & & 6 & & EXP & $\begin{array}{l}\text { diamond coated and uncoated } \\
\text { UDX twist drill }\end{array}$ \\
\hline 20 & $\mathrm{CF}$ & & UD & & & & $\mathrm{CS}$ & \\
\hline 21 & $\mathrm{CF}$ & & UD & 55 & 25 & 0.4545 & EXP & $\begin{array}{l}\text { seco sd205A-11.138-53- } \\
12 \text { r1-c1 special twist drill and } \\
\text { tivoly } 82366511000 \text { end mill }\end{array}$ \\
\hline 22 & $\mathrm{CF}$ & & $45 / 45 / 90 / 90 / 45 / 45 / 0 / 45$ & 100 & 18.2 & 0.182 & EXP & $\begin{array}{l}\text { Sandvik corodrill R846 twist } \\
\text { drill }\end{array}$ \\
\hline 23 & $\mathrm{CF}$ & $58 \%$ & UD-0/45/90/-45 & & 4 & & EXP & carbide step drills \\
\hline
\end{tabular}




\begin{tabular}{|c|c|c|c|c|c|c|c|c|}
\hline 24 & $\mathrm{CF}$ & & $\begin{array}{l}\text { Woven } 0 / 90 \text { tested at } 0 \text {, } \\
-45,45,90\end{array}$ & 8 & 4 & 0.5 & EXP & AlCrN-coated and HSS drills \\
\hline 25 & $\begin{array}{l}\mathrm{CF} \\
\text { and } \\
\mathrm{Ti}\end{array}$ & $59 \%$ & UD-90, $-45,0,45$ & 80 & 20 & 0.26 & EXP & AlTiN coated WC drills \\
\hline 27 & $\mathrm{CF}$ & $65 \%$ & $\begin{array}{l}\text { UD- }[0 / 0 / 0 / \\
(135 / 0 / 45 / 90 \\
\end{array}$ & 24 & 3 & 0.125 & EXP & \\
\hline 28 & $\mathrm{CF}$ & $60 \%$ & bidirectional & 32 & 8 & 0.25 & EXP & \\
\hline 29 & $\mathrm{CF}$ & $59 \%$ & UD-0/45/90/135 & 78 & 15 & 0.1923 & EXP & diamond coated carbide \\
\hline 30 & $\mathrm{CF}$ & & UD- 0 and 45 & & & & EXP & $\begin{array}{l}\text { polycrystalline diamond } \\
\text { (PCD) }\end{array}$ \\
\hline 33 & $\mathrm{CF}$ & $60 \%$ & woven & 8 & 2 & 0.25 & EXP & \\
\hline 34 & $\mathrm{CF}$ & $55 \%$ & $\begin{array}{l}\text { woven- }[(0,90) /(30,60) / \\
(30,60) /(0,90) / /(90,0) / \\
(60,30) /(60,30) /(90,0)]\end{array}$ & & 4 & & EXP & AlTiN-coated solid carbide \\
\hline 35 & $\mathrm{CF}$ & & UD-0 & 40 & 5 & 0.125 & EXP & tungsten carbide \\
\hline 36 & & & UD-0 & 40 & 5 & 0.125 & EXP & \\
\hline 37 & $\mathrm{CF}$ & $51 \%$ & & 32 & 4 & 0.125 & EXP & WC tungsten carbide \\
\hline 38 & $\mathrm{CF}$ & $60 \%$ & $\begin{array}{l}\text { weave } 0 / 90 \text { and } 45 /-45 \\
\text { thickness }(25 \mathrm{~mm}) \text { and } \\
\text { symmetric- } 10 \text { ply's } 0 /- \\
45 / 90 / 45 / 0 \text { and } \\
\text { symmetric } 20 \text { ply's } \\
0 / 45 / 90 / 45 / 0\end{array}$ & & & & EXP & \\
\hline 40 & $\mathrm{CF}$ & $60 \%$ & UD & 40 & 5 & 0.125 & EXP & PCD end mills \\
\hline 41 & $\mathrm{CF}$ & & UD & & & & EXP & \\
\hline 42 & $\mathrm{CF}$ & $59 \%$ & $\begin{array}{l}\text { UD-90/-45/0/45/90/- } \\
45 / 0 / 45\end{array}$ & 16 & 4.16 & 0.26 & EXP & tungsten carbide \\
\hline 43 & & $60 \%$ & UD & & 4.9 & & EXP & \\
\hline 45 & $\mathrm{CF}$ & $65 \%$ & UD & & 6 & & EXP & \\
\hline 46 & & & Woven & 35 & 6.35 & 0.1814 & EXP & \\
\hline 47 & $\mathrm{CF}$ & & MD-plain weave & 10 & 2.5 & 0.25 & EXP & burr router bit \\
\hline 48 & & & UD & & 4 & & EXP & \\
\hline 49 & $\begin{array}{l}\mathrm{CF} \\
\text { and } \\
\mathrm{Ar}\end{array}$ & $65 \%$ & $\begin{array}{l}\mathrm{UD}-0^{\circ}, 45^{\circ}, 90^{\circ} \text { and } \\
135^{\circ}\end{array}$ & & & & CS & \\
\hline 51 & $\mathrm{CF}$ & $64 \%$ & $\begin{array}{l}\text { UD-90, }-45,45,0,45,- \\
45,45,-45,0,-45,45,90\end{array}$ & 24 & 4.44 & 0.185 & EXP & CVD diamond coated carbide \\
\hline 52 & $\mathrm{CF}$ & $64 \%$ & $\begin{array}{l}{\left[90^{\circ},-45^{\circ}, 45^{\circ}, 0^{\circ}, 45^{\circ},\right.} \\
-45^{\circ}, 45^{\circ},-45^{\circ}, 0^{\circ}, \\
\left.-45^{\circ}, 45^{\circ}, 90^{\circ}\right]\end{array}$ & 24 & 4.44 & 0.185 & EXP & $\begin{array}{l}\text { CVD diamond-coated carbide } \\
\text { tool with six straight flutes }\end{array}$ \\
\hline 53 & $\mathrm{CF}$ & & $\begin{array}{l}\text { UD- } \\
{\left[0^{\circ} / 90^{\circ} / 45^{\circ} / 90^{\circ} / 45^{\circ} / 90^{\circ} /\right.} \\
-45^{\circ} / 90^{\circ} / 45^{\circ} / 90^{\circ} /- \\
\left.45^{\circ} / 90^{\circ} / 0^{\circ}\right]\end{array}$ & 114 & 25.4 & 0.22 & EXP & 2-flute tungsten carbide \\
\hline 54 & $\mathrm{CF}$ & $60 \%$ & $0 / 90 / 45 /-45$ & & 5 & & EXP & \\
\hline 56 & $\mathrm{CF}$ & $65 \%$ & $\begin{array}{l}\text { UD sperate- } \\
0,30,60,90,120,150\end{array}$ & & 6.75 & & EXP & uncoated tungsten carbide \\
\hline 57 & $\mathrm{CF}$ & & UD- 0 to 180 & 40 & 5 & 0.125 & EXP & $\begin{array}{l}\text { Polycrystalline diamond } \\
\text { (PCD) end mills }\end{array}$ \\
\hline 58 & $\mathrm{CF}$ & $60 \%$ & UD-0 & 40 & 5 & 0.125 & EXP & $\begin{array}{l}\text { polycrystalline diamond } \\
\text { (PCD) end mills }\end{array}$ \\
\hline 60 & $\mathrm{CF}$ & & {$[0 / 90]$} & 16 & 2 & 0.125 & EXP & $\begin{array}{l}\text { three flute solid carbide } \\
\text { milling tool with nano-copper } \\
\text { coating }\end{array}$ \\
\hline 61 & $\mathrm{CF}$ & & UD- $[0 / 90]$ & 16 & 3.1 & 0.1938 & EXP & $\begin{array}{l}\text { polycrystalline diamond } \\
\text { (PCD) }\end{array}$ \\
\hline
\end{tabular}




\begin{tabular}{|c|c|c|c|c|c|c|c|c|}
\hline 63 & $\mathrm{CF}$ & & $\begin{array}{l}\text { UD-0 and MD- } \\
45 / 135 / 090\end{array}$ & & 10 & & EXP & four-blade carbide \\
\hline 64 & $\mathrm{CF}$ & & UD-0 & & 10 & & EXP & $\begin{array}{l}\text { four-blade special solid } \\
\text { carbide }\end{array}$ \\
\hline 65 & $\mathrm{CF}$ & & UD- $[45 / 0 /-45 / 90]$ & 48 & 6 & 0.125 & EXP & twist drill \\
\hline 67 & $\mathrm{CF}$ & & & & 4.5 & & EXP & PCD double peek angle \\
\hline 68 & $\mathrm{CF}$ & $65 \%$ & $45 / 90 /-45 / 0$ & 48 & 9.16 & 0.1908 & EXP & $\begin{array}{l}\text { CVD diamond-coated brad } \\
\text { spur drill and uncoated } \\
\text { tungsten carbide twist drill } \\
\text { and uncoated solid carbide } \\
\text { dagger drill }\end{array}$ \\
\hline 70 & $\mathrm{CF}$ & & Woven-0/90 & 40 & 10 & 0.25 & EXP & $\begin{array}{l}\text { WC, TiAlN coated, and } \\
\text { diamond coated }\end{array}$ \\
\hline 71 & $\mathrm{CF}$ & & $0 / 45$ & & & & $\mathrm{CS}$ & \\
\hline 72 & & & BD- $0 / 90$ and UD & 35 & 5 and 4.5 & 0.14 & EXP & \\
\hline
\end{tabular}

* 9,10,26,31,32,39,44,50,55,59,62,66,69 were removed from table for not providing enough parameters. Abbreviations are shown in List of Abbreviations.

As shown from the search, more than $80 \%$ of the articles written about the topic are experiments. The initial comparison was made to compare the workpiece used in each experiment, focusing mainly on the fiber orientation, fiber volume, number of layers, layer thickness, and tool used. The layer thickness varied between articles but was always between $0.125 \mathrm{~mm}$ and $0.5 \mathrm{~mm}$ per layer. Out of the 72 articles found, ten articles used a $0.125 \mathrm{~mm}$ layer thickness, and 5 used a $0.25 \mathrm{~mm}$ layer thickness. The remaining articles used a layer thickness between $0.132 \mathrm{~mm}$ and $0.5 \mathrm{~mm}$. The most used layer thicknesses used for experiments were $0.125 \mathrm{~mm}$ and $0.25 \mathrm{~mm}$. The number of layers used was usually between 14 and 48 layers. The maximum was 144 and a minimum of 8 layers. 6 articles set up their workpiece with 40 layers, from which 5 had a workpiece thickness of $5 \mathrm{~mm}$ and a layer thickness of 0.125 . The table shows that setup was the most used one. The workpiece thickness was between $2 \mathrm{~mm}$ and $25.4 \mathrm{~mm}$, where the typical thickness was on the lower end of that range, around 4 to $6 \mathrm{~mm}$.

Another critical aspect is the fiber orientation, which is almost consistent across all the articles. Out of the 72 articles, only 53 documented the fiber placement. Out of those, 46 articles placed them in a unidirectional orientation, with each layer at a different angle. The angle placement is also consistent and is set at 0, 45, 90, and -45 degrees and then repeated for the number of layers used. Seven of the remaining articles chose a woven fiber placement at 0 and 90 degrees. 
The fiber volume for all reported workpieces was between $40 \%-70 \%$, except for one article that tested a workpiece at $17.5 \%$ in addition to the $40 \%$. The average percentage of fiber volume used and the most common is $60 \%$. There was no standard tool used in all the articles; however, five used diamond coated, 4 used tungsten carbide, and 6 used polycrystalline diamond (PCD) bits.

Two articles set up their experiment with multiple passes to reduce delamination in the workpiece. The first article made a small diameter hole first, and then the second cut was set to the required diameter hole, which avoided the damages done from the first cut. The second article used the same concept but in terms of depth of cut, not hole diameter. A comparison was made between a single pass with a depth of cut of $100 \mu \mathrm{m}$ and multiple passes (two passes) with each depth of cut of $50 \mu \mathrm{m}$. Using the multiple pass method reduced the breakage length by $56.42 \%$ compared to the single-pass method. Another article compared single-step drilling to peck drilling and showed that single-step is better.

Four articles studied the effect of temperature on delamination and quality. Three of those studied the direct effect of heat on the workpiece, and the fourth studied the effect of heat on the drill, which causes tool wear, leading to lower surface roughness and higher delamination. Out of the 72 articles, only one article suggested a lower cutting speed and a larger depth of cut to increase surface quality.

Another setup used was cutting at different angles. One article tested their workpiece by performing inclination milling, and another tried cutting with an angle to the fiber orientation.

Another article gave conflicting results by showing that increasing the depth of cut leads to higher delamination, contradicting a previous article that suggested a higher depth of cut. This article also examines the effect of fiber orientation and rake angle on cutting force and delamination. Also, only one article used helical milling for hole making and suggested that optimum parameters were reached. 


\subsection{Discussion}

For CNC milling, drilling into carbon-reinforced laminates increases tool wear, which tends to damage the workpiece. Throughout the articles included in the literature review, several different types of cutting tools (bits) were used to determine which is best suited to decrease delamination and tool wear. Multiple experiments showed that diamond-coated carbide bits reduce tool wear and increase surface quality, corroborated by a website on the challenges of CFRP and how to machine it successfully.[74]

Another critical factor for the good surface quality of milled CFRP parts is fiber placement. The results suggest that woven fiber placement leads to reduced delamination due to the fibers overlapping one another. Most of the experiments are set up with unidirectional fiber placement in which each layer is placed at a single angle of $0,45,90$, and -45 . This eliminates push-out delamination since each layer is not overlapping, and the angle placement increases strength. However, fiber placement affects cutting forces significantly due to the angle of contact.

To increase surface quality and reduce delamination, machine settings were set up to increase cutting speed and reduce feedrate. Reducing the feedrate also lowered the cutting forces. This, in turn, reduced tool wear and lead to better surface quality. Tool wear leads to uncut fibers, poor hole quality, and surface quality. The heat generated from contact between the tool and the workpiece leads to increased tool wear, and higher thrust forces both tend to increase delamination issues. Both feedrate and cutting speed influence heat generation during CNC milling of CFRP processing significantly. Although all reviewed articles except one [61] agree that a lower feedrate and higher cutting speed increase quality, a very high cutting speed would increase heat generation where the CFRP temperature would reach glass transition temperature and deform the material, leading to poor surface roughness.

Sharizal et al. compared single-step and peck drilling concluded that single-step drilling was more feasible due to the decrease in the time it takes to drill, and it reduced delamination by reducing exit delamination from peck drilling where the drill had to exit and enter multiple times.[53] 


\subsection{Identified Research Gap}

The primary purpose of this article is to find the influencing factors for the quality of machined CFRP. The initial search conducted resulted in 132 articles, of which only 72 articles were available and relevant. The articles found in the search concluded that those factors are layer height, fiber placement, fiber weight, and machine settings.

There are many different setups to increase the quality of milling carbon fiber reinforced polymers; however, from the search done, it is shown that most experiments were set up with an $0.125 \mathrm{~mm}$ fiber layer thickness, $5 \mathrm{~mm}$ workpiece thickness, $60 \%$ fiber volume, and either a diamond-coated carbide drill, tungsten carbide drill or PCD (polycrystalline diamond) drill. Another one of the key factors to good quality is machine settings.

Future work could be narrowing the settings to near-optimal in terms of tool used, machine settings, workpiece properties, and toolpath. An experiment could be set up to compare different tool materials and their effect on CFRP quality. Other factors that could be included are depth of cut, feedrate, and toolpath type. None of the articles found in the search compared tool materials or investigated the effect of different toolpaths on dimensional accuracy and surface roughness. Also, only a few articles included depth of cut as a factor in their experiment; however, they did not truly show which is most suitable for milling CFRP. 


\section{Experimental Plan}

\subsection{Research Objective}

This experiment's research goal is to determine optimal feedrates, tool coatings, and depths of cut to achieve lower surface delamination and higher dimensional accuracy in milling carbon-reinforced polymers by milling multiple slots using different combinations of the factors listed above and determining which are significant and which level is more suitable. The literature review (see section 2) concluded that machine settings, fiber weight, fiber orientation, and layer thickness were the most significant factors affecting milled CFRP surface roughness and dimensional accuracy. However, it also showed that little work is available investigating which specific feedrate, tool coating, or depth of cut has a higher effect on CFRP. In addition, little work has been done to investigate the impact of the toolpath type on those aspects. For this thesis, Autodesk Fusion 360 was used to design and generate the milling toolpath. Fusion 360 offers multiple toolpath types that allow better milling results depending on the design. However, numerous toolpaths available for slots, and none of the reviewed articles show which is more suitable. The toolpaths available have different cutting patterns, affecting the operation's surface quality, accuracy, and cost. The research objective of this thesis is to address this research gap.

The research approach to address this research gap aims at testing different tool coatings, feedrate, and depths of cut combinations to determine the optimal combination to achieve the highest surface quality and lowest delamination for CFRP composites. An initial experiment was conducted to determine the toolpath that leads to the lowest surface roughness and highest dimensional accuracy. For the factor level determination, four different tool coatings (Diamond, Diamondlike Carbon, TiCN, and TiN and TiAlN) will be used with varying feedrates (0.03, 0.1, and $0.15 \mathrm{~mm} / \mathrm{rev})$ and depths of cut $(0.05,0.075$, and $0.15 \mathrm{in})$. The cutting speed is constant at 4500 RPM for all runs. A full factorial design with three replications was used to demonstrate the settings that lead to better results. The milled slots were then measured for dimensional accuracy and surface roughness using a digital caliper and mechanical profiler. After collecting all relevant data, a JMP analysis was conducted to indicate the significant factors that affect the two aspects this thesis focuses on, dimensional accuracy and surface roughness. 


\subsection{Experiments}

\subsubsection{Experimental Materials and Equipment}

The workpiece used in this experiment was a $24 \times 2 \times 0.5$ in block of CFRP composite. The fiber volume of the block was $53 \%$ with 0 and 90 -degree alternating plies of unidirectional fibers. The layer thickness was 0.0066 in, and the surface layers are woven with $3 \mathrm{~K}$ plain weave carbon fiber fabric. This is a standard block obtained from McMaster CARR and conforms to the needed parameters. The initial experiment (see section 3.2.2) performed to determine the suitable toolpath to be used was done using a 2x2 in block and 1/8 in AlTiBN square end mill cutting bits.

The remainder of the workpiece was cut into $2 \times 2$ in blocks and used for the factor level determination (see section 3.2.3). The tools used in this experiment are all 1/8 in carbide square end mills with different coatings. The four coatings used in this experiment are shown in Table 2 below. The bill of materials is shown in Table 3 .

Table 2: Tool geometry

\begin{tabular}{|c|c|c|c|c|}
\hline Tool Coating & $\begin{array}{c}\text { Diameter } \\
\text { (in) }\end{array}$ & \# Flutes & $\begin{array}{c}\text { Length } \\
\text { (in) }\end{array}$ & $\begin{array}{c}\text { Flute Length } \\
\text { (in) }\end{array}$ \\
\hline Diamond & 0.125 & 4 & 1.5 & 0.5 \\
\hline Titanium Carbonitride & 0.125 & 3 & 1.5 & 0.25 \\
\hline Diamondlike Carbon & 0.125 & 4 & 1.5 & 0.625 \\
\hline $\begin{array}{c}\text { Titanium Nitride and } \\
\text { Titanium Aluminum Nitride }\end{array}$ & 0.125 & 4 & 2 & 0.375 \\
\hline
\end{tabular}




\begin{tabular}{|c|c|c|}
\hline Part & Quantity & Part \# \\
\hline Diamond Coated & 3 & 3725A141 \\
\hline TiCN & 3 & 8829A62 \\
\hline DLC & 3 & 4119A15 \\
\hline TiN and TiAlN & 3 & 2792N1 \\
\hline AlTiBN & 8 & B07FSJLMJ5 \\
\hline Carbon Fiber Bar & 1 & 8194K143 \\
\hline Tormach PCNC 1100 & - & - \\
\hline Dektak XT Stylus Profiler & - & - \\
\hline
\end{tabular}

All parts are obtained from McMaster-Carr with their corresponding part \# excluding the AlTiBN coated bits obtained from amazon.

All designs and toolpaths were done using Autodesk Fusion 360. The CNC milling machine used for this experiment was the Tormach PCNC 1100 located in ESB G85 at West Virginia University (WVU). The Tormach PCNC 1100 has a working area of 18 in x 9.5 in $\mathrm{x}$ 16.25 in, as shown in Figure 4. It offers a spindle speed of up to 5140 RPM; however, 4500 RPM was used in this research due to mechanical issues occurring at higher speeds. The milling machine has a maximum feedrate of 110 IPM in the $\mathrm{x}$ and $\mathrm{y}$ directions and 90 IPM in the $\mathrm{z}$ direction.

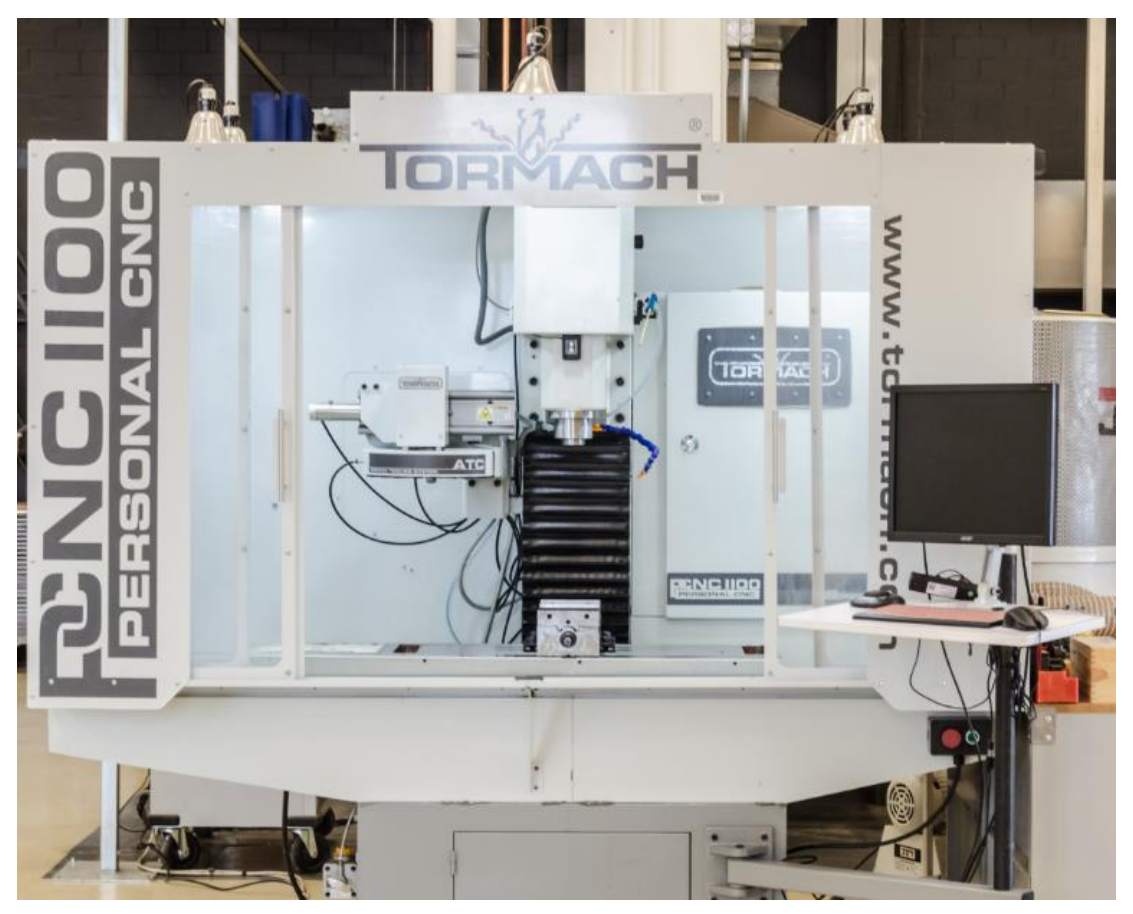

Figure 4: Tormach PCNC 1100 located in ESB G85 at WVU 
A Bruker Dektak XT Stylus profilometer provided in the cleanroom at West Virginia University was used to measure each slot's surface roughness. The machine offers nanometer resolution and a work area of 6 in. The Dektak profilometer, shown in Figure 5, measures surface roughness by moving a $2 \mu \mathrm{m}$ diameter stylus on the part's surface in one direction. The machine then mechanically measures the difference in heights between the starting and ending points, as shown in Figure 6. The profiler then calculates the average roughness of the profile. The machine settings listed in Table 4 were unchanged for all measurements.

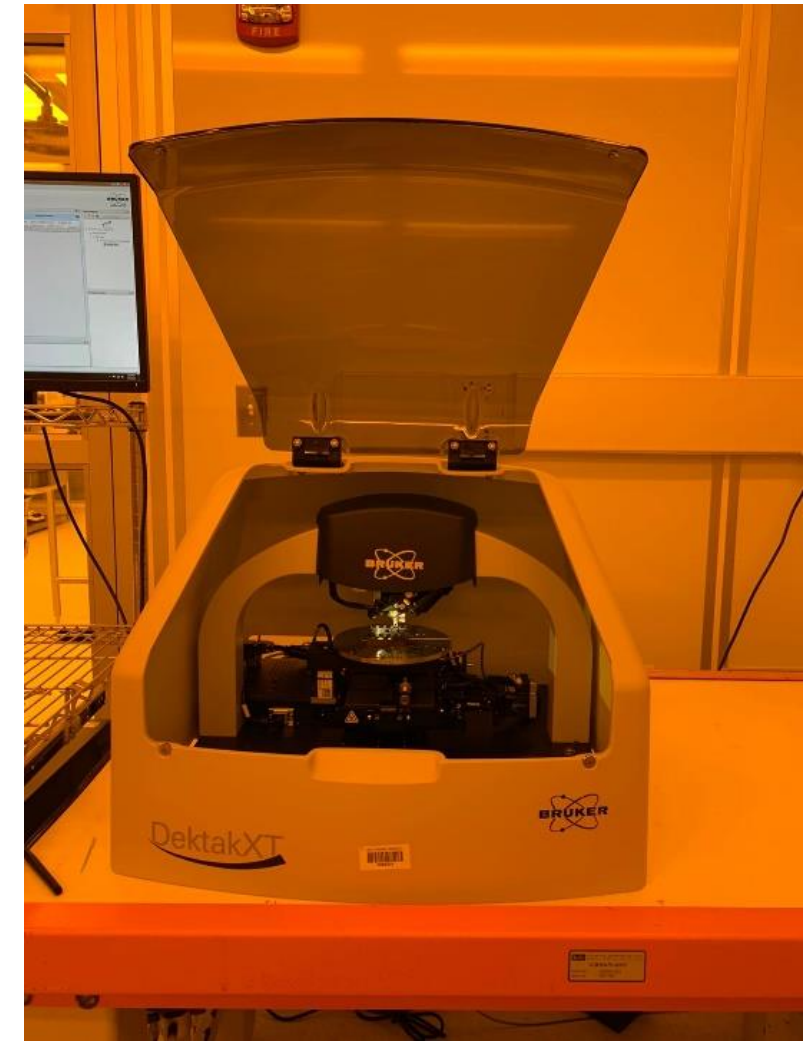

Figure 5: Dektak XT Stylus profilometer located in the cleanroom at WVU 


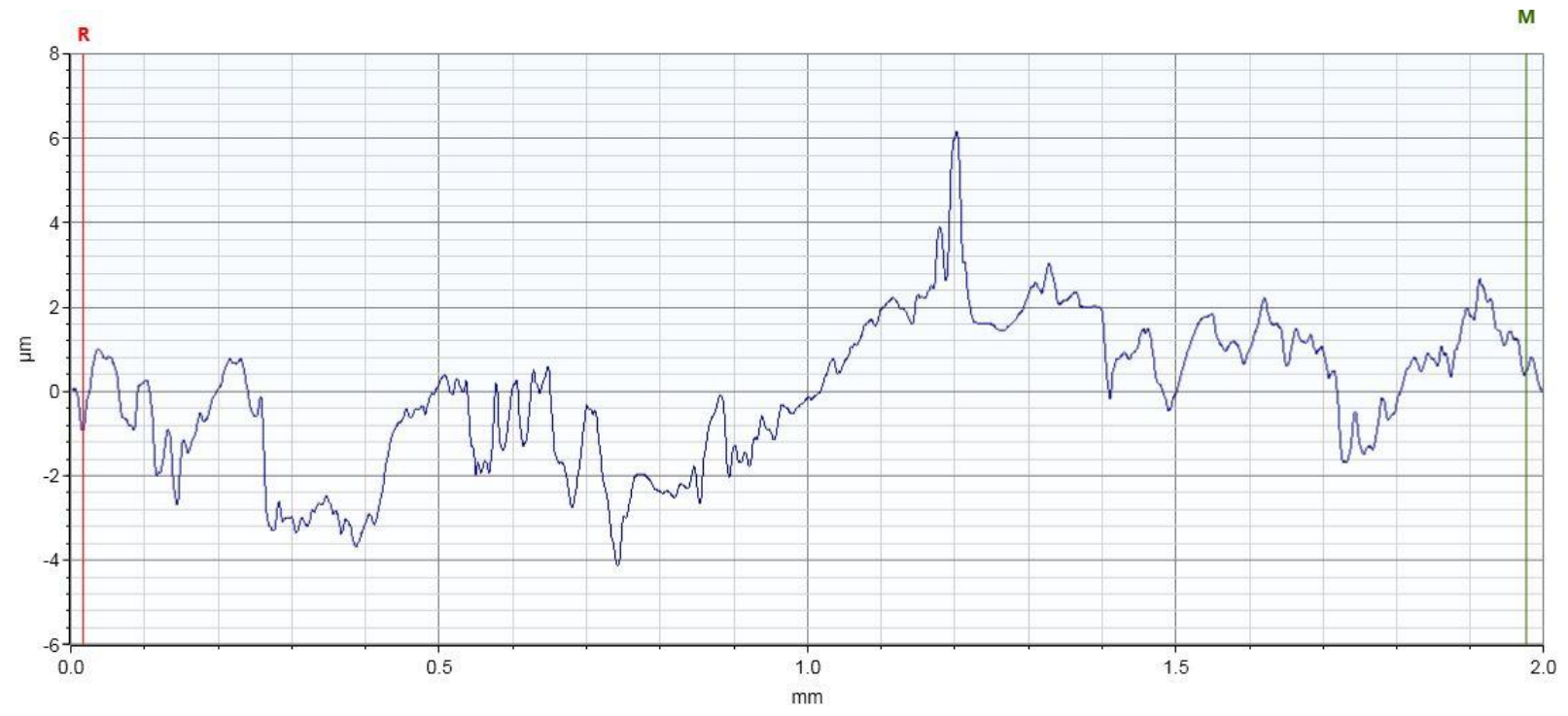

Figure 6: Data output from Dektak profilometer.

Table 4: Dektak profilometer measurement settings

\begin{tabular}{|c|c|}
\hline Scan Type & Standard Scan \\
\hline Range & $6.5 \mu \mathrm{m}$ \\
\hline Profile & Hills \& Valleys \\
\hline Stylus Type & Radius: $2 \mu \mathrm{m}$ \\
\hline Stylus Force & $10 \mathrm{mg}$ \\
\hline Length & $2000 \mu \mathrm{m}$ \\
\hline Duration & $10 \mathrm{sec}$ \\
\hline
\end{tabular}

After completing the milling operation, results were determined based on the accuracy/tolerance of the slot and the surface roughness using metrology equipment and surface imaging machines, respectively. Machining time for each machine settings combination was calculated to determine machining cost. The data obtained were then entered into JMP to determine the near-optimal settings for milling CFRP. Extra material was considered for milling more slots if needed. 


\subsubsection{Toolpath Determination Setup (Pre-Experiment)}

The initial experiment's main objective was to determine which toolpath available in Fusion 360 leads to higher accuracy and lower surface roughness. The design used for this experiment consisted of 14 slots on a $2 \times 2$ in block of CFRP. There were seven toolpath types available that were used for milling the slots:

1. 2D Adaptive

2. 2D Contour

3. 3D Pencil

4. 3D Pocket

5. 3D Adaptive

6. 3D Contour

7. 2D Pocket

Each toolpath type was used to mill two slots. In addition, each toolpath was milled using a different bit to reduce the effect of tool wear and allow future studies of the tool wear effect of different toolpaths. Figure 7 shows the design used for the toolpath determination.

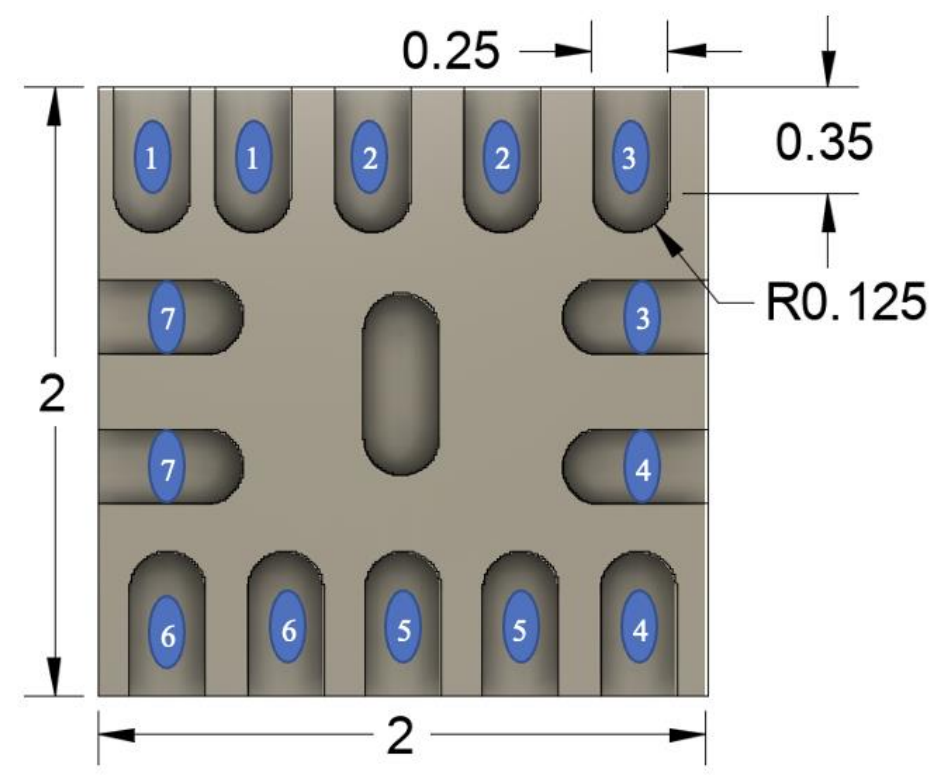

Figure 7: Design used for Toolpath Determination 
The numbers shown on the workpiece in Figure 7 correspond to the toolpath used, listed above. All slots were identical in dimensions to allow comparison. Each slot had a length of 0.475 in, a width of 0.25 in, and a depth of 0.15 in. The center slot was used as a test to determine if the chosen feedrate and cutting speed are suitable and would not damage either the bit or the material. An AlTiBN bit was used to mill the slots. Each toolpath type was milled with a new bit to reduce tool wear. The machine settings shown in Table 5 were used for all toolpaths.

Table 5: Machine Settings used for Toolpath Determination

\begin{tabular}{|c|c|}
\hline Setting & Value \\
\hline Cutting Speed & $4500 \mathrm{RPM}$ \\
\hline Feedrate & $26.5748 \mathrm{in} / \mathrm{min}$ \\
\hline Depth of Cut & $0.15 \mathrm{in}$ \\
\hline
\end{tabular}

The slots designed for this experiment were milled at the edge to allow the mechanical profiler to measure the surface roughness. There was an optical profiler available; however, it relies on light to measure surface roughness. The material created too many interferences during the readings, which led to incorrect measurements.

\subsubsection{Factor Level Determination Setup}

This experiment aims to determine the near-optimal feedrate, depth of cut, and tool coating to mill CFRP successfully. Three bits will be used for each coat to reduce the tool wear effect on the experimental results. Each bit will be used to mill twelve slots for a total of 36 slots per coating. In addition, there will be three different feedrates and depths of cut tested for a total of 144 slots. The design to be milled is shown in Figure 8, and the machine settings are shown in Table 6. Overall, there are 36 slots milled per coating, 48 slots per depth of cut, and 48 slots per feedrate. By milling multiple slots using different combinations of the levels listed, the settings that lead to better results can be determined. This experiment shows which combination mills CFRP better and which individual settings are recommended. 


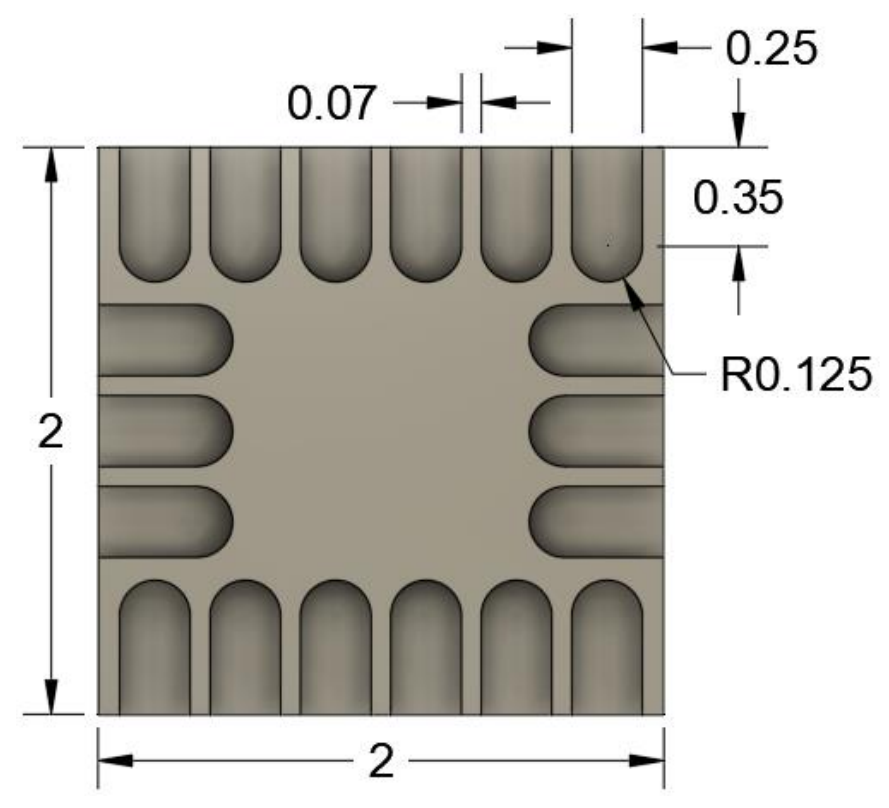

Figure 8: Design used for Factor Level Determination

The feedrates used below in Table 6 were chosen based on the literature review. These were the ranges in which all the surveyed articles decided to conduct their experiment. Since none of the articles found compared multiple depths of cut, those values were chosen to demonstrate the effect of multiple passes on dimensional accuracy. They are explicitly chosen to mill the slot in either one, two, or three passes. The CFRP block has a thickness of 0.5 in with a layer thickness of 0.0066 in and a surface thickness of 0.125 in. Each epoxy layer was roughly 0.0002 in thick. With a slot depth of 0.15 in, 4 layers of epoxy and 5 layers of CFRP, including the surface weave, are cut during the operation. The slot depth is about 0.0044 in into the fifth layer of CFRP. This ensures that the surface roughness measurement is on a CFRP layer instead of an epoxy layer which would lead to inconclusive results.

Table 6: Machine settings used for the experiment

\begin{tabular}{|c|c|c|c|c|c|}
\hline \multicolumn{2}{|c|}{$\begin{array}{c}\text { Cutting speed is set to } \\
\text { 4500 RPM }\end{array}$} & \multicolumn{4}{|c|}{ Feedrate (in/min) $[\mathrm{mm} / \mathrm{rev}]$} \\
\cline { 2 - 6 } & $5.3150[0.03]$ & $17.7165[0.10]$ & $26.5748[0.15]$ & $88.5827[0.5]$ \\
\hline \multirow{2}{*}{$\begin{array}{c}\text { Depth of Cut } \\
\text { (in) }\end{array}$} & 0.05 & & & & \\
\cline { 2 - 6 } & 0.075 & & & & \\
\cline { 2 - 6 } & 0.15 & & & & \\
\hline
\end{tabular}




\section{Experimental Results}

Data were collected on each slot for each experiment using a digital caliper for dimensional accuracy and a mechanical profiler for surface roughness. After collecting each slot's width, length, and height, the equation below was used to calculate RMS. The Dektak XT profilometer was used to measure the surface roughness.

$$
R M S=\sqrt{\frac{\left(\frac{\text { Width }-6.35}{6.35}\right)^{2}+\left(\frac{\text { Length }-12.06}{12.06}\right)^{2}+\left(\frac{\text { Height }-3.81}{3.81}\right)^{2}}{3}} * 100
$$

\subsection{Toolpath Determination (Pre-Experiment)}

Autodesk Fusion 360 offers many types of toolpaths to achieve the designed shape. There were a total of 7 available toolpaths that mill slots. Each toolpath was used to mill two slots at a constant feedrate and depth of cut of $26.5748 \mathrm{in} / \mathrm{min}$ and $0.15 \mathrm{in}$, respectively. After machining the part, machining time, cost, dimensional accuracy, and surface roughness were determined. The toolpath that led to higher dimensional accuracy and lower surface roughness was then used to complete the remainder of the experiment.

Each toolpath type performs the milling operation differently, which leads to different machining times, which correspond to different costs. The machining time and cost for one slot for each toolpath type are shown in Table 7. Each toolpath removes material by moving in a different pattern. For example, both 2D and 3D Adaptive Clearing toolpaths move in a semicircular or circular pattern. 2D Contour, 3D Contour, and 3D Pencil toolpaths move in a line that performs one pass along the edge of the slot, while 2D and 3D Pocket toolpaths move in a spiral to remove material. Examples of each toolpath removal pattern are shown in Figure 9. 


\begin{tabular}{|c|c|c|}
\hline Toolpath Type & $\begin{array}{c}\text { Machining Time per slot } \\
(\mathrm{sec})\end{array}$ & $\begin{array}{c}\text { Machining Time per slot } \\
\text { Cost }(\$)\end{array}$ \\
\hline 2D Adaptive Clearing & 42 & $\$ 0.28$ \\
\hline 2D Contour & 5 & $\$ 0.03$ \\
\hline 2D Pocket & 5 & $\$ 0.03$ \\
\hline 3D Pencil & 2 & $\$ 0.01$ \\
\hline 3D Pocket & 24 & $\$ 0.16$ \\
\hline 3D Adaptive Clearing & 46 & $\$ 0.31$ \\
\hline 3D Contour & 12 & $\$ 0.08$ \\
\hline
\end{tabular}

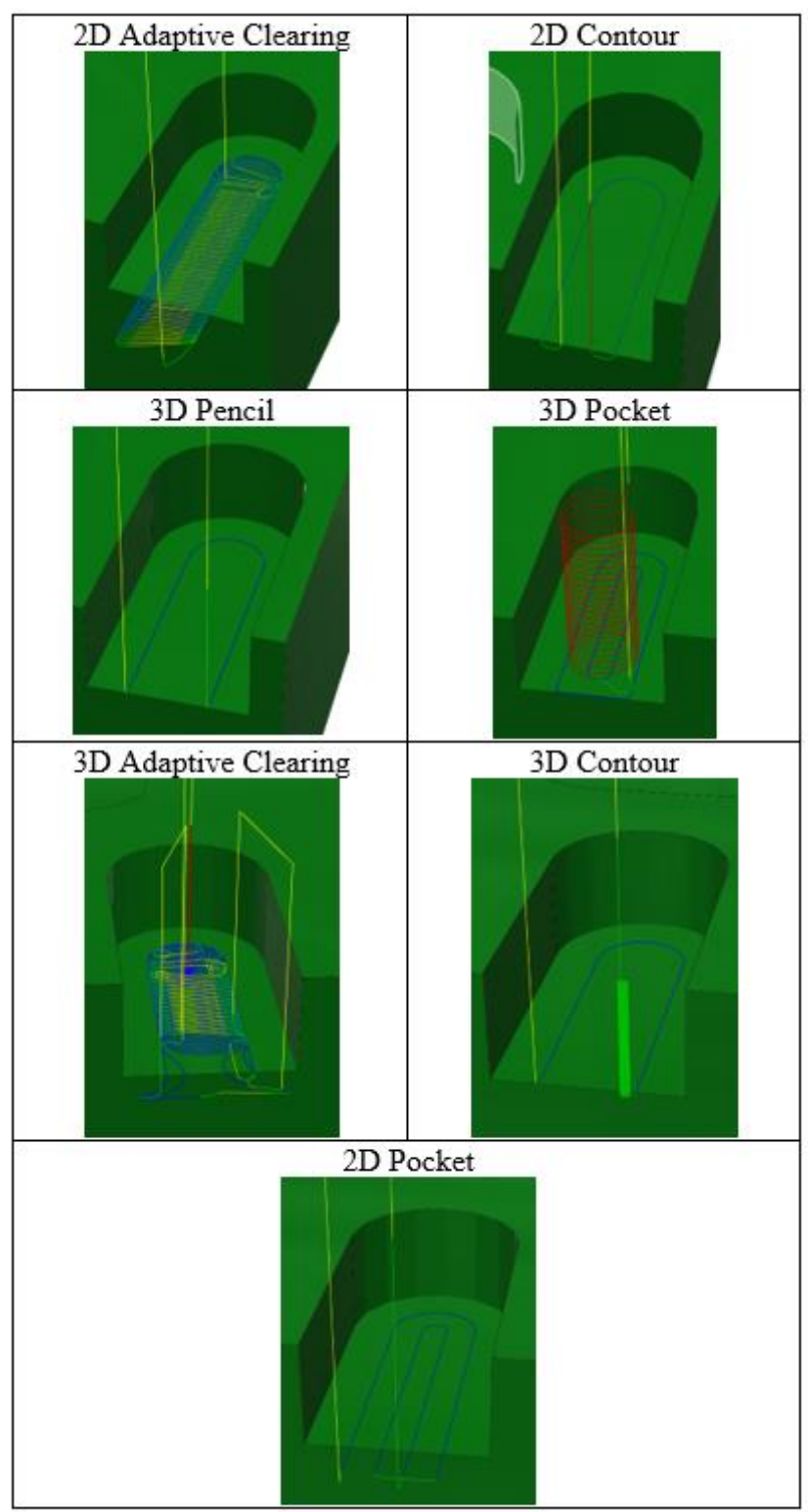

Figure 9: Material removal pattern for each toolpath 
The Contour, Pocket, and Adaptive Clearing toolpaths each have a 2D and 3D option. While they both remove material in the same manner, the machining times are different. This is due to the direction and speed the bit approaches the material for each type. For example, in 2D Pocket, the bit moves down away from the stock material and then approaches from the side of the block and removes material. In contrast, 3D Pocket toolpaths bore into the slot and remove the material, which leads to the extra 19 seconds used. Figure 10 demonstrates how each toolpath approaches the stock material.

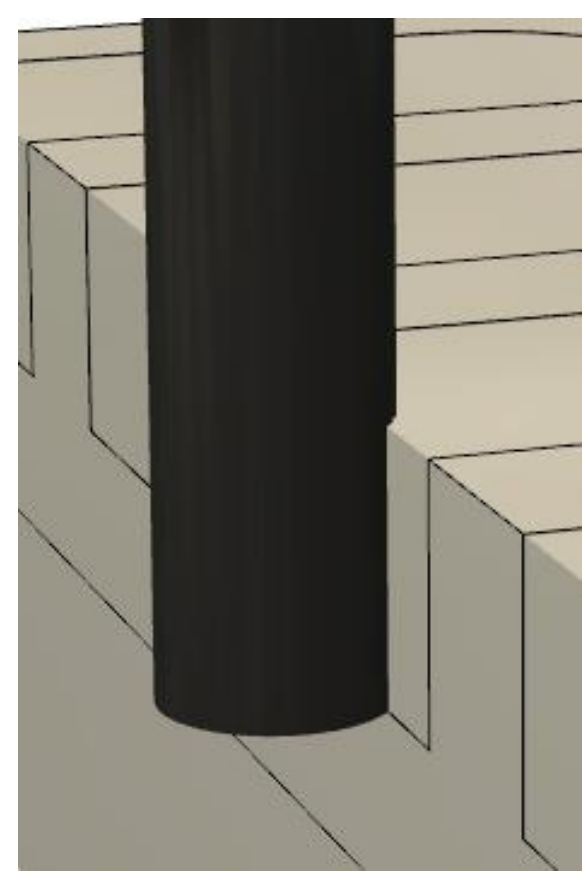

(a)

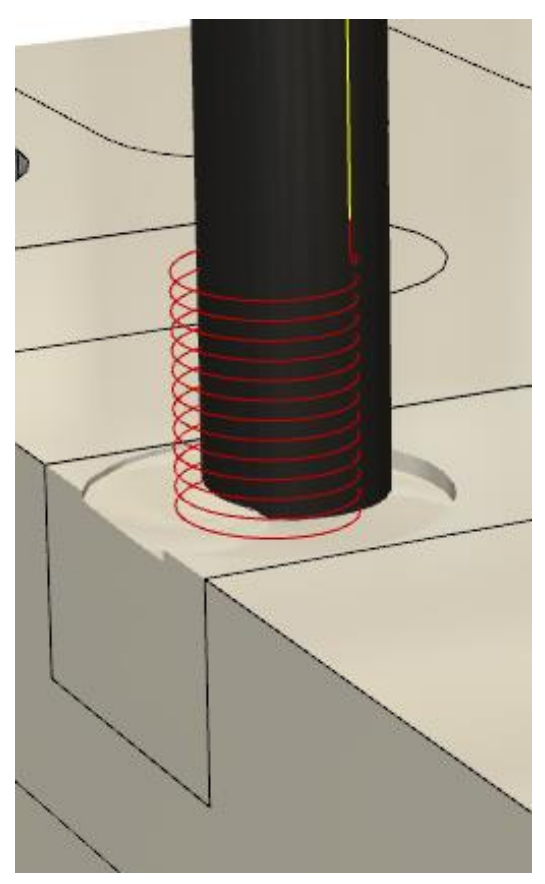

(b)

Figure 10: (a) 2D Pocket. (b) 3D Pocket

2D Contour, 3D Contour, and 3D Pencil toolpaths are only suitable for milling slots with a width of two times the bit diameter. Since these toolpaths remove material along the edge of the slot only, material is left in the middle when the width is larger than two times the bit, as shown in Figure 11. The slot below has a width of 0.6 in, while the bit is only 0.125 in in diameter, therefore leaving a large piece of material not removed in the middle. For this slot to be successfully milled using one of the three toolpaths mentioned, an 0.3 in diameter bit should be used. For this experiment, an 0.125 in diameter bit was used; therefore, an 0.25 in wide slot was designed to compare the different toolpaths. 


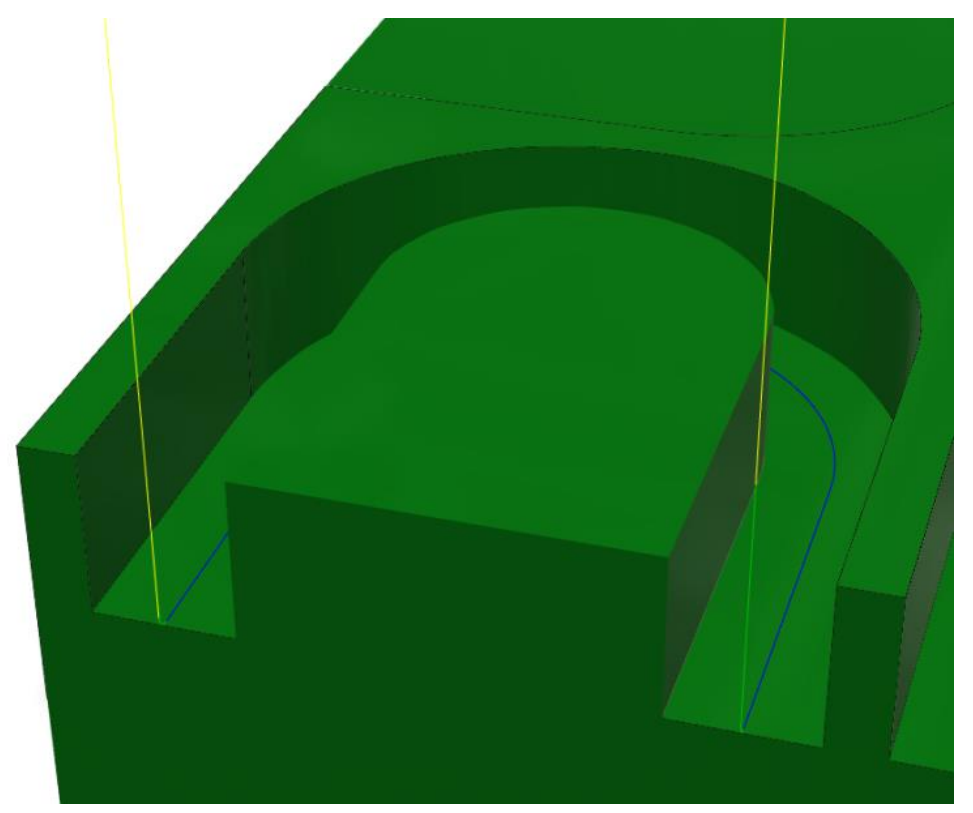

Figure 11: Example of a slot larger than two times the bit diameter

The milled stock consists of 14 identical slots and one center slot used as a test run to ensure all settings are achievable. The part machined is shown in Figure 12.

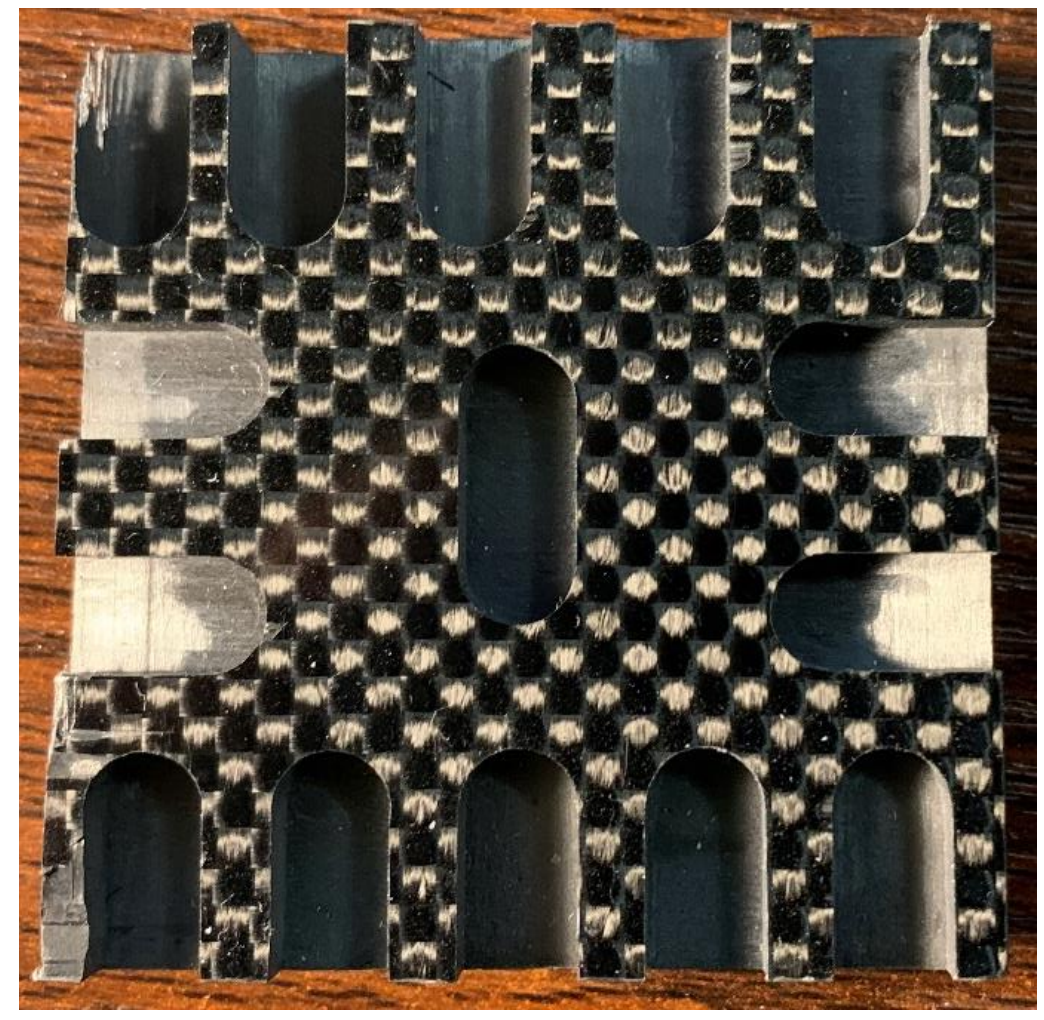

Figure 12: Milled part used for toolpath determination 
The surface roughness was measured along the center of each slot. The width of the slot was approximately the same size as the Dektak's measuring arm to ensure an accurate reading. Due to the different cutting pattern for each toolpath type, different parts of the slot could be rougher than others. As shown in Figure 13, 2D adaptive (a) and 2D Pocket (c) have multiple passes to ensure all material is removed, however for 2D Contour (b) there is only one pass which could lead to a rougher surface in the center if the bit diameter is not 0.125 in exactly. None of the roughness measurements were outliers and were within the range calculated for all slots.

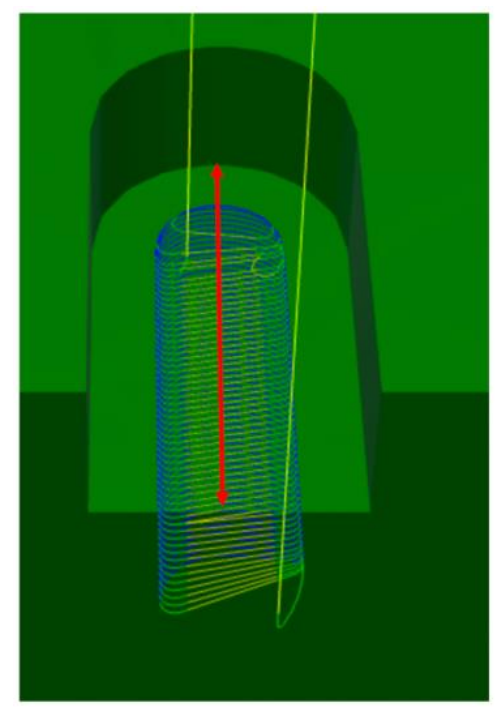

(a)

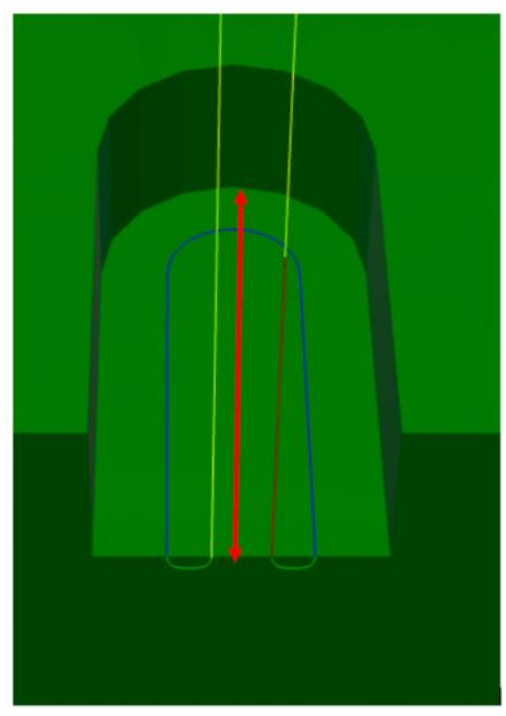

(b)

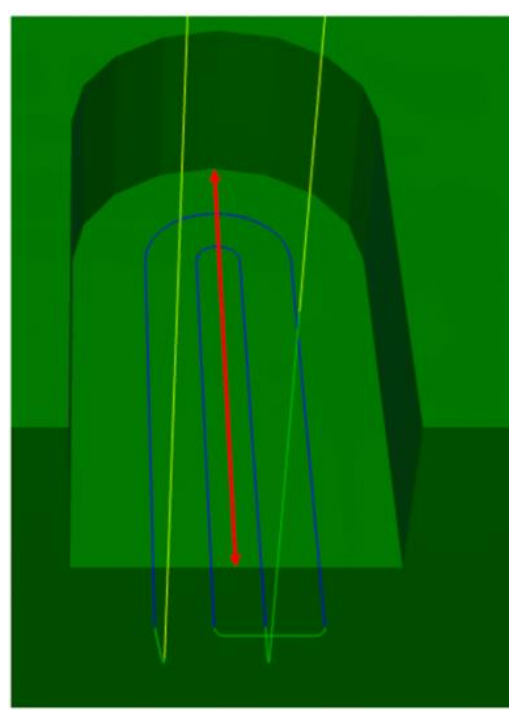

(c)

Figure 13: Surface roughness measurement location. (a) 2D Adaptive (b) 2D Contour (c) 2D Pocket

The length, width, and height of each slot was measured using a caliper. Multiple measurements were taken to check if there are different results in different parts of the slot, however, the discrepancies were nonexistent. Due to the shape of the slot, the length was difficult to measure and required multiple tries to get an accurate reading from the top of the arc to the bottom of the slot. There were also no outliers in the dimensional data. The location of each measurement is shown in Figure 14. There were multiple equations that can be used to measure the deviation from the design dimensions, however, Root Mean Square (RMS) was chosen based on previous work. 


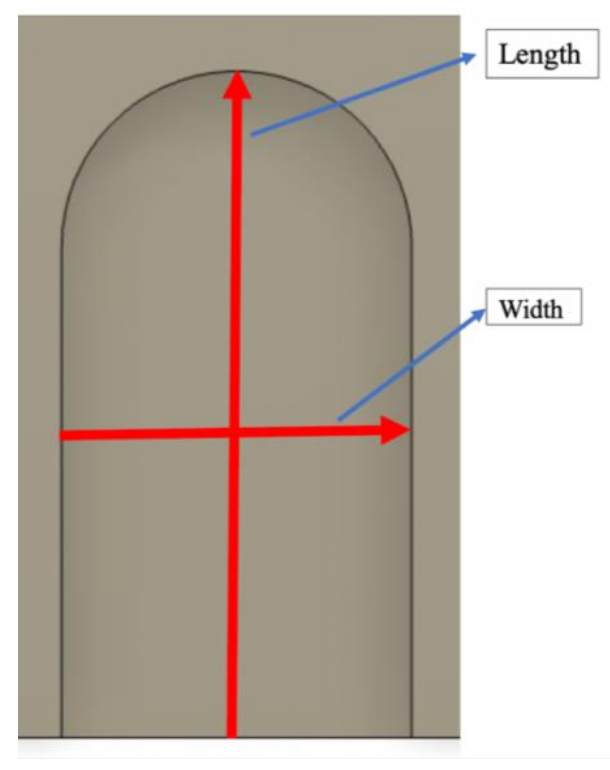

(a)

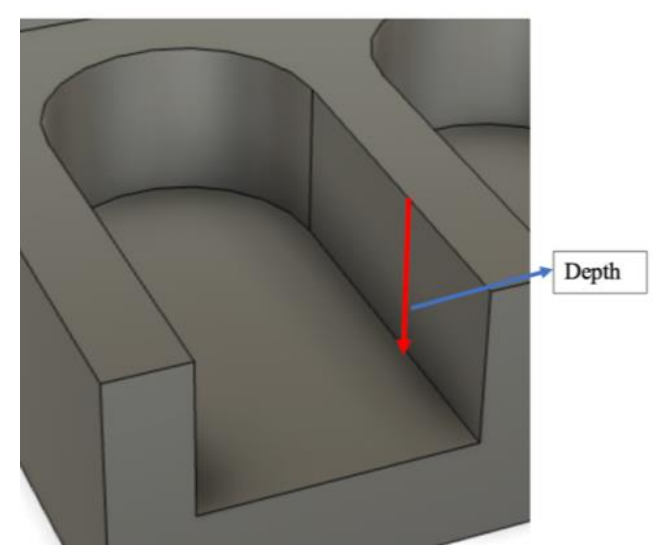

(b)

Figure 14: Dimensional data measuring locations

After conducting the initial experiment at a constant feedrate, depth of cut and cutting speed, and varying toolpath types, a digital caliper was used to measure each slot's width, length, and height. The surface roughness was then collected using the Bruker Dektak XT Stylus profilometer. The data obtained for each measurement is shown in Table 8.

Table 8: Data obtained for each toolpath

\begin{tabular}{|c|c|c|c|c|c|}
\hline Toolpath & $\begin{array}{c}\text { Width } \\
(\mathbf{m m})\end{array}$ & $\begin{array}{c}\text { Length } \\
(\mathbf{m m})\end{array}$ & $\begin{array}{c}\text { Height } \\
(\mathbf{m m})\end{array}$ & $\begin{array}{c}\text { RMS } \\
(\mathbf{m m})\end{array}$ & $\begin{array}{c}\text { Surface Roughness } \\
(\boldsymbol{\mu m})\end{array}$ \\
\hline 2D Adaptive & 6.32 & 12.02 & 3.62 & 2.90 & 1.420 \\
\hline 2D Adaptive & 6.29 & 12.12 & 3.58 & 3.54 & 1.517 \\
\hline 2D Contour & 6.27 & 12.16 & 3.58 & 3.59 & 1.099 \\
\hline 2D Contour & 6.18 & 12.22 & 3.63 & 3.23 & 1.537 \\
\hline 2D Pocket & 6.25 & 11.14 & 3.90 & 4.70 & 1.348 \\
\hline 2D Pocket & 6.27 & 11.46 & 3.95 & 3.64 & 1.370 \\
\hline 3D Pencil & 6.26 & 12.30 & 3.33 & 7.41 & 1.000 \\
\hline 3D Pencil & 6.22 & 12.38 & 3.30 & 7.97 & 1.087 \\
\hline 3D Pocket & 6.30 & 11.90 & 3.37 & 6.73 & 1.233 \\
\hline 3D Pocket & 6.33 & 12.01 & 3.44 & 5.61 & 1.833 \\
\hline 3D Adaptive & 6.39 & 11.88 & 3.57 & 3.76 & 1.097 \\
\hline 3D Adaptive & 6.36 & 11.99 & 3.78 & 0.57 & 1.257 \\
\hline 3D Contour & 6.20 & 11.84 & 3.76 & 1.88 & 1.432 \\
\hline 3D Contour & 6.18 & 12.06 & 3.82 & 1.55 & 1.427 \\
\hline
\end{tabular}




\subsection{Factor Level Determination}

The initial feedrates used were $0.03,0.15$, and $0.5 \mathrm{~mm} / \mathrm{rev}$. However, the $0.5 \mathrm{~mm} / \mathrm{rev}$ feedrate was too high during the first run and broke the bit. Therefore, a lower feedrate, 0.10 $\mathrm{mm} / \mathrm{rev}$, was chosen to avoid further damage to the bits and material. The selected new feedrate was within the range of feedrates used in the literature review. All slots were milled using the 2D Contour toolpath, which was determined in the initial experiment. After performing the milling operation using the Tormach PCNC 1100 mill, the Dektak XT stylus profilometer used in the initial experiment was used to gather the surface roughness measurements for each slot. A total of 8 blocks were milled with 18 slots per block. Figure 15 demonstrates one of the milled blocks.

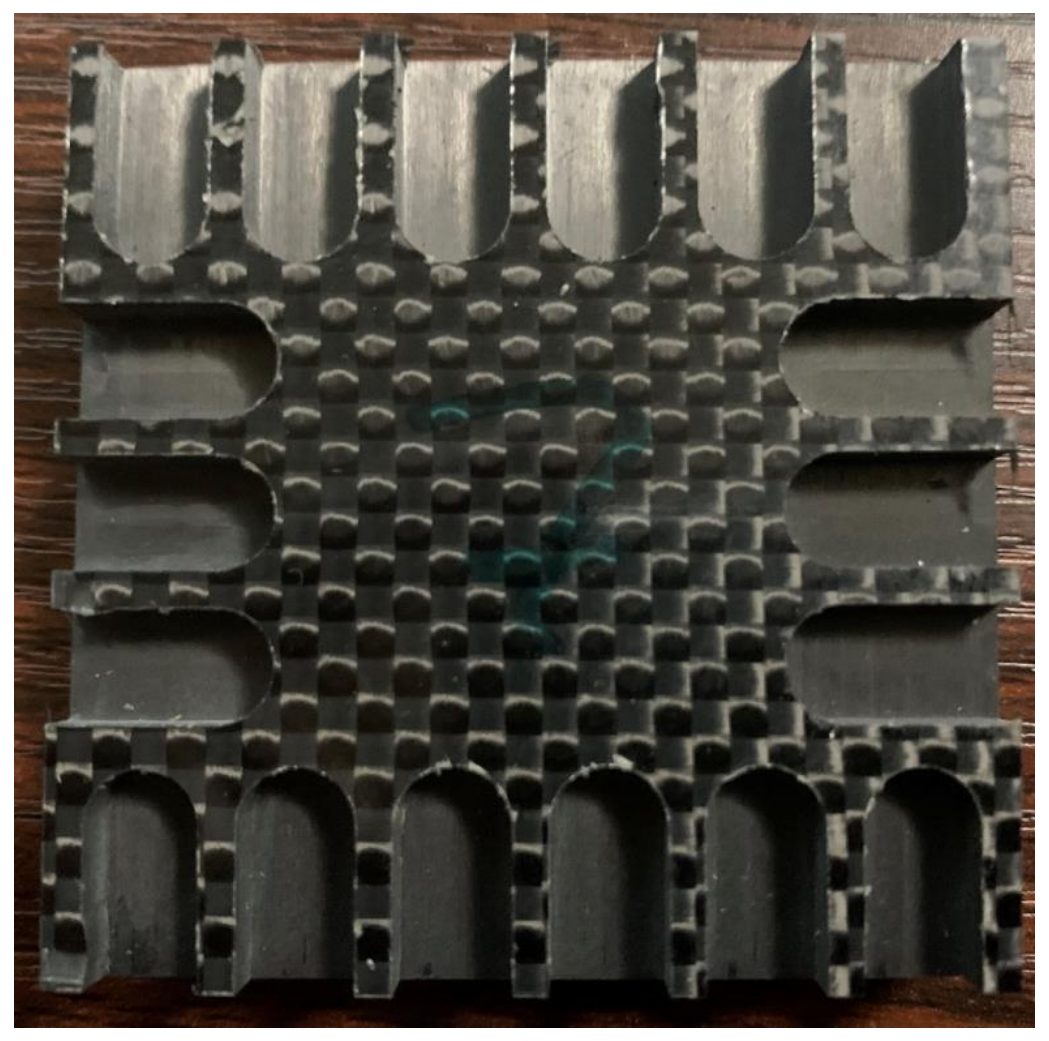

Figure 15: Milled block

This experiment was designed as a full factorial with three replications to ensure enough data to demonstrate which combination leads to better results. The factorial design was generated in JMP and randomized to reduce the tool wear effect on the operation. The number of slots was divided equally and randomly among the number of bits to eliminate the tool wear effect further. The dimensional accuracy and surface roughness data collected are shown in Table 9. 
Table 9: Data obtained for each slot.

\begin{tabular}{|c|c|c|c|c|c|c|c|c|}
\hline Slot \# & $\begin{array}{l}\text { RMS } \\
(\mathbf{m m})\end{array}$ & $\begin{array}{c}\text { Surface } \\
\text { Roughness } \\
(\mu \mathrm{m})\end{array}$ & Slot \# & $\begin{array}{l}\text { RMS } \\
(\mathbf{m m})\end{array}$ & $\begin{array}{c}\text { Surface } \\
\text { Roughness } \\
(\mu \mathrm{m})\end{array}$ & Slot \# & $\begin{array}{l}\text { RMS } \\
(\mathbf{m m})\end{array}$ & $\begin{array}{c}\text { Surface } \\
\text { Roughness } \\
(\mu \mathrm{m})\end{array}$ \\
\hline 1 & 1.44 & 0.964 & 49 & 2.27 & 1.064 & 97 & 2.73 & 0.679 \\
\hline 2 & 2.23 & 0.908 & 50 & 2.55 & 0.810 & 98 & 2.48 & 1.095 \\
\hline 3 & 1.79 & 0.604 & 51 & 1.74 & 1.102 & 99 & 2.35 & 0.532 \\
\hline 4 & 1.63 & 0.728 & 52 & 1.71 & 1.201 & 100 & 2.06 & 0.919 \\
\hline 5 & 1.88 & 0.857 & 53 & 1.05 & 1.453 & 101 & 3.35 & 1.001 \\
\hline 6 & 4.19 & 1.116 & 54 & 3.97 & 1.398 & 102 & 3.78 & 0.860 \\
\hline 7 & 3.77 & 0.859 & 55 & 4.22 & 1.695 & 103 & 3.36 & 1.349 \\
\hline 8 & 3.69 & 0.966 & 56 & 4.02 & 1.412 & 104 & 4.09 & 0.816 \\
\hline 9 & 2.55 & 1.035 & 57 & 2.92 & 1.410 & 105 & 3.48 & 0.904 \\
\hline 10 & 5.18 & 1.147 & 58 & 3.98 & 1.335 & 106 & 4.26 & 1.280 \\
\hline 11 & 7.87 & 1.689 & 59 & 3.03 & 1.443 & 107 & 2.80 & 1.182 \\
\hline 12 & 7.43 & 1.744 & 60 & 2.28 & 0.689 & 108 & 2.83 & 1.137 \\
\hline 13 & 4.16 & 0.854 & 61 & 2.49 & 0.589 & 109 & 3.98 & 0.979 \\
\hline 14 & 2.87 & 0.431 & 62 & 2.12 & 1.033 & 110 & 2.26 & 0.851 \\
\hline 15 & 3.73 & 0.656 & 63 & 2.20 & 0.882 & 111 & 3.05 & 0.918 \\
\hline 16 & 2.75 & 0.708 & 64 & 3.09 & 1.229 & 112 & 2.67 & 0.758 \\
\hline 17 & 3.01 & 1.315 & 65 & 4.35 & 1.330 & 113 & 3.87 & 1.113 \\
\hline 18 & 2.27 & 1.219 & 66 & 2.00 & 1.329 & 114 & 4.29 & 0.876 \\
\hline 19 & 13.63 & 0.836 & 67 & 2.27 & 1.539 & 115 & 2.98 & 1.213 \\
\hline 20 & 12.57 & 1.335 & 68 & 2.50 & 1.775 & 116 & 4.27 & 0.983 \\
\hline 21 & 12.36 & 1.113 & 69 & 2.28 & 1.566 & 117 & 2.05 & 0.830 \\
\hline 22 & 3.89 & 1.138 & 70 & 3.42 & 1.136 & 118 & 3.11 & 0.877 \\
\hline 23 & 3.68 & 0.692 & 71 & 2.71 & 1.302 & 119 & 3.61 & 0.932 \\
\hline 24 & 1.68 & 1.195 & 72 & 3.29 & 1.110 & 120 & 3.07 & 1.078 \\
\hline 25 & 3.44 & 0.796 & 73 & 3.45 & 0.707 & 121 & 2.84 & 1.013 \\
\hline 26 & 1.51 & 1.061 & 74 & 2.48 & 1.313 & 122 & 2.93 & 1.004 \\
\hline 27 & 1.73 & 0.984 & 75 & 2.10 & 1.027 & 123 & 2.46 & 0.822 \\
\hline 28 & 3.55 & 1.338 & 76 & 3.63 & 1.330 & 124 & 1.14 & 0.891 \\
\hline 29 & 3.32 & 1.089 & 77 & 2.40 & 0.968 & 125 & 2.89 & 0.840 \\
\hline 30 & 3.66 & 1.404 & 78 & 2.94 & 1.230 & 126 & 2.04 & 0.911 \\
\hline 31 & 3.48 & 0.913 & 79 & 3.01 & 0.767 & 127 & 4.45 & 0.941 \\
\hline 32 & 3.49 & 1.145 & 80 & 2.98 & 1.150 & 128 & 3.84 & 0.777 \\
\hline 33 & 2.96 & 1.016 & 81 & 3.20 & 1.074 & 129 & 4.18 & 1.148 \\
\hline 34 & 3.16 & 0.561 & 82 & 2.68 & 1.650 & 130 & 3.90 & 1.005 \\
\hline 35 & 3.24 & 1.233 & 83 & 2.84 & 1.168 & 131 & 4.53 & 0.815 \\
\hline 36 & 3.12 & 0.802 & 84 & 3.21 & 1.126 & 132 & 4.36 & 0.683 \\
\hline 37 & 3.82 & 1.006 & 85 & 3.00 & 1.173 & 133 & 3.47 & 0.757 \\
\hline 38 & 3.63 & 1.022 & 86 & 3.25 & 1.016 & 134 & 3.14 & 0.667 \\
\hline 39 & 2.54 & 1.277 & 87 & 2.21 & 0.936 & 135 & 2.90 & 0.866 \\
\hline 40 & 3.18 & 1.521 & 88 & 2.65 & 1.039 & 136 & 4.89 & 0.915 \\
\hline 41 & 3.01 & 1.786 & 89 & 2.39 & 0.793 & 137 & 4.58 & 1.104 \\
\hline 42 & 3.05 & 1.239 & 90 & 3.94 & 0.706 & 138 & 3.09 & 1.138 \\
\hline 43 & 3.01 & 0.781 & 91 & 3.83 & 0.891 & 139 & 3.81 & 0.842 \\
\hline 44 & 2.71 & 1.780 & 92 & 3.82 & 1.084 & 140 & 3.77 & 0.593 \\
\hline 45 & 2.24 & 1.083 & 93 & 4.30 & 1.192 & 141 & 3.90 & 0.994 \\
\hline 46 & 3.66 & 1.347 & 94 & 3.83 & 0.816 & 142 & 2.91 & 1.171 \\
\hline 47 & 3.61 & 1.545 & 95 & 3.71 & 0.756 & 143 & 3.18 & 0.757 \\
\hline 48 & 3.68 & 1.441 & 96 & 3.56 & 1.140 & 144 & 3.04 & 0.933 \\
\hline
\end{tabular}


Each slot's surface roughness was measured separately using the Dektak XT Stylus profilometer. For each slot, a surface roughness value and profile were obtained, as shown in Figure 16.
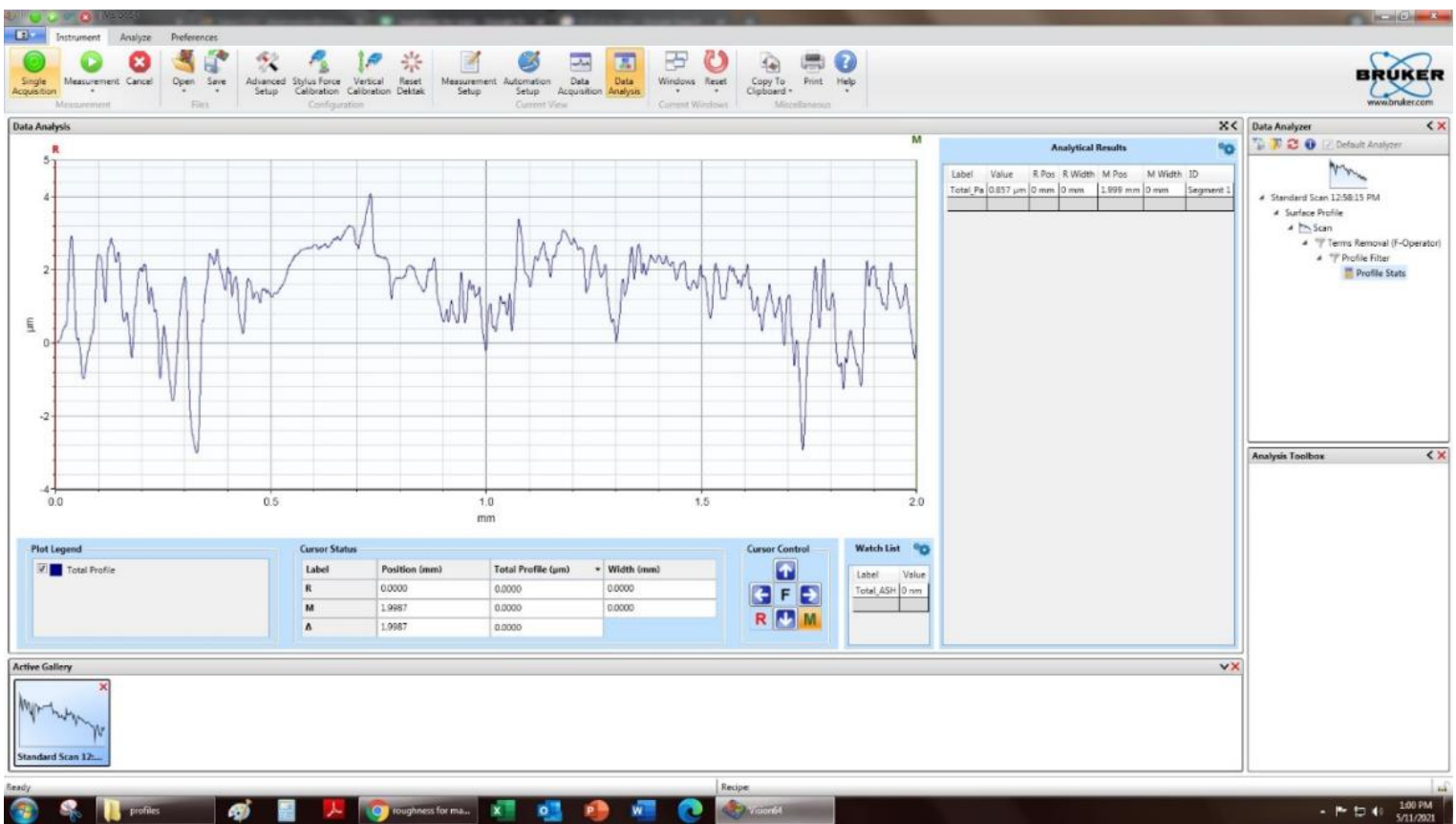

Figure 16: Surface roughness value and profile for slot 5

The $2 \mu \mathrm{m}$ diameter stylus was used to measure a $2 \mathrm{~mm}$ portion of the slot at a speed of $200 \mu \mathrm{m} / \mathrm{s}$. Figure 17 shows the stylus placement on the part's surface.

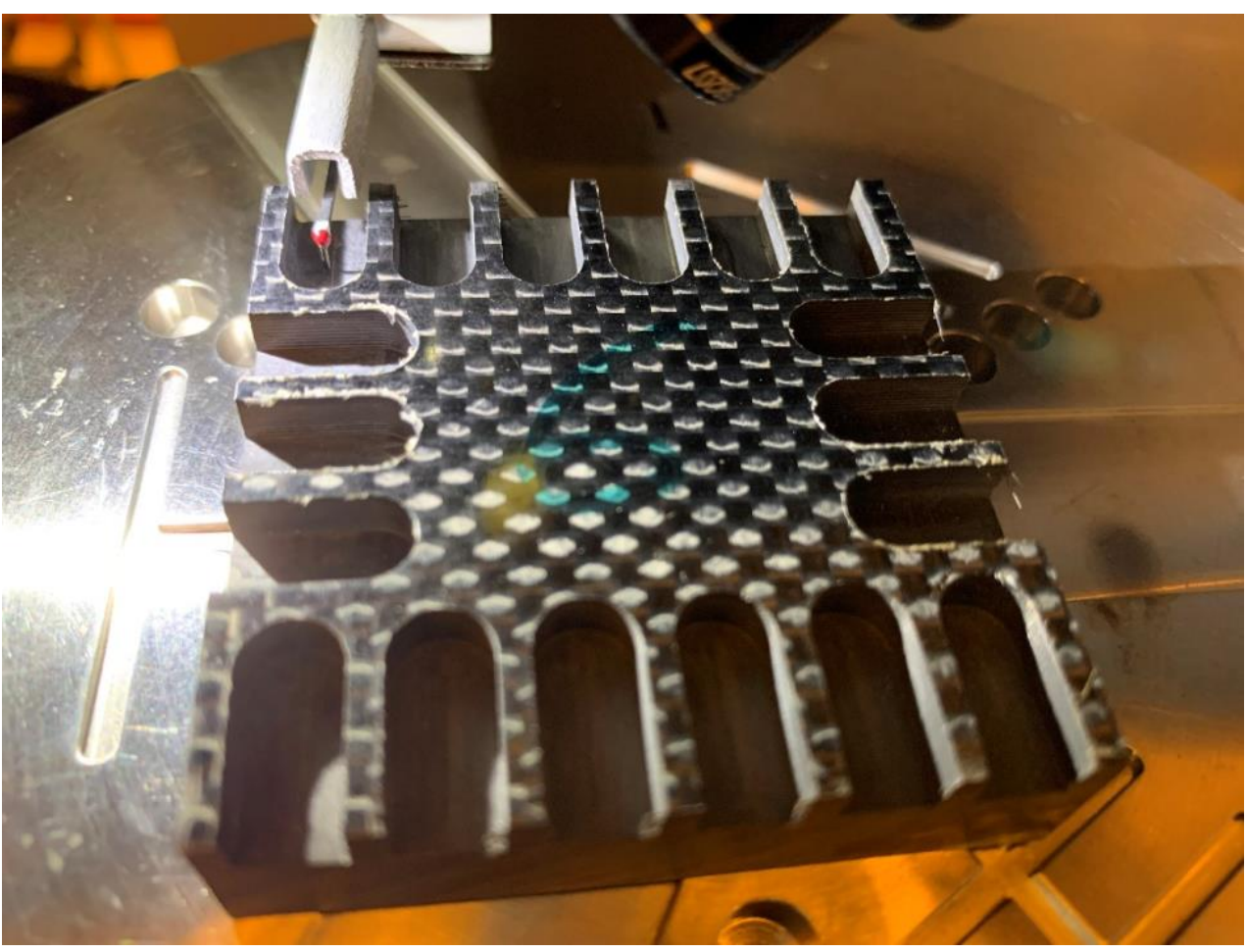

Figure 17: CFRP surface roughness measurement 


\section{Discussion}

This section interprets and discusses the results obtained to determine the optimal settings to use when CNC milling CFRP to increase dimensional accuracy and reduce surface roughness. Two experiments were set up, the first to determine which toolpath type leads to better results and the second to determine the combination of tool coating, feedrate, and depth of cut, using the toolpath type found in the first experiment, which leads to higher dimensional accuracy and lower surface roughness. The dimensional and roughness data to determine which toolpath type to use were shown in section 4.1. Section 4.2 then shows the data collected by running an experiment with varying feedrates, depths of cut, and tool coatings. Section 5.1 discusses the results obtained in the initial experiment and includes the effect of cost when choosing a toolpath type. Section 5.2 goes over the results from the factor level determination and shows which factor levels lead to better results.

\subsection{Toolpath Determination (Pre-Experiment)}

The initial experiment determined which toolpath type leads to better dimensional accuracy and surface roughness while minimizing cost was determined to be the 2D Contour toolpath. A 2D Contour toolpath was eligible to be used because the slot width did not exceed two times the bit diameter. This toolpath was chosen based on surface roughness, dimensional accuracy, and cost. Although the cost for this experiment was not a significant factor, in manufacturing in general, the cost is very important and affects the manufacturing capabilities available for a product. Although 3D toolpaths were included in the experiment, they can not be used for the factor level determination due to the inability to adjust the depth of cut. However, they were added to show the capabilities of those toolpaths for future work. 
A JMP analysis was performed to identify which of the toolpath types are significant factors affecting dimensional accuracy and surface roughness. Concerning surface roughness, none of the toolpath types had a significant effect; however, for dimensional accuracy, the toolpath type did affect the milled slot. Both 3D Adaptive and 3D Contour toolpaths had a significant effect on the accuracy of the slot, and 3D Pencil toolpaths had some significant effect. All other toolpath types do not have a significant effect on dimensional accuracy. The JMP profiler shows that 3D Pencil is the best 3D toolpath and 2D Contour is the best 2D one. Table 10 shows the ranking of each toolpath in terms of dimensional accuracy and surface roughness when the cost is excluded and included.

Table 10: Ranking of each toolpath

\begin{tabular}{|c|c|c|}
\hline & Excluding Cost & Including Cost \\
\hline 1 & 3D Pencil & 3D Pencil \\
\hline 2 & 3D Contour & 2D Contour \\
\hline 3 & 2D Contour & 3D Contour \\
\hline 4 & 2D Adaptive & 2D Pocket \\
\hline 5 & 2D Pocket & 3D Pocket \\
\hline 6 & 3D Pocket & 2D Adaptive \\
\hline 7 & 3D Adaptive & 3D Adaptive \\
\hline
\end{tabular}




\subsection{Factor Level Determination}

The toolpath type determined in the initial experiment, 2 Contour, was then used to generate toolpaths using three levels of feedrates, three levels of depths of cut, and four tool coatings. After milling each of the 144 slots and obtaining the dimensional accuracy and surface roughness data, a JMP analysis was conducted to determine which combination leads to better accuracy and surface roughness.

An issue that arises with milling CFRP is delamination due to chipping during the operation. Due to the nature of the material, having fibers placed in a matrix, instead of the bit cutting the material, it can either chip, peel up or push out the fibers, as shown in Figure 18 and Figure 19. There are multiple ways to reduce delamination during milling, the most common issue is incorrect machine settings. Delamination can occur if the feedrate is too high and the cutting speed is too low. To ensure that the material is cut correctly, the bit needs to be spinning at very high speeds and low feedrates. In the literature review, most articles used cutting speeds around 12000 RPM; however, for this experiment, a cutting speed of 4500 RPM was used due to the limitations of the available CNC mill. To offset that decrease in cutting speed, lower feedrates were chosen to ensure that the material is cut correctly. Fiber peel-up and push-out mainly occur during drilling CFRP due to low cutting speeds or wore out cutting bits. Worn-out cutting bits can also cause delamination at the edges or surface of the milled part due to being dull and not cutting the fiber correctly, increasing surface roughness.
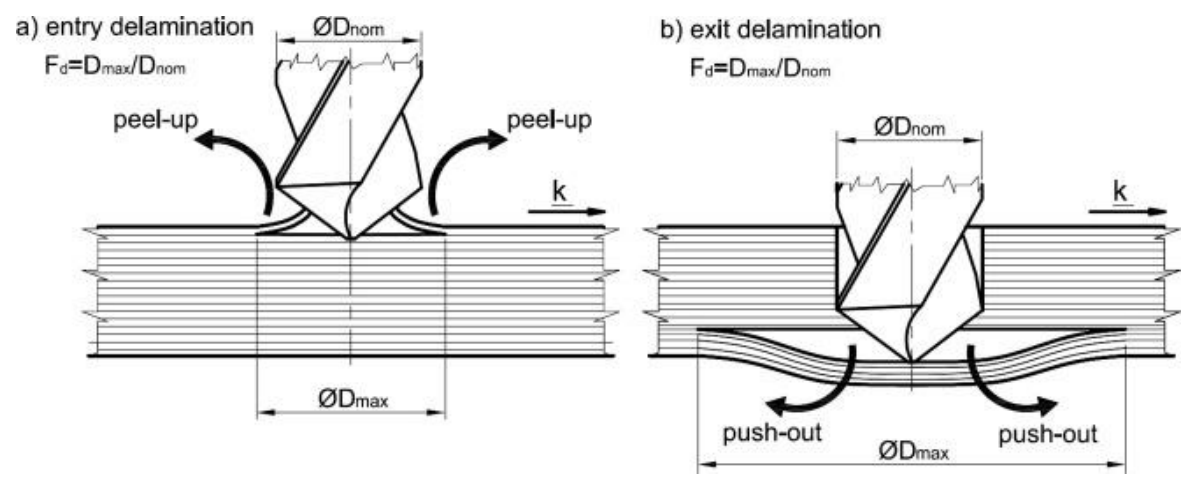

Figure 18: Peel up and push out delamination in CFRP. [84] 
All slots had delamination at the edges. As shown in Figure 19, the slot does not appear to be damaged at the edges; however, at the nanoscale, there is some damage in slot 7 and a lot of damage in slot 5. Although this kind of delamination does not affect the results of this experiment, in mechanical uses, this part could fail due to damaged material. Therefore, ensuring that delamination doesn't occur or is minimized is crucial to the part's structural integrity.

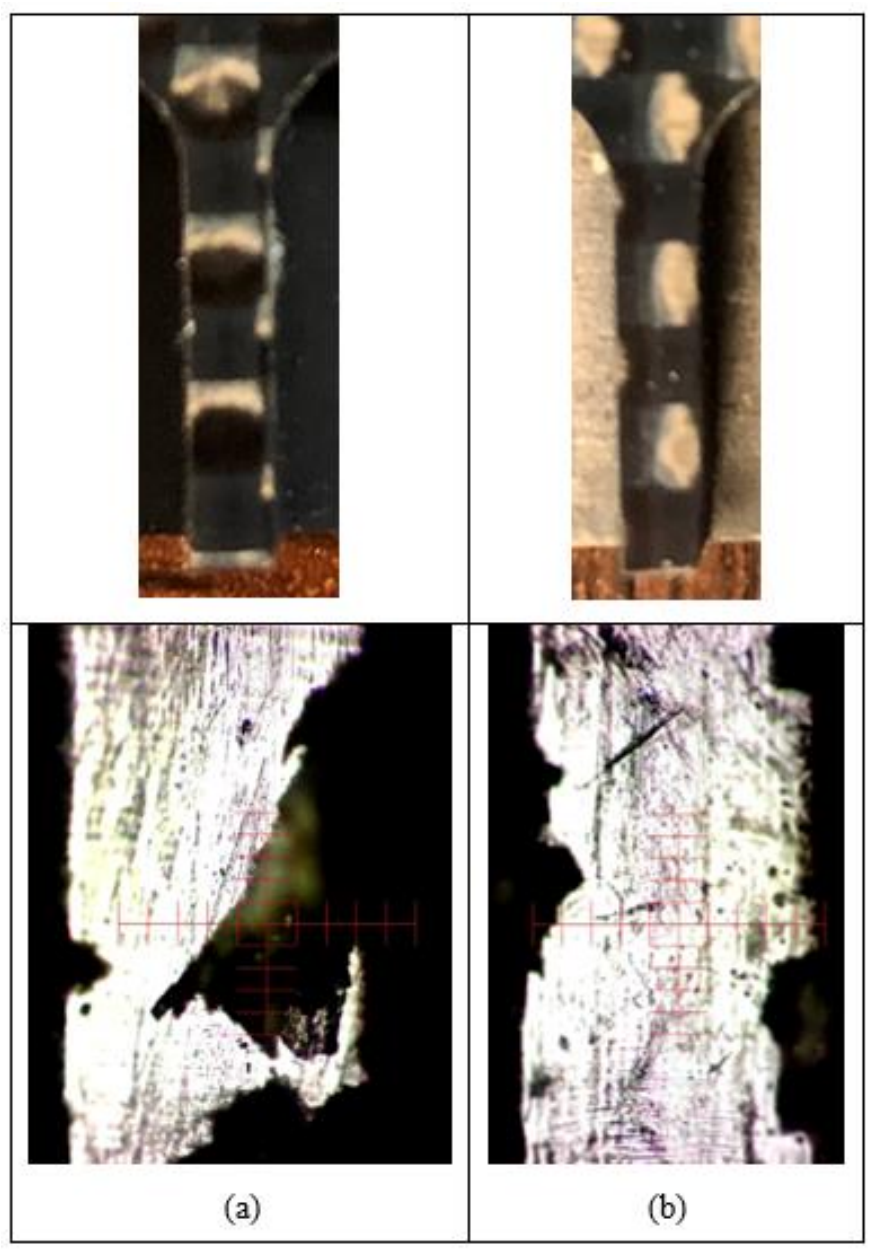

Figure 19: Chipping on slot edges. (a) slot 5 (b) slot 7

After collecting all the data, another JMP analysis was performed using feedrate, tool coating, and depth of cut as the main factors. The interaction effect of feedrate and depth of cut and tool coating and depth of cut were added to show the impact of the different combinations. The interaction effect feedrate and tool coating led to an error that miscalculated the tool coating effect. Therefore it was removed from the analysis due to insufficient degrees of freedom. 


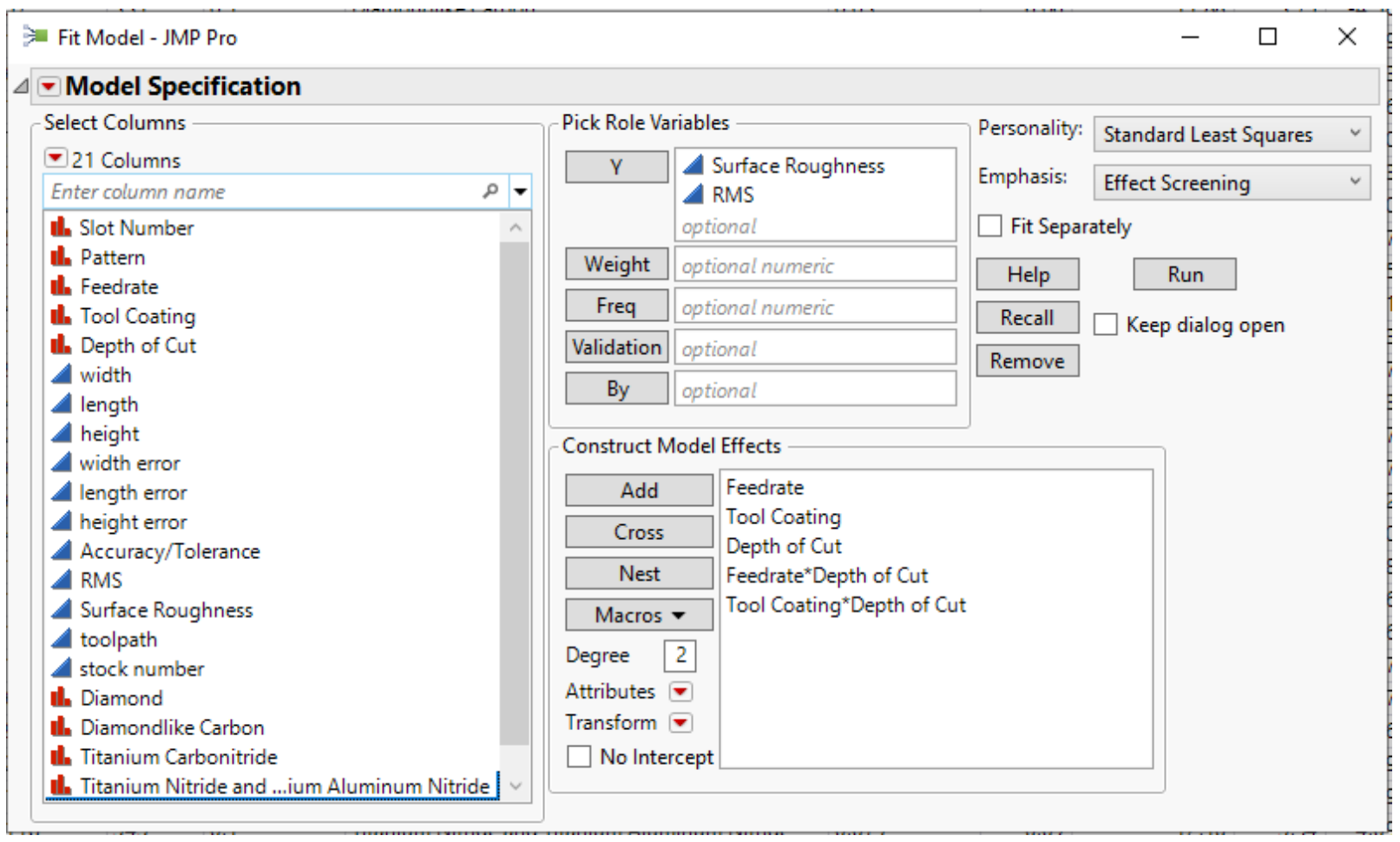

Figure 20: JMP model fitting.

All factors were analyzed with respect to dimensional accuracy and surface roughness.

Tables 11-14 show the significant factors and levels on dimensional accuracy and surface roughness. Feedrate was the only significant factor for both criteria, which agrees with the literature review that feedrate is one of the most critical factors when milling CFRP. Tool coating is a significant factor on surface roughness and somewhat significant on dimensional accuracy. This could be because better/stronger coatings cut CFRP fibers completely and cause less delamination, resulting in better roughness. The depth of cut has some significant effect on surface roughness but none on dimensional accuracy. The interaction effect feedrate and depth of cut is somewhat significant in terms of dimensional accuracy; while, tool coating and depth of cut are more significant concerning dimensional accuracy. Both interaction effects are not an important factor on surface roughness. 
Table 11: Effect tests on dimensional accuracy

$\begin{array}{lrrrrr}\text { Source } & \text { Nparm } & \text { DF } & \text { Sum of Squares } & \text { F Ratio } & \text { Prob > F } \\ \text { Feedrate } & 3 & 2 & 49.810581 & 14.6492 & <.0001^{*} \\ \text { Tool Coating } & 3 & 3 & 18.170111 & 3.5625 & 0.0162^{*} \\ \text { Depth of Cut } & 2 & 1 & 5.809504 & 3.4171 & 0.0669 \\ \text { Feedrate*Depth of Cut } & 6 & 5 & 25.833172 & 3.0390 & 0.0127^{*} \\ \text { Tool Coating*Depth of Cut } & 6 & 6 & 39.376198 & 3.8602 & 0.0014^{*}\end{array}$

Table 12: Significant effects on dimensional accuracy

\begin{tabular}{|c|c|}
\hline Term & Prob $>|t|$ \\
\hline Intercept & $<.0001 *$ \\
\hline Feedrate[0.03] & $<.0001^{*}$ \\
\hline Feedrate[0.15] & 0.5179 \\
\hline Feedrate[0.5] & $0.0466^{*}$ \\
\hline Feedrate[0.1] & 0.1244 \\
\hline Tool Coating[Diamond] & $0.0045^{*}$ \\
\hline Tool Coating[Titanium Carbonitride] & 0.3183 \\
\hline Tool Coating[Diamondlike Carbon] & $0.0274^{*}$ \\
\hline Tool Coating[Titanium Nitride and Titanium Aluminum Nitride] & 0.8103 \\
\hline Depth of Cut[0.05] & 0.2809 \\
\hline Depth of Cut[0.075] & $0.0148^{*}$ \\
\hline Depth of Cut[0.15] & 0.8655 \\
\hline Feedrate[0.03]*Depth of Cut[0.05] & 0.7931 \\
\hline Feedrate[0.03]*Depth of Cut[0.075] & $0.0105^{*}$ \\
\hline Feedrate[0.03]*Depth of Cut[0.15] & 0.3524 \\
\hline Feedrate[0.15]*Depth of Cut[0.05] & 0.1996 \\
\hline Feedrate[0.15]*Depth of Cut[0.075] & $0.0003^{*}$ \\
\hline Feedrate[0.15]*Depth of Cut[0.15] & 0.6729 \\
\hline Feedrate[0.5]*Depth of Cut[0.05] & 0.7707 \\
\hline Feedrate[0.5]*Depth of Cut[0.075] & 1.0000 \\
\hline Feedrate[0.5]*Depth of Cut[0.15] & 0.7707 \\
\hline Feedrate[0.1] $]^{*}$ Depth of Cut[0.05] & 0.8117 \\
\hline Feedrate[0.1 $]^{*}$ Depth of Cut[0.075] & 0.2835 \\
\hline Feedrate[0.1]*Depth of Cut[0.15] & 0.7887 \\
\hline Tool Coating[Diamond] ${ }^{*}$ Depth of Cut $[0.05]$ & $0.0196^{*}$ \\
\hline Tool Coating[Diamond] ${ }^{*}$ Depth of Cut $[0.075]$ & $<.0001^{*}$ \\
\hline Tool Coating[Diamond] ${ }^{*}$ Depth of Cut $[0.15]$ & $0.0134^{*}$ \\
\hline Tool Coating[Titanium Carbonitride] ${ }^{*}$ Depth of Cut[0.05] & 0.3789 \\
\hline Tool Coating[Titanium Carbonitride] ${ }^{\star}$ Depth of Cut $[0.075]$ & 0.1131 \\
\hline Tool Coating[Titanium Carbonitride] ${ }^{*}$ Depth of Cut[0.15] & 0.4739 \\
\hline Tool Coating[Diamondlike Carbon]*Depth of Cut[0.05] & 0.4219 \\
\hline Tool Coating[Diamondlike Carbon] ${ }^{*}$ Depth of Cut[0.075] & $0.0224^{*}$ \\
\hline Tool Coating[Diamondlike Carbon] ${ }^{*}$ Depth of Cut[0.15] & 0.1322 \\
\hline Tool Coating[Titanium Nitride and Titanium Aluminum Nitride $]^{*}$ Depth of Cut[0.05] & 0.4528 \\
\hline Tool Coating[Titanium Nitride and Titanium Aluminum Nitride $]^{*}$ Depth of Cut $[0.075]$ & 0.2867 \\
\hline Tool Coating[Titanium Nitride and Titanium Aluminum Nitride $]^{*}$ Depth of $\mathrm{Cl}$ & 0.7493 \\
\hline
\end{tabular}


Table 13: Effect tests on surface roughness

$\begin{array}{lrrrrr}\text { Source } & \text { Nparm } & \text { DF } & \text { Sum of Squares } & \text { F Ratio } & \text { Prob > F } \\ \text { Feedrate } & 3 & 2 & 1.2734975 & 10.0271 & <.0001^{*} \\ \text { Tool Coating } & 3 & 3 & 2.6109013 & 13.7049 & <.0001^{*} \\ \text { Depth of Cut } & 2 & 1 & 0.3158138 & 4.9732 & 0.0275^{*} \\ \text { Feedrate*Depth of Cut } & 6 & 5 & 0.3815797 & 1.2018 & 0.3123 \\ \text { Tool Coating*Depth of Cut } & 6 & 6 & 0.2781252 & 0.7300 & 0.6263\end{array}$

Table 14: Significant effects on surface roughness

\begin{tabular}{|c|c|}
\hline Term & Prob $>|t|$ \\
\hline Intercept & $<.0001 *$ \\
\hline Feedrate[0.03] & $<.0001^{*}$ \\
\hline Feedrate[0.15] & 0.1118 \\
\hline Feedrate[0.5] & $0.0003 *$ \\
\hline Feedrate[0.1] & $0.0189 *$ \\
\hline Tool Coating[Diamond] & $0.0431^{*}$ \\
\hline Tool Coating[Titanium Carbonitride] & 0.5675 \\
\hline Tool Coating[Diamondlike Carbon] & $<.0001^{*}$ \\
\hline Tool Coating[Titanium Nitride and Titanium Aluminum Nitride] & $0.0007^{*}$ \\
\hline Depth of Cut[0.05] & 0.0532 \\
\hline Depth of Cut[0.075] & 0.2259 \\
\hline Depth of Cut[0.15] & 0.1555 \\
\hline Feedrate[0.03]*Depth of Cut[0.05] & 0.2996 \\
\hline Feedrate[0.03]*Depth of Cut[0.075] & 0.0691 \\
\hline Feedrate[0.03]*Depth of Cut[0.15] & 0.0628 \\
\hline Feedrate[0.15]*Depth of Cut[0.05] & 0.1608 \\
\hline Feedrate[0.15]*Depth of Cut[0.075] & 0.7416 \\
\hline Feedrate[0.15] ${ }^{\star}$ Depth of Cut[0.15] & 0.2137 \\
\hline Feedrate[0.5]*Depth of Cut[0.05] & 0.1457 \\
\hline Feedrate[0.5 ${ }^{\star}$ Depth of Cut $[0.075]$ & 1.0000 \\
\hline Feedrate[0.5 $]^{\star}$ Depth of Cut[0.15] & 0.1457 \\
\hline Feedrate[0.1 $]^{\star}$ Depth of Cut[0.05] & 0.1514 \\
\hline Feedrate[0.1 $]^{\star}$ Depth of Cut[0.075] & 0.1468 \\
\hline Feedrate[0.1]*Depth of Cut[0.15] & 0.4403 \\
\hline Tool Coating[Diamond]*Depth of Cut[0.05] & 0.8936 \\
\hline Tool Coating[Diamond]*Depth of Cut[0.075] & 0.9469 \\
\hline Tool Coating[Diamond]*Depth of Cut[0.15] & 0.9467 \\
\hline Tool Coating[Titanium Carbonitride] ${ }^{\star}$ Depth of Cut[0.05] & 0.8465 \\
\hline Tool Coating[Titanium Carbonitride $]^{\star}$ Depth of Cut[0.075] & 0.8070 \\
\hline Tool Coating[Titanium Carbonitride]*Depth of Cut[0.15] & 0.6605 \\
\hline Tool Coating[Diamondlike Carbon] ${ }^{*}$ Depth of Cut[0.05] & 0.1365 \\
\hline Tool Coating[Diamondlike Carbon]*Depth of Cut[0.075] & 0.7201 \\
\hline Tool Coating[Diamondlike Carbon]Depth of Cut[0.15] & 0.2561 \\
\hline Tool Coating[Titanium Nitride and Titanium Aluminum Nitride $]^{\star}$ Depth of Cut[0.05] & 0.1227 \\
\hline Tool Coating[Titanium Nitride and Titanium Aluminum Nitride] ${ }^{\star}$ Depth of Cut[0.075] & 0.9648 \\
\hline Tool Coating[Titanium Nitride and Titanium Aluminum Nitride $]^{\star}$ Depth of Cut[0.15] & 0.1328 \\
\hline
\end{tabular}


The $0.5 \mathrm{~mm} / \mathrm{rev}(88.5827 \mathrm{in} / \mathrm{min}$ ) feedrate initially chosen was able to mill 2 slots, however, it broke during the cutting of the third slot. It was then replaced with the $0.1 \mathrm{~mm} / \mathrm{rev}$ (17.7165 in/min) feedrate. Although the bit used was diamond coated, due to the high feedrate the cutting forces were too high and led to the broken bit. This shows that high feedrates when milling CFRP damages the bit and the material which corresponds to the articles found that lower feedrates lead to better milled CFRP by reducing cutting forces therefore reducing delamination and tool wear.

The JMP profiler was used to determine the most desirable operating conditions for each factor and choosing the most suitable level depending on the expected outcome of the milling operation. When dimensional accuracy and surface roughness are equally important, a feedrate of $0.03 \mathrm{~mm} / \mathrm{rev}$, TiN and TiAlN tool coating, and a depth of cut of 0.05 in lead to better results. Based on the literature review, low feedrate and diamond coated tools were said to cut CFRP better; however, this experiment showed that feedrate does need to be low, but a TiN and TiAlN tool coating has better results. Not enough information was given in previous work on the depth of cut, but this experiment shows that depth of cut is somewhat important and does not need to be too low. In this case, the slot milled in 3 passes led to the best results.

While this configuration is best when dimensional accuracy and surface roughness are important, the operating conditions change if only one aspect is important. Surface roughness uses the same operating conditions listed whether or not dimensional accuracy is important. On the other hand, when dimensional accuracy is more important, a Diamondlike Carbon tool (DLC) coating and a depth of cut of 0.075 in are more suitable for better results. When cost is an equally important factor, which it usually is, a higher feedrate of $0.15 \mathrm{~mm} / \mathrm{rev}$ is better to mill the slot in less time, reducing machining cost. When only dimensional accuracy and surface roughness are important, at best operating conditions, an average dimensional accuracy of $2.49 \%$ and average surface roughness of $0.628 \mu \mathrm{m}$ can be obtained at the cost of $\$ 0.25$ per slot or $\$ 14.71 / \mathrm{in}^{3}$. When cost is included, the dimensional accuracy decreases to $3.20 \%$ and surface roughness to $0.882 \mu \mathrm{m}$ at the cost of $\$ 0.09$ per slot or $\$ 5.29 / \mathrm{in}^{3}$. 
A coolant was used during the milling operation to reduce the heat generated. Based on the literature review, heat generation causes delamination in the material and damages the tool used. An example of the setup is shown below in Figure 21. There was no visible damage to the material or the tools. Air pressure was also used to remove the milled chips from the block while being cut to ensure that they do not interfere with the cutting.

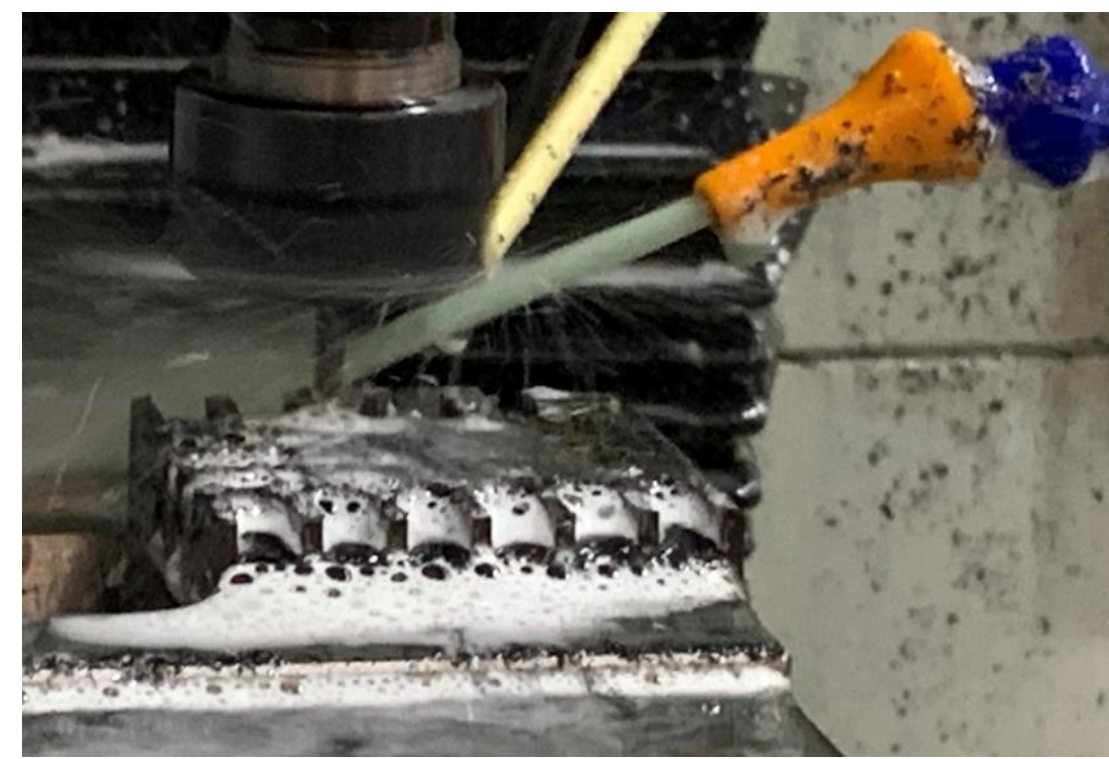

Figure 21: Milling operation.

This analysis determined the desirable outcome using a slot two times the diameter of the bit which led to 2D Contour. However, if milling a slot that bigger or smaller than two times the diameter then 2D Contour, 3D Contour and 3D Pencil cannot be used, therefore 2D Adaptive clearing would lead to better results. During the analysis, a correlation between the cutting pattern and the dimensional accuracy and surface roughness was observed. 2D Adaptive, 3D Adaptive, 2D Pocket and 3D Pocket toolpaths had the lowest dimensional accuracy and surface roughness, while 3D Pencil, 2D Contour, 3D Contour had the best. The lower four toolpaths have a longer cutting pattern where they move back and forth multiple times to mill the slot while the better three only do one pass around the slot. This could be because the more movement the bit performs during the operation the higher the delamination is in the material leading to worse results. 
Figures 17-19 show the effect of different levels of the factors on surface roughness. All the profiles were exported from the Dektak XT Stylus Profilometer. Figure 22 shows the effect of the three levels of feedrate on surface roughness. The $0.03 \mathrm{~mm} / \mathrm{rev}$ (blue line) has the lowest overall step height, which corresponds to the analysis and literature review that a lower feedrate leads to better surface roughness. Figure 23 compares the different tool coatings. While Titanium Nitride and Titanium Aluminum Nitride is the best tool coating tested for dimensional accuracy and surface roughness, Diamond coated tools are better for surface roughness, and Diamondlike Carbon coated tools lead to the roughest surface. Depth of cut also follows the same trend as feedrate, that a lower level leads to better surface roughness, as shown in Figure 24.

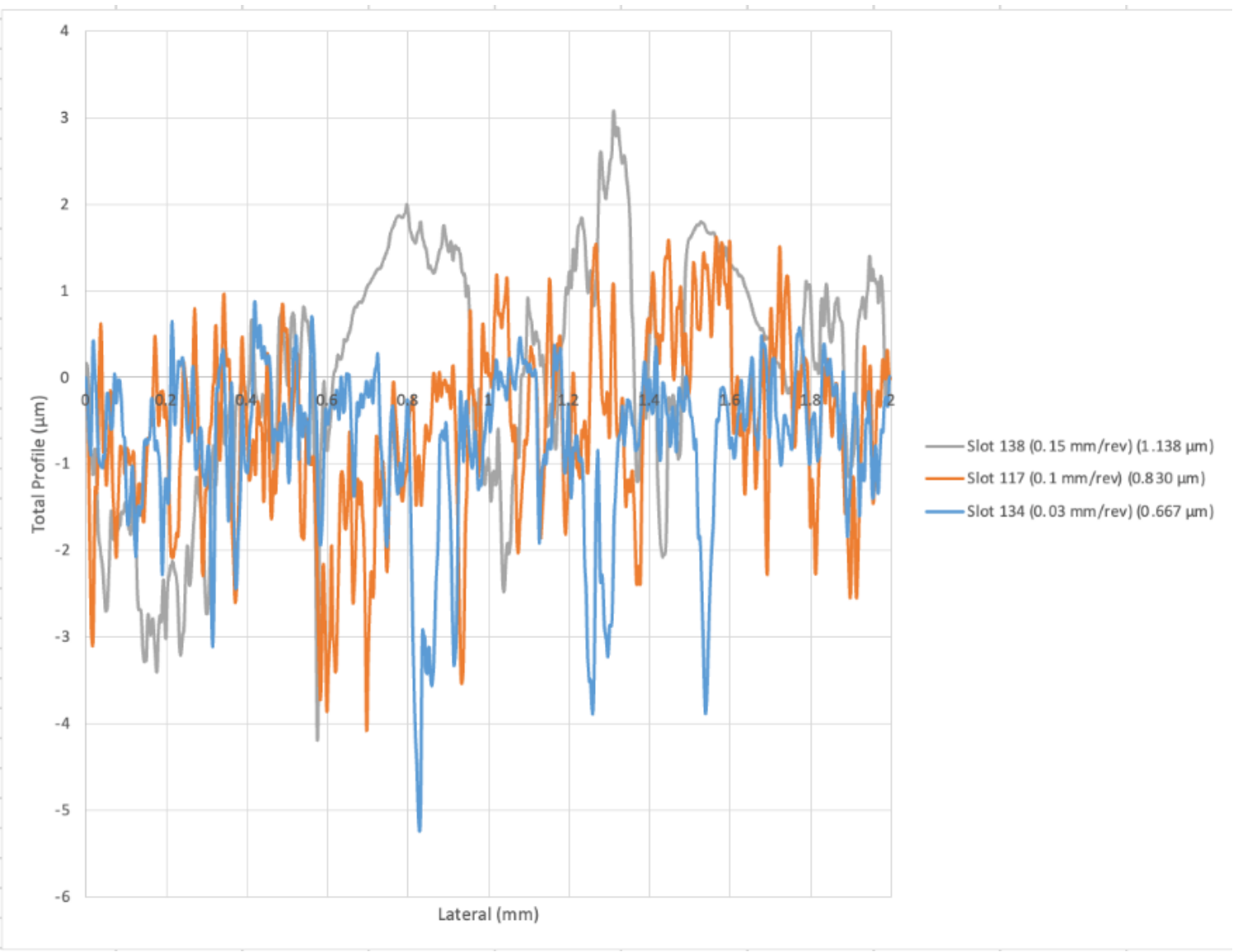

Figure 22: Effect of feedrate on surface roughness 


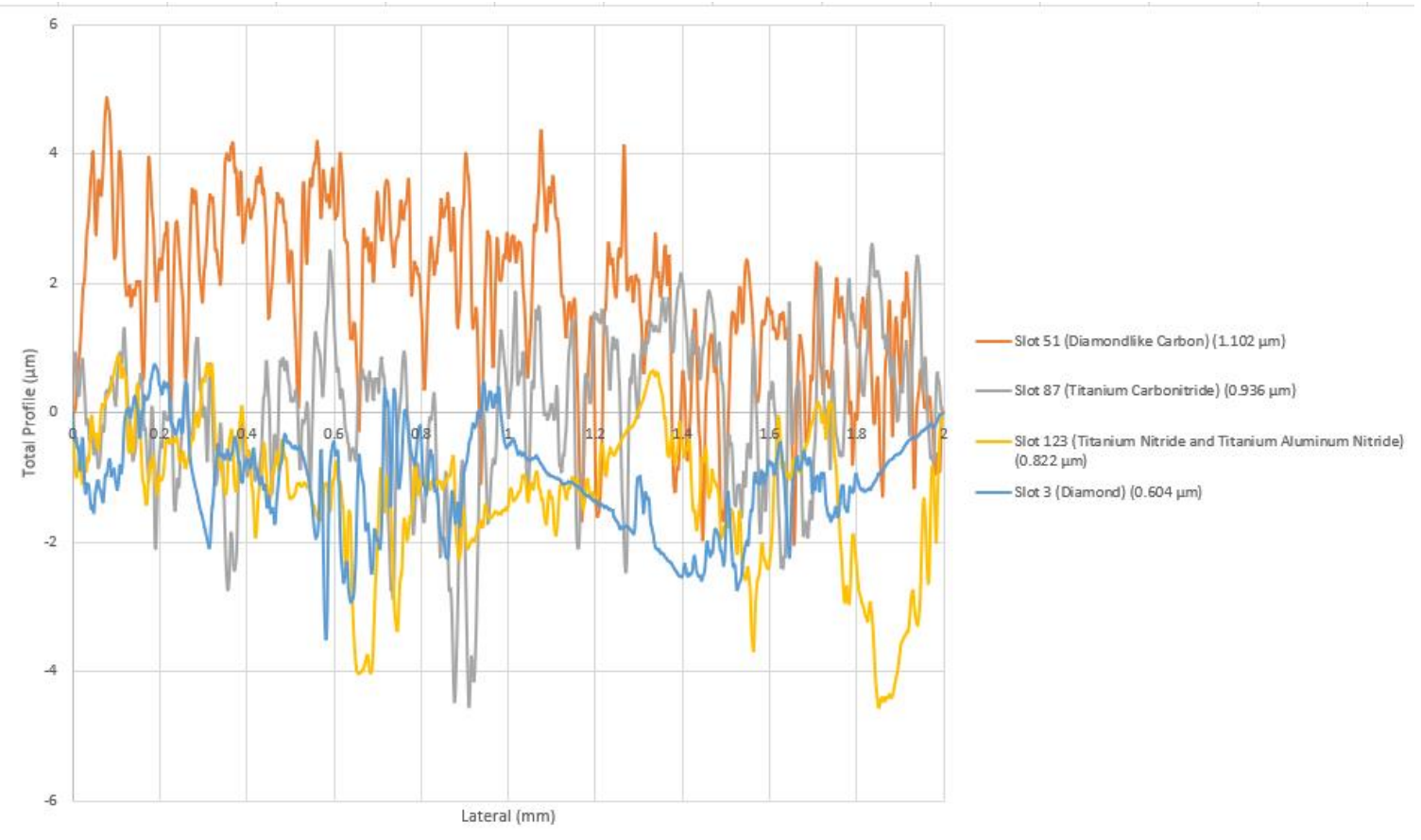

Figure 23: Effect of tool coating on surface roughness

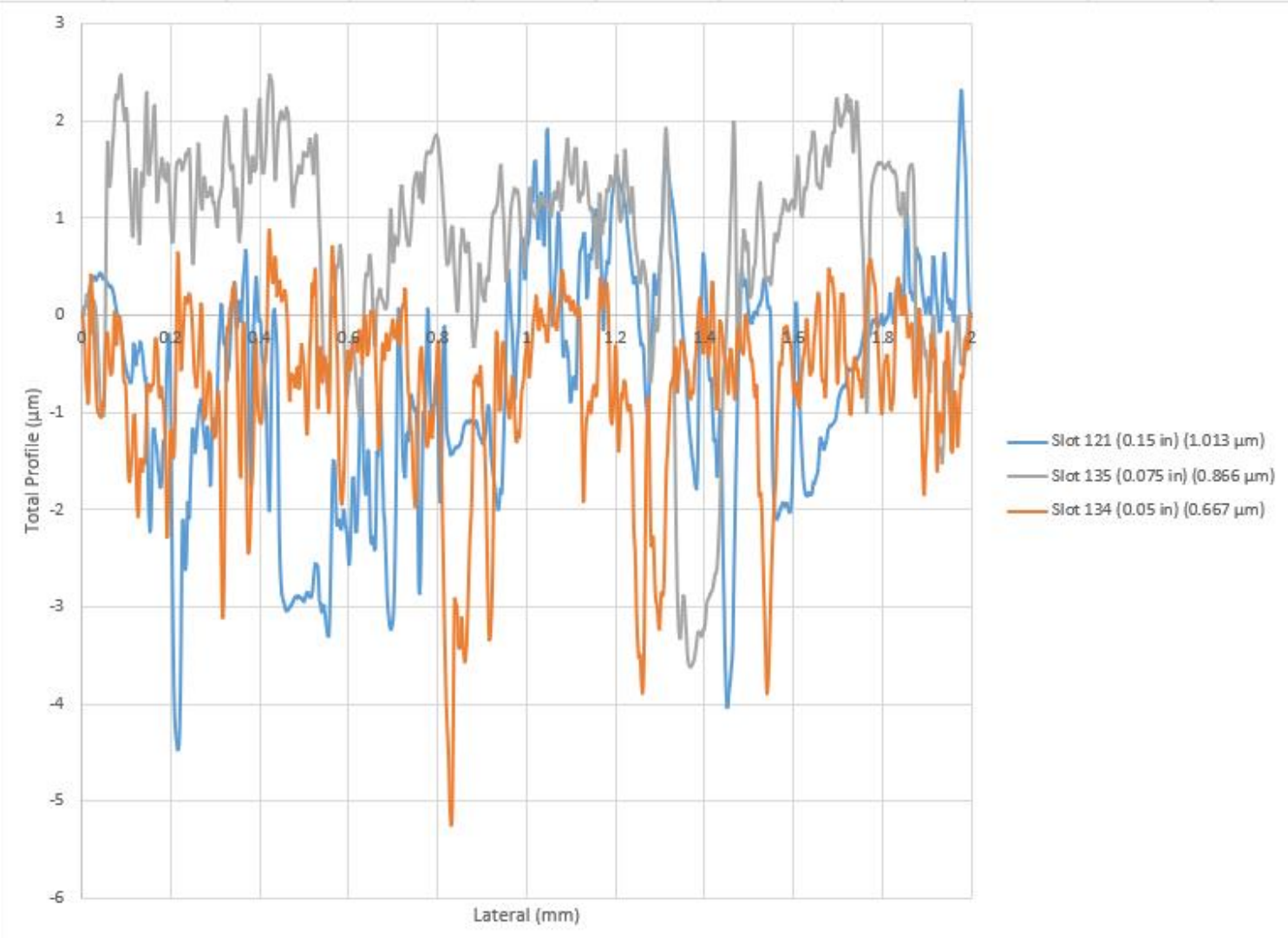

Figure 24: Effect of depth of cut on surface roughness 


\section{Conclusion}

\subsection{Conclusion}

In conclusion, the use of CFRP in the manufacturing industry has skyrocketed in recent years, leading to the need to manufacture CFRP given its difficulties successfully. Although many manufacturing methods can produce parts made with CFRP, CNC Milling offers low costs at low volumes, a good surface finish, and a tight tolerance.

Determining which toolpath type, tool coating, feedrate, and depth of cut to use is vital in machining CFRP. Therefore, this thesis conducted an experiment and determined which toolpath, machine settings, and tool materials among the tested achieve the most desirable outcome. Two experiments were designed to determine the optimal levels to use when milling CFRP. The factors tested were chosen based on insufficient information found in previous work during the conducted literature review. Little work is done on the impact of the toolpath type or the effect of different levels of the factors listed above on the operation. This research gap is addressed in this thesis.

The first experiment compared the dimensional accuracy and surface quality of the toolpath types available on fusion 360. Seven toolpaths were used to mill slots at a constant depth of cut and feedrate using a Tormach PCNC 1100. The slots were then measured with a caliper and the Dektak XT Stylus Profilometer, a mechanical profiler. The data collected was then analyzed in JMP. The analysis determined that 3D Pencil was the best 3D toolpath in terms of dimensional accuracy and surface roughness and 2D Contour is the best 2D toolpath type.

The second experiment tested different combinations of three levels of feedrate, three levels of depth of cut, and four levels of tool coatings using the 2D Contour toolpath type determined in the initial experiment. Three replications were used to reduce the effect of tool wear on the results. The main effects, as well as their interaction effects, were analyzed. The experiment showed that feedrate, tool coating, and depth of cut are crucial factors in milling CFRP successfully. The analysis results showed that selecting a low feedrate $(0.03 \mathrm{~mm} / \mathrm{rev})$ and depth of cut ( 0.05 in) with a Titanium Nitride and Titanium Aluminum Nitride leads to better milled CFRP parts. 


\subsection{Limitations and Future Work}

This thesis did not include the effect of heat generation or tool wear on the milled part's

dimensional accuracy and surface roughness due to the unavailability of the required devices to measure both aspects.

Further work could be done to compare different fiber placements or matrix weights. An experiment could be conducted to determine the effect of fiber weight, fiber placement, or layer thickness on dimensional accuracy, surface roughness, or material strength. Another experiment that could be conducted is to compare dimensional accuracy and surface roughness among different materials using the same factor combinations across all materials. Heat generation and tool wear affect CFRP delamination and could be inspected in a future experiment to choose a feedrate and tool coating that reduces their effect. 


\section{Work Cited}

[1] Abhishek, Kumar, et al. "Multi-Objective Optimisation during Drilling of CFRP Composites: A PCAFuzzy Taguchi Integrated Approach." International Journal of Industrial and Systems Engineering, vol. 26, no. 2, 2017, pp. 182-200. DOI.org (Crossref), doi:10.1504/IJISE.2017.083672

[2] Abhishek, Kumar, et al. "Optimization of Thrust, Torque, Entry, and Exist Delamination Factor during Drilling of CFRP Composites." The International Journal of Advanced Manufacturing Technology, vol. 76, no. 1-4, Jan. 2015, pp. 401-416. DOI.org (Crossref), doi:10.1007/s00170014-6199-3.

[3] Altin Karataş, Meltem, and Hasan Gökkaya. "A Review on Machinability of Carbon Fiber Reinforced Polymer (CFRP) and Glass Fiber Reinforced Polymer (GFRP) Composite Materials." Defence Technology, vol. 14, no. 4, Aug. 2018, pp. 318-326. DOI.org (Crossref), doi:10.1016/j.dt.2018.02.001.

[4] Ashworth, Sam, et al. "Effects of Machine Stiffness and Cutting Tool Design on the Surface Quality and Flexural Strength of Edge Trimmed Carbon Fibre Reinforced Polymers." Composites Part A: Applied Science and Manufacturing, vol. 119, Apr. 2019, pp. 88-100. DOI.org (Crossref), doi:10.1016/j.compositesa.2019.01.019.

[5] Caggiano, Alessandra, et al. "Characterization of a New Dry Drill-Milling Process of Carbon Fibre Reinforced Polymer Laminates." Materials, vol. 11, no. 8, Aug. 2018, p. 1470. DOI.org (Crossref), doi:10.3390/ma11081470.

[6] Cai, Xiaojiang, et al. "An Experimental Investigation on Precision Machining Mechanism of Carbon Fibre Reinforced Polymer" International Journal of Abrasive Technology, vol. 9, no 1, 2019, pp. 16-30. DOI.org (Crossref), doi:10.1504/IJAT.2019.097965.

[7] Catche, Soraya, et al. "Analysis of Hole Wall Defects of Drilled Carbon Fiber Reinforced Polymer Laminates." Journal of Composite Materials, vol. 49, no. 10, May 2015, pp. 1223-1240. DOI.org (Crossref), doi:10.1177/0021998314532668.

[8] Çelik, Ali, et al. "Investigation on the Performance of SiAlON Ceramic Drills on Aerospace Grade CFRP Composites." Journal of Materials Processing Technology, vol. 223, Sept. 2015, pp. 3947. DOI.org (Crossref), doi:10.1016/j.jmatprotec.2015.03.040.

[9] Chandramohan, D., and B. Murali. "MACHINING OF COMPOSITES - A REVIEW." Academic Journal of Manufacturing Engineering, vol. 12, no. 3, 2014, pp. 67-71

[10] Che, Demeng, et al. "Machining of Carbon Fiber Reinforced Plastics/Polymers: A Literature Review." Journal of Manufacturing Science and Engineering, vol. 136, no. 3, June 2014, p. 034001. DOI.org (Crossref), doi:10.1115/1.4026526. 
[11] D, Rajkumar, et al. "Experimental Investigation and Analysis of Factors Influencing Delamination and Thrust Force during Drilling of Carbon-Fibre Reinforced Polymer Composites." Pigment \& Resin Technology, vol. 46, no. 6, Nov. 2017, pp. 507-524. DOI.org (Crossref), doi:10.1108/PRT10-2016-0097.

[12] Dang, Jiaqiang, et al. "Experimental Investigation on Mechanical Drilling of a Newly Developed CFRP/Al Co-Cured Material." The International Journal of Advanced Manufacturing Technology, vol. 106, no. 3-4, Jan. 2020, pp. 993-1004. DOI.org (Crossref), doi:10.1007/s00170-019-04659-1.

[13] Díaz-Álvarez, José, et al. "Theoretical Estimation of Thermal Effects in Drilling of Woven Carbon Fiber Composite." Materials, vol. 7, no. 6, June 2014, pp. 4442-4454. DOI.org (Crossref), doi:10.3390/ma7064442.

[14] Feito, Norberto, Antonio Diaz-Álvarez, et al. "Experimental Analysis of Special Tool Geometries When Drilling Woven and Multidirectional CFRPs." Journal of Reinforced Plastics and Composites, vol. 35, no. 1, Jan. 2016, pp. 33-55. DOI.org (Crossref), doi: $10.1177 / 0731684415612931$.

[15] Feito, Norberto, José Díaz-Álvarez, et al. "Experimental Analysis of the Influence of Drill Point Angle and Wear on the Drilling of Woven CFRPs." Materials, vol. 7, no. 6, May 2014, pp. 42584271. DOI.org (Crossref), doi:10.3390/ma7064258.

[16] Fernandez-Vidal, Severo, et al. "Tool Wear Mechanism in Cutting of Stack CFRP/UNS A97075." Materials, vol. 11, no. 8, July 2018, p. 1276. DOI.org (Crossref), doi:10.3390/ma11081276.

[17] Ferreira, José, et al. "Effect of Machining Parameters on the Mechanical Properties of High Dosage Short -Carbon- Fiber Reinforced Composites." Frattura Ed Integrità Strutturale, vol. 13, no. 48, Mar. 2019, pp. 249-256. DOI.org (Crossref), doi:10.3221/IGF-ESIS.48.26.

[18] Garcia, A., et al. "Automatic Evaluation of Non-Destructive Testing of Composites." Insight - NonDestructive Testing and Condition Monitoring, vol. 56, no. 6, June 2014, pp. 319-325. DOI.org (Crossref), doi:10.1784/insi.2014.56.6.319.

[19] Gaugel, Simon, et al. "A Comparative Study on Tool Wear and Laminate Damage in Drilling of Carbon-Fiber Reinforced Polymers (CFRP)." Composite Structures, vol. 155, Nov. 2016, pp. 173-183. DOI.org (Crossref), doi:10.1016/j.compstruct.2016.08.004.

[20] Geier, Norbert, et al. "Advanced Cutting Tools and Technologies for Drilling Carbon Fibre Reinforced Polymer (CFRP) Composites: A Review." Composites Part A: Applied Science and Manufacturing, vol. 125, Oct. 2019, p. 105552. DOI.org (Crossref), doi:10.1016/j.compositesa.2019.105552.

[21] Geier, Norbert, and Tibor Szalay. "Optimisation of Process Parameters for the Orbital and Conventional Drilling of Uni-Directional Carbon Fibre-Reinforced Polymers (UD-CFRP)." Measurement, vol. 110, Nov. 2017, pp. 319-334. DOI.org (Crossref), doi:10.1016/j.measurement.2017.07.007. 
[22] Girot, Franck, et al. "New Analytical Model for Delamination of CFRP during Drilling." Journal of Materials Processing Technology, vol. 240, Feb. 2017, pp. 332-343. DOI.org (Crossref), doi:10.1016/j.jmatprotec.2016.10.007.

[23] Haeger, Andreas, et al. "Effect of Drilling-Induced Damage on the Open Hole Flexural Fatigue of Carbon/Epoxy Composites." Composite Structures, vol. 215, May 2019, pp. 238-248. DOI.org (Crossref), doi:10.1016/j.compstruct.2019.02.025.

[24] Harris, Muhammad, et al. "Carbon Fiber-Reinforced Polymer Composite Drilling via Aluminum Chromium Nitride-Coated Tools: Hole Quality and Tool Wear Assessment." Journal of Reinforced Plastics and Composites, vol. 36, no. 19, Oct. 2017, pp. 1403-1420. DOI.org (Crossref), doi:10.1177/0731684417709359.

[25] Isbilir, Ozden, and Elaheh Ghassemieh. "COMPARATIVE STUDY OF TOOL LIFE AND HOLE QUALITY IN DRILLING OF CFRP/TITANIUM STACK USING COATED CARBIDE DRILL." Machining Science and Technology, vol. 17, no. 3, July 2013, pp. 380-409. DOI.org (Crossref), doi:10.1080/10910344.2013.806098.

[26] Jamshidi, Maryam, et al. "Fractal Analysis Implementation for Tool Wear Monitoring Based on Cutting Force Signals during CFRP/Titanium Stack Machining." The International Journal of Advanced Manufacturing Technology, vol. 106, no. 9-10, Feb. 2020, pp. 3859-3868. DOI.org (Crossref), doi:10.1007/s00170-019-04880-y.

[27] Jia, Zhenyuan, et al. "Temperature Effects in End Milling Carbon Fiber Reinforced Polymer Composites." Polymer Composites, vol. 39, no. 2, Feb. 2018, pp. 437-447. DOI.org (Crossref), doi:10.1002/pc.23954.

[28] K., Shunmugesh, and Panneerselvam Kavan. "Investigation and Optimization of Machining Parameters in Drilling of Carbon Fiber Reinforced Polymer (CFRP) Composites." Pigment \& Resin Technology, vol. 46, no. 1, Jan. 2017, pp. 21-30. DOI.org (Crossref), doi:10.1108/PRT-032016-0029.

[29] Karpat, Yiğit, Umut Karagüzel, et al. "A Thermo-Mechanical Model of Drill Margin-Borehole Surface Interface Contact Conditions in Dry Drilling of Thick CFRP Laminates." International Journal of Machine Tools and Manufacture, vol. 154, July 2020, p. 103565. DOI.org (Crossref), doi:10.1016/j.ijmachtools.2020.103565.

[30] Karpat, Yiğit, Onur Bahtiyar, et al. "Mechanistic Force Modeling for Milling of Unidirectional Carbon Fiber Reinforced Polymer Laminates." International Journal of Machine Tools and Manufacture, vol. 56, May 2012, pp. 79-93. DOI.org (Crossref), doi:10.1016/j.ijmachtools.2012.01.001.

[31] Kourra, Nadia, Jason M. Warnett, Alex Attridge, Aishah Dahnel, et al. "A Metrological Inspection Method Using Micro-CT for the Analysis of Drilled Holes in CFRP and Titanium Stacks." The International Journal of Advanced Manufacturing Technology, vol. 88, no. 5-8, Feb. 2017, pp. 1417-1427. DOI.org (Crossref), doi:10.1007/s00170-016-8691-4. 
[32] Kourra, Nadia, Jason M. Warnett, Alex Attridge, Ercihan Kiraci, et al. "Metrological Study of CFRP Drilled Holes with X-Ray Computed Tomography." The International Journal of Advanced Manufacturing Technology, vol. 78, no. 9-12, June 2015, pp. 2025-2035. DOI.org (Crossref), doi:10.1007/s00170-014-6734-2.

[33] Krishnaraj, Vijayan, et al. "Optimization of Machining Parameters at High Speed Drilling of Carbon Fiber Reinforced Plastic (CFRP) Laminates." Composites Part B: Engineering, vol. 43, no. 4, June 2012, pp. 1791-1799. DOI.org (Crossref), doi:10.1016/j.compositesb.2012.01.007.

[34] Kumar, Dhiraj, and Kk Singh. "Investigation of Delamination and Surface Quality of Machined Holes in Drilling of Multiwalled Carbon Nanotube Doped Epoxy/Carbon Fiber Reinforced Polymer Nanocomposite." Proceedings of the Institution of Mechanical Engineers, Part L: Journal of Materials: Design and Applications, vol. 233, no. 4, Apr. 2019, pp. 647-663. DOI.org (Crossref), doi:10.1177/1464420717692369.

[35] Li, Hao, Xuda Qin, Gaiyun He, et al. "An Energy Based Force Prediction Method for UD-CFRP Orthogonal Machining." Composite Structures, vol. 159, Jan. 2017, pp. 34-43. DOI.org (Crossref), doi:10.1016/j.compstruct.2016.09.051.

[36] Li, Hao, Xuda Qin, Tian Huang, et al. "Machining Quality and Cutting Force Signal Analysis in UDCFRP Milling under Different Fiber Orientation." The International Journal of Advanced Manufacturing Technology, vol. 98, no. 9-12, Oct. 2018, pp. 2377-2387. DOI.org (Crossref), doi:10.1007/s00170-018-2312-3.

[37] Li, Hao Nan, et al. "Damage Behaviors of Unidirectional CFRP in Orthogonal Cutting: A Comparison between Single- and Multiple-Pass Strategies." Composites Part B: Engineering, vol. 185, Mar. 2020, p. 107774. DOI.org (Crossref), doi:10.1016/j.compositesb.2020.107774.

[38] Miller, J, et al. "Machining and Drilling of Carbon Fiber Reinforced Plastic (CFRP) Composites" Sampe Journal, vol. 49, no. 2, 2013, pp. 36-46.

[39] Lorincz, Jim. "Materials Choices Test Innovative Cutting Solutions" Manufacturing Engineering, vol. 158 , no. 2, February 2017, pp. 74-80.

[40] Ming, Weiwei, et al. "Modelling and Experiment of Milling Force under All Fibre Orientation Angles in Slot Milling of Unidirectional CFRP Laminates." International Journal of Manufacturing Research, vol. 14, no. 2, 2019, p. 145. DOI.org (Crossref), doi:10.1504/IJMR.2019.100022.

[41] Pereszlai, Csongor, and Norbert Geier. "Comparative Analysis of Wobble Milling, Helical Milling and Conventional Drilling of CFRPs." The International Journal of Advanced Manufacturing Technology, vol. 106, no. 9-10, Feb. 2020, pp. 3913-3930. DOI.org (Crossref), doi:10.1007/s00170-019-04842-4.

[42] Prakash, Rangasamy, et al. "High-Speed Edge Trimming of CFRP and Online Monitoring of Performance of Router Tools Using Acoustic Emission." Materials, vol. 9, no. 10, Sept. 2016, p. 798. DOI.org (Crossref), doi:10.3390/ma9100798. 
[43] Qiu, Xinyi, et al. "Study on Chisel Edge Drilling Behavior and Step Drill Structure on Delamination in Drilling CFRP." Composite Structures, vol. 203, Nov. 2018, pp. 404-413. DOI.org (Crossref), doi:10.1016/j.compstruct.2018.07.007.

[44] Rajkumar, D., et al. "Optimization of Machining Parameters on Microdrilling of CFRP Composites by Taguchi Based Desirability Function Analysis." Indian Journal of Engineering \& Material Sciences, vol. 24, no. 5, October 2017, pp. 331-338.

[45] Seeholzer, Lukas, et al. "Analytical Force Model for Drilling out Unidirectional Carbon Fibre Reinforced Polymers (CFRP)." Journal of Materials Processing Technology, vol. 278, Apr. 2020, p. 116489. DOI.org (Crossref), doi:10.1016/j.jmatprotec.2019.116489.

[46] Shaban, Yasser, et al. "Process Control Based on Pattern Recognition for Routing Carbon Fiber Reinforced Polymer." Journal of Intelligent Manufacturing, vol. 28, no. 1, Jan. 2017, pp. 165179. DOI.org (Crossref), doi:10.1007/s10845-014-0968-6.

[47] Sheikh-Ahmad, Jamal, et al. "Machining Damage in Edge Trimming of CFRP." Materials and Manufacturing Processes, vol. 27, no. 7, July 2012, pp. 802-808. DOI.org (Crossref), doi:10.1080/10426914.2011.648253.

[48] Shetty, Nagaraja, et al. "Soft Computing Techniques during Drilling of Bi-Directional Carbon Fiber Reinforced Composite." Applied Soft Computing, vol. 41, Apr. 2016, pp. 466-478. DOI.org (Crossref), doi:10.1016/j.asoc.2016.01.016.

[49] Shi, Zy, et al. "A Review on Research Progress of Machining Technologies of Carbon FiberReinforced Polymer and Aramid Fiber-Reinforced Polymer." Proceedings of the Institution of Mechanical Engineers, Part C: Journal of Mechanical Engineering Science, vol. 233, no. 13, July 2019, pp. 4508-4520. DOI.org (Crossref), doi:10.1177/0954406219830732.

[50] Shunuan, Liu, et al. "On Full Life-Cycle Instantaneous Force Predicting When Drilling CFRP-Metal Stacks." The International Journal of Advanced Manufacturing Technology, vol. 88, no. 1-4, Jan. 2017, pp. 651-661. DOI.org (Crossref), doi:10.1007/s00170-016-8794-y.

[51] Slamani, Mohamed, et al. "Comparison of Two Models for Predicting Tool Wear and Cutting Force Components during High Speed Trimming of CFRP." International Journal of Material Forming, vol. 8, no. 2, Apr. 2015, pp. 305-316. DOI.org (Crossref), doi:10.1007/s12289-014-1170-2.

[52] Slamani, Mohamed, et al. "Influence of Machining Parameters on Surface Quality during High Speed Edge Trimming of Carbon Fiber Reinforced Polymers." International Journal of Material Forming, vol. 12, no. 3, May 2019, pp. 331-353. DOI.org (Crossref), doi:10.1007/s12289-0181419-2.

[53] Sobri, Sharizal Ahmad, et al. "Drilling Strategy for Thick Carbon Fiber Reinforced Polymer Composites (CFRP): A Preliminary Assessment." Journal of Engineering and Technological Sciences, vol. 50, no. 1, 2018, pp. 21-39. DOI.org (Crossref), doi:10.5614/j.eng.technol.sci.2018.50.1.2. 
[54] Sun, Lei, et al. "Mechanism of Reduction of Damage during Helical Milling of Titanium/CFRP/Aluminium Stacks." The International Journal of Advanced Manufacturing Technology, vol. 107, no. 11-12, Apr. 2020, pp. 4741-4753. DOI.org (Crossref), doi:10.1007/s00170-020-05177-1.

[55] Vigneshwaran, S., et al. "Review on Machinability of Fiber Reinforced Polymers: A Drilling Approach." Silicon, vol. 10, no. 5, Sept. 2018, pp. 2295-2305. DOI.org (Crossref), doi:10.1007/s12633-018-9764-9.

[56] Voss, Robert, et al. "Influence of Fibre Orientation, Tool Geometry and Process Parameters on Surface Quality in Milling of CFRP." CIRP Journal of Manufacturing Science and Technology, vol. 18, Aug. 2017, pp. 75-91. DOI.org (Crossref), doi:10.1016/j.cirpj.2016.10.002.

[57] Wang, Changying, Weiwei Ming, Qinglong An, et al. "Machinability Characteristics Evolution of CFRP in a Continuum of Fiber Orientation Angles." Materials and Manufacturing Processes, vol. 32, no. 9, July 2017, pp. 1041-1050. DOI.org (Crossref), doi:10.1080/10426914.2016.1269915.

[58] Wang, Changying, Gongyu Liu, Qinglong An, et al. "Occurrence and Formation Mechanism of Surface Cavity Defects during Orthogonal Milling of CFRP Laminates." Composites Part B: Engineering, vol. 109, Jan. 2017, pp. 10-22. DOI.org (Crossref), doi:10.1016/j.compositesb.2016.10.015.

[59] Wang, Fu-ji, Bo-yu Zhang, Meng Zhao, et al. "Evolution Laws of Fiber-Matrix Interface Cracks in Machining of Carbon Fiber Reinforced Polymer." The International Journal of Advanced Manufacturing Technology, vol. 101, no. 1-4, Mar. 2019, pp. 963-977. DOI.org (Crossref), doi:10.1007/s00170-018-2992-8.

[60] Wang, Gong-Dong, Stephen Kirwa Melly, and Nan Li. "Experimental Studies on a Two-Step Technique to Reduce Delamination Damage during Milling of Large Diameter Holes in CFRP/Al Stack." Composite Structures, vol. 188, Mar. 2018, pp. 330-339. DOI.org (Crossref), doi:10.1016/j.compstruct.2018.01.039.

[61] Wang, Haijin, Jie Sun, Jianfeng Li, et al. "Evaluation of Cutting Force and Cutting Temperature in Milling Carbon Fiber-Reinforced Polymer Composites." The International Journal of Advanced Manufacturing Technology, vol. 82, no. 9-12, Feb. 2016, pp. 1517-25. DOI.org (Crossref), doi:10.1007/s00170-015-7479-2.

[62] Wang, Haijin, Jie Sun, Dandan Zhang, et al. "The Effect of Cutting Temperature in Milling of Carbon Fiber Reinforced Polymer Composites." Composites Part A: Applied Science and Manufacturing, vol. 91, Dec. 2016, pp. 380-387. DOI.org (Crossref), doi:10.1016/j.compositesa.2016.10.025.

[63] Wang, Haiyan, Xuda Qin, and Hao Li. "Machinability Analysis on Helical Milling of Carbon Fiber Reinforced Polymer." Journal of Advanced Mechanical Design, Systems, and Manufacturing, vol. 9, no. 5, 2015, pp. JAMDSM0057-JAMDSM0057. DOI.org (Crossref), doi:10.1299/jamdsm.2015jamdsm0057.

[64] Wang, Haiyan, Xuda Qin, Dongxu Wu, et al. "Optimization of Cutting Parameters in Helical Milling of Carbon Fiber Reinforced Polymer." Transactions of Tianjin University, vol. 24, no. 1, Jan. 2018, pp. 91-100. DOI.org (Crossref), doi:10.1007/s12209-017-0079-5. 
[65] Wang, Hongxiao, et al. "Effects of Drilling Area Temperature on Drilling of Carbon Fiber Reinforced Polymer Composites Due to Temperature-Dependent Properties." The International Journal of Advanced Manufacturing Technology, vol. 96, no. 5-8, May 2018, pp. 2943-2951. DOI.org (Crossref), doi:10.1007/s00170-018-1810-7.

[66] Xiao, Jianzhang, et al. "An Analytical Approach to Cutting Force Prediction in Milling of Carbon Fiber Reinforced Polymer Laminates." Machining Science and Technology, vol. 22, no. 6, Nov. 2018, pp. 1012-1028. DOI.org (Crossref), doi:10.1080/10910344.2018.1449214.

[67] Xu, Chengyang, et al. "Design of Internal-Chip-Removal Drill for CFRP Drilling and Study of Influencing Factors of Drilling Quality." The International Journal of Advanced Manufacturing Technology, vol. 106, no. 5-6, Jan. 2020, pp. 1657-1669. DOI.org (Crossref), doi:10.1007/s00170-019-04698-8.

[68] Xu, Jinyang, et al. "Study of Drilling-Induced Defects for CFRP Composites Using New Criteria." Composite Structures, vol. 201, Oct. 2018, pp. 1076-1087. DOI.org (Crossref), doi:10.1016/j.compstruct.2018.06.051.

[69] Xu, Jinyang, and Mohamed El Mansori. "Numerical Study on the Chip Removal and Surface Quality of CFRP/Ti6Al4V Stacks." INDIAN J ENG MATER SCI, 2019, p. 10.

[70] Yaşar, Nafiz, and Mustafa Günay. "Experimental Investigation on Novel Drilling Strategy of CFRP Laminates Using Variable Feedrate." Journal of the Brazilian Society of Mechanical Sciences and Engineering, vol. 41, no. 3, Mar. 2019, p. 150. DOI.org (Crossref), doi:10.1007/s40430-0191658-2.

[71] Zenia, S., et al. "Numerical Analysis of the Interaction between the Cutting Forces, Induced Cutting Damage, and Machining Parameters of CFRP Composites." The International Journal of Advanced Manufacturing Technology, vol. 78, no. 1-4, Apr. 2015, pp. 465-480. DOI.org (Crossref), doi:10.1007/s00170-014-6600-2.

[72] Zhu, Pingyu, et al. "Measuring the Two-Dimensional Temperature Profile of Carbon Fiber Reinforced Polymers During Drilling Using Distributed Fiber Sensing." Journal of Lightwave Technology, vol. 37, no. 18, Sept. 2019, pp. 4687-4696. DOI.org (Crossref), doi:10.1109/JLT.2019.2916914.

[73] Airbus. (2019, August 21st). Composites: Airbus continues to shape the future. Retrieved September 07th, 2020, from https://www.airbus.com/newsroom/news/en/2017/08/composites--airbuscontinues-to-shape-the-future.html

[74] Benes, J. (2009, August 11th). CFRP: A Mixed Bag of Challenges. Retrieved September 07th, 2020, from https://www.americanmachinist.com/archive/features/article/21895993/cfrpa-mixed-bag-ofchallenges

[75] Carbon fiber reinforced polymer. (2020, August 27th). Retrieved September 07th, 2020, from https://en.wikipedia.org/wiki/Carbon_fiber_reinforced_polymer

[76] Staff. (2010, November 30th). Why CFRP? Retrieved September 07th, 2020, from https://www.compositesworld.com/articles/why-cfrp 
[77] AERO - Boeing 787 from the ground up. (n.d.). Retrieved March 15th, 2021, from https://www.boeing.com/commercial/aeromagazine/articles/qtr_4_06/article_04_2.html

[78] Dexcraft. (2015, October 07th). Carbon fiber vs. aluminum - comparison of materials. Retrieved March 16th, 2021, from http://www.dexcraft.com/articles/carbon-fiber-composites/aluminium-vscarbon-fiber-comparison-of-materials/\#thermal_expansion

[79] Kopeliovich, D. (2012, June 02nd). Carbon Fiber Reinforced Polymer Composites. Retrieved March 16th, 2021, from https://www.substech.com/dokuwiki/doku.php?id=carbon_fiber_reinforced_polymer_composites

[80] Morabito, A. (2020, July 06th). Carbon fiber vs. steel: Element 6 composites. Retrieved March 16th, 2021, from https://element6composites.com/carbon-fiber-vs-steel-which-is-stronger/

[81] What is carbon fiber? (2020, June 10th). Retrieved March 16th, 2021, from https://www.innovativecomposite.com/what-is-carbon-fiber/

[82] Harik, Ramy and Wuest, Thorsten. (2019). "Introduction to Advanced Manufacturing." doi: $10.4271 / 9780768093278$.

[83] Zhang, et al. "Effect of the Microstructure of Carbon Fiber Reinforced Polymer on Electrochemical Behavior." Journal of The Electrochemical Society. Vol. 165, Jan. 2018, pp. C647-C656. DOI.org (Crossref), doi:10.1149/2.0881810jes.

[84] Geier, Norbert, et al. "Advanced cutting tools and technologies for drilling carbon fibre reinforced polymer (CFRP) composites: A review." Composites Part A: Applied Science and Manufacturing. Vol. 125, Oct. 2019, p. 105552. DOI.org (Crossref), http://dx.doi.org/10.1016/j.compositesa.2019.105552

[85] VendOp. "CNC Machining vs. Injection Molding, Which Is the Right Choice?" VendOp, 16 Feb. 2016, www.vendop.com/blog/cnc-machining-vs-injection-molding-which-is-the-right-choice/ 


\section{Appendix}

\section{Appendix A: Tormach PCNC 1100 Software and Equipment}

\section{Figure A.1: Tormach PCNC 1100}

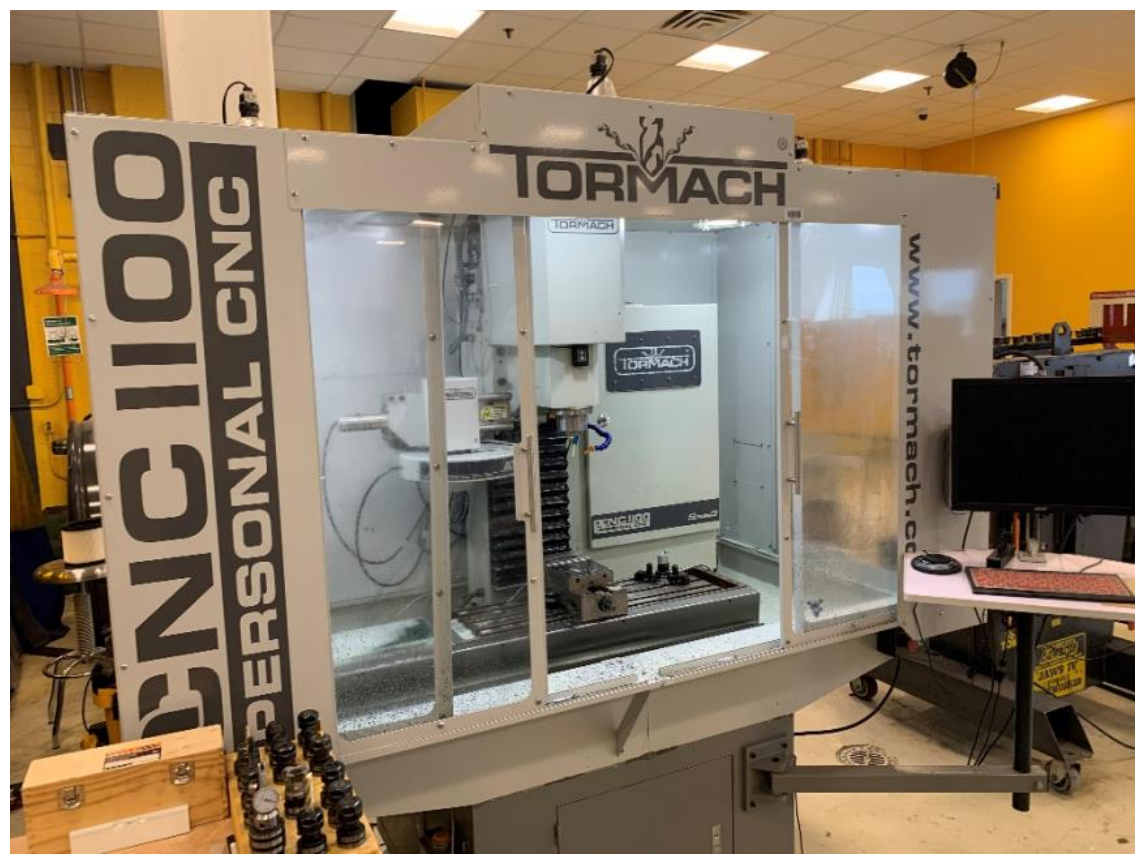

Figure A.2: Work Area

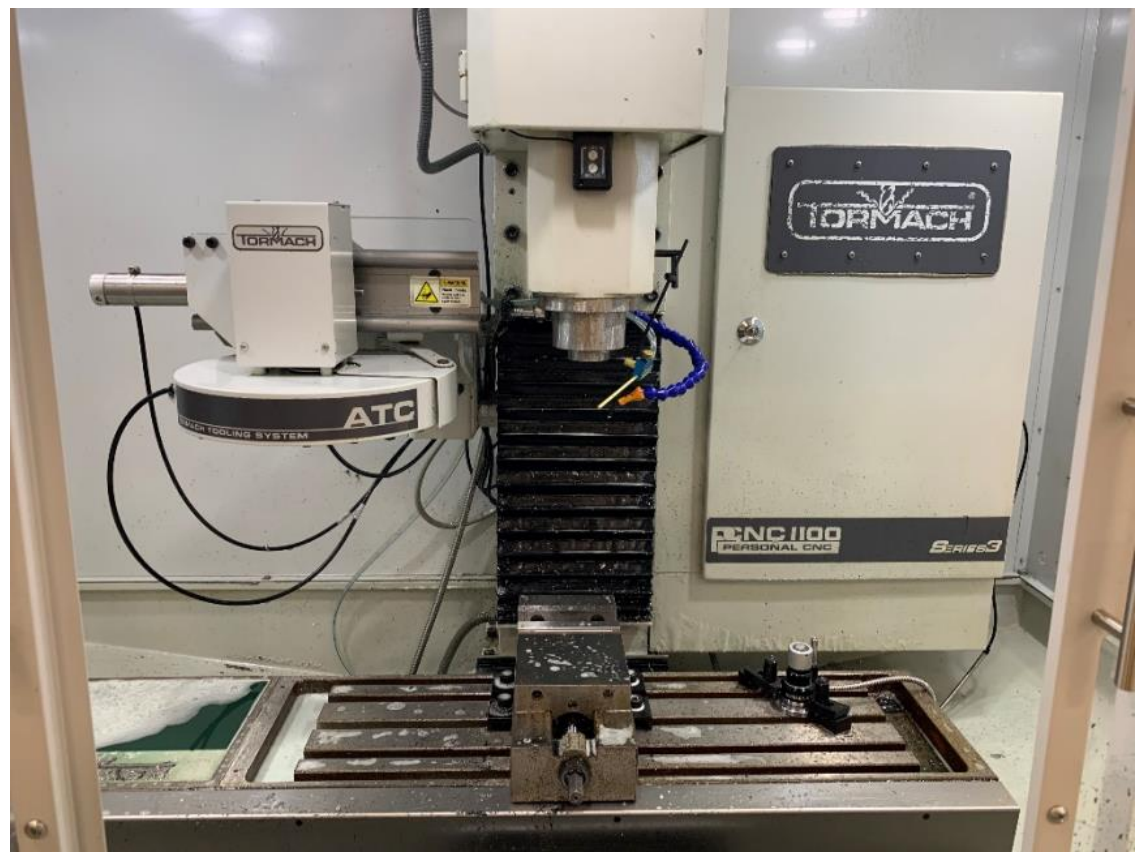


Figure A.3: Tool Holders

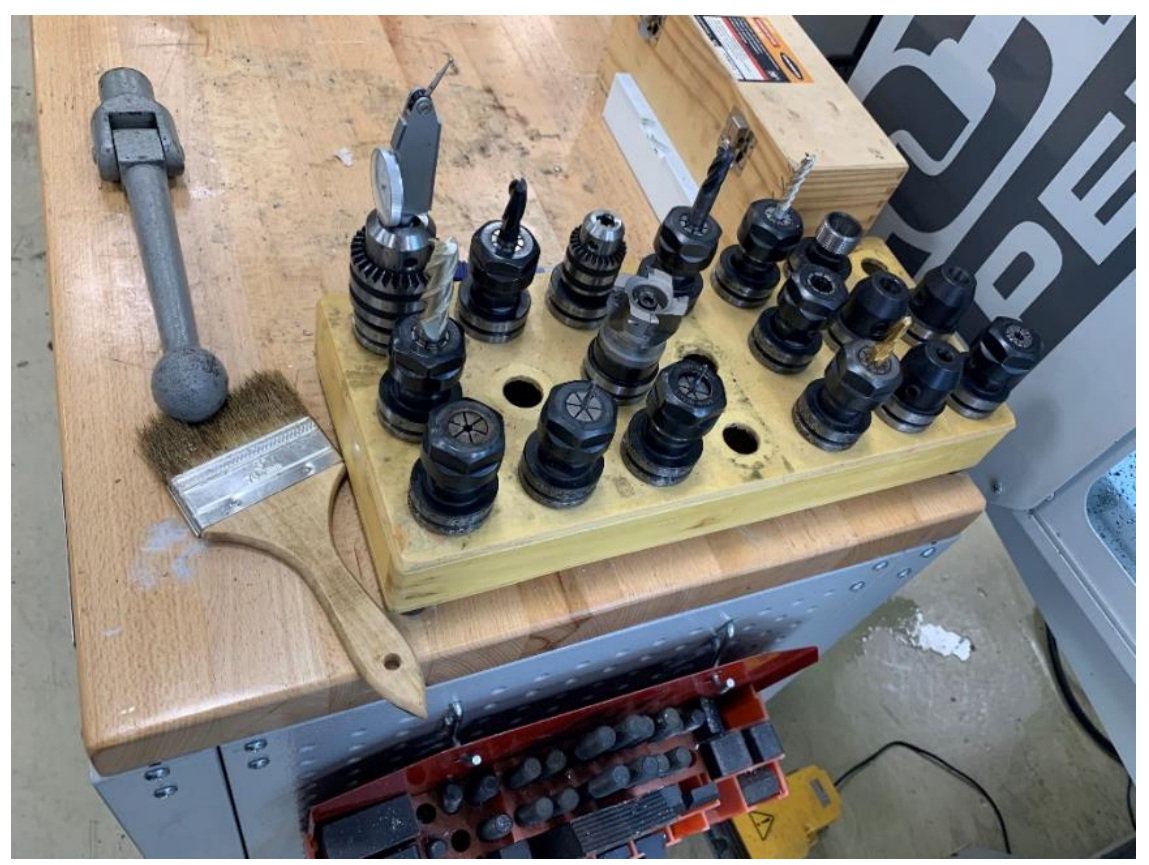

Figure A.4: Referencing

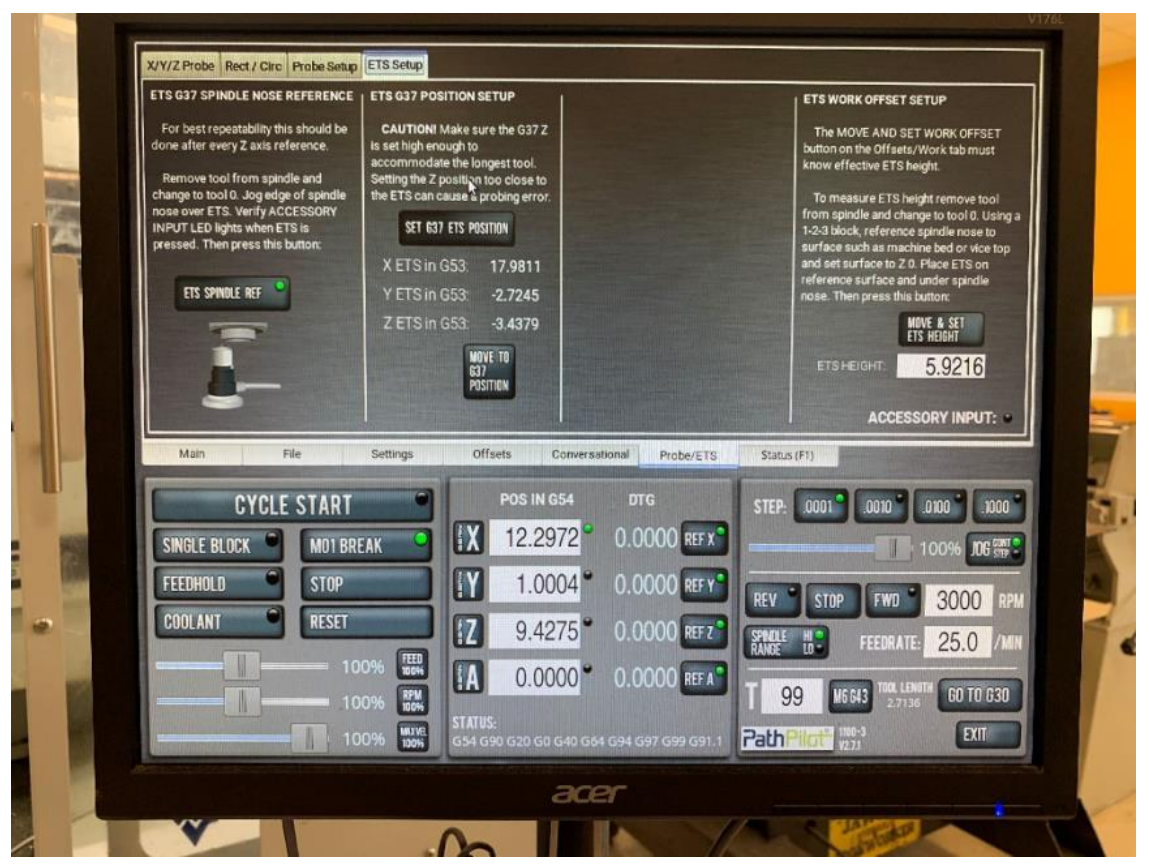




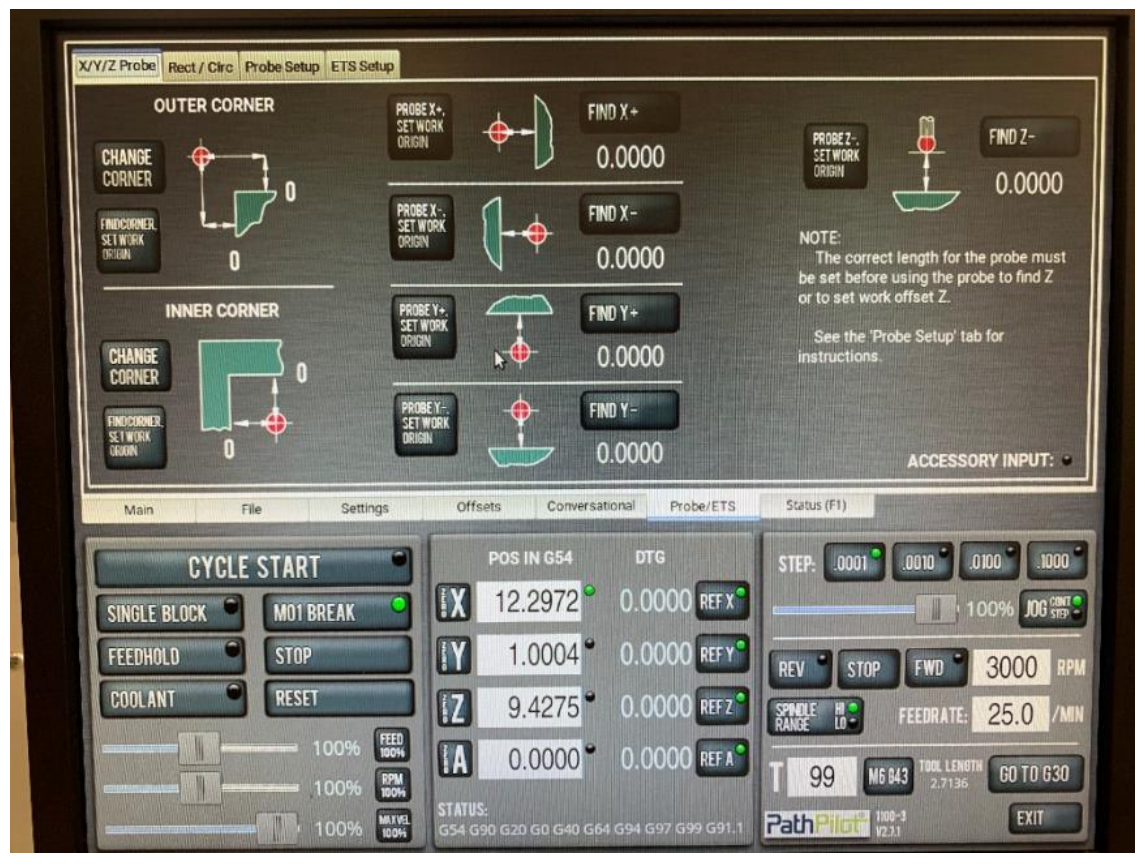

Figure A.6: CNC Mill file upload

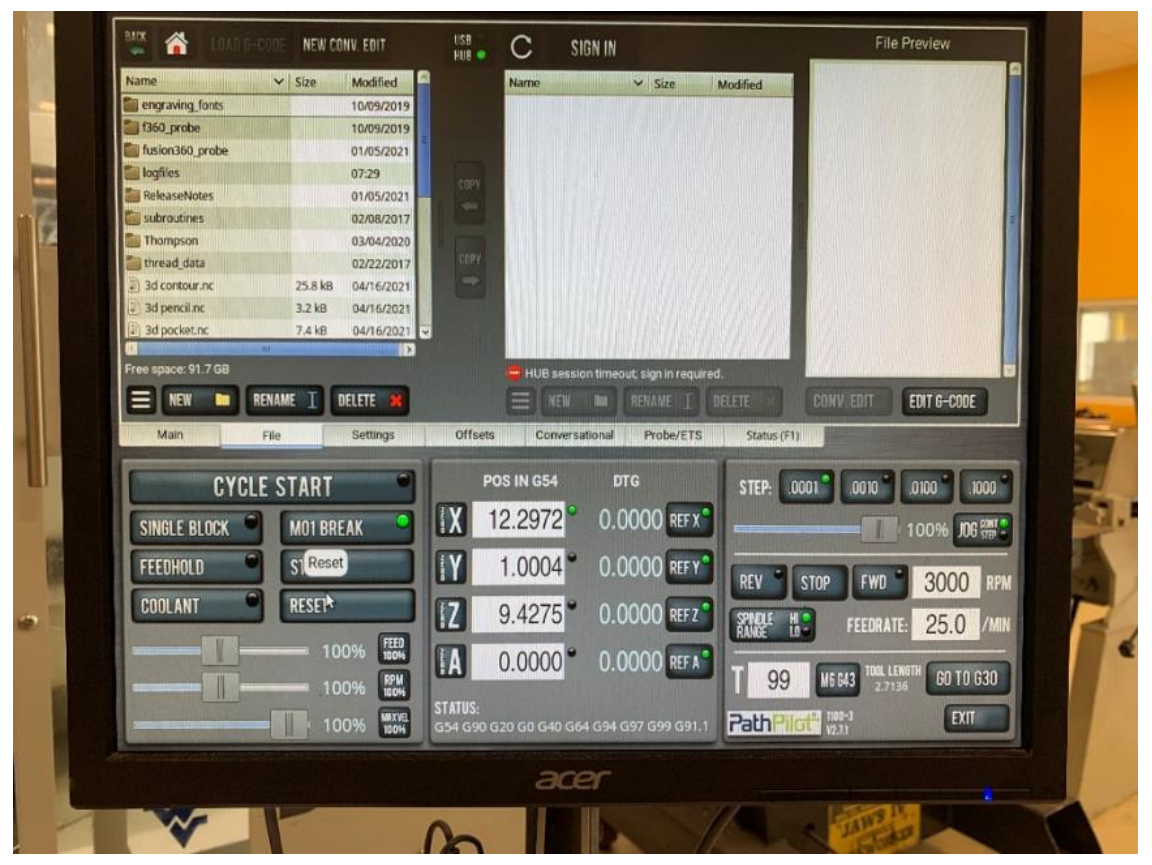


Figure A.7: Origin

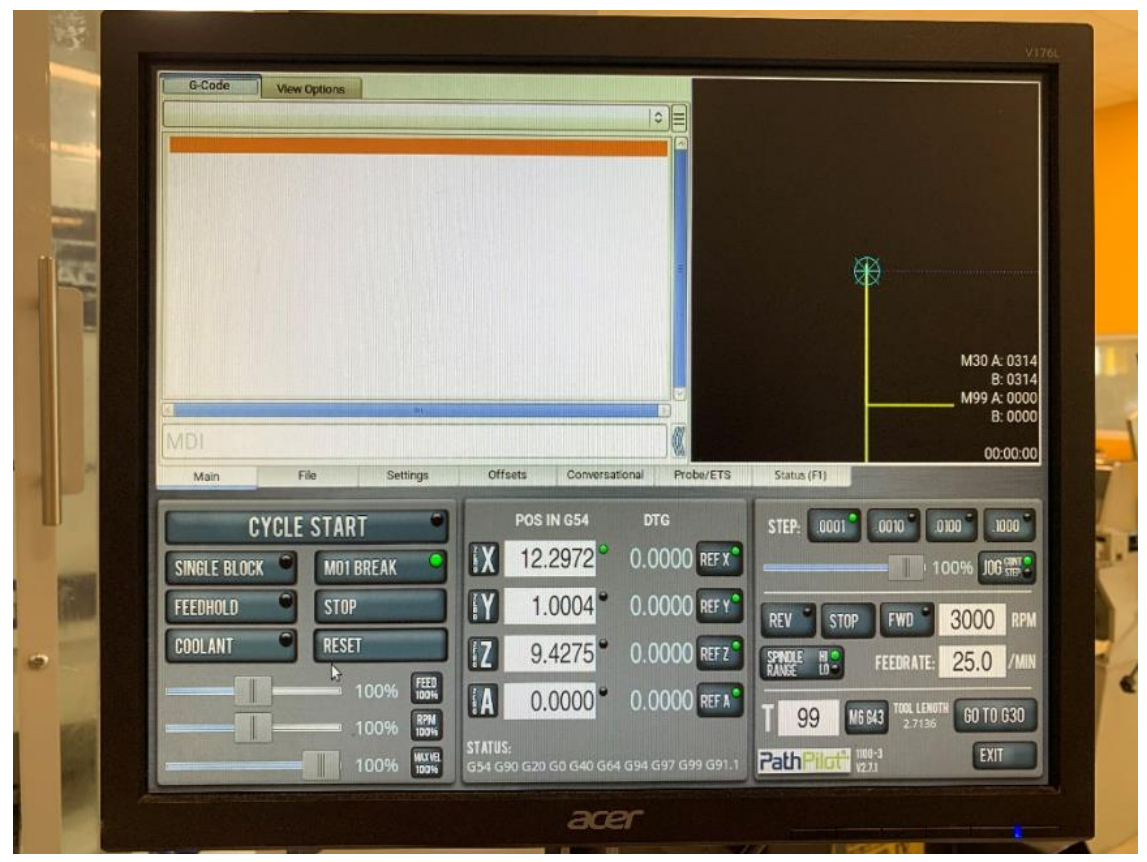

Figure A.8: G-Code

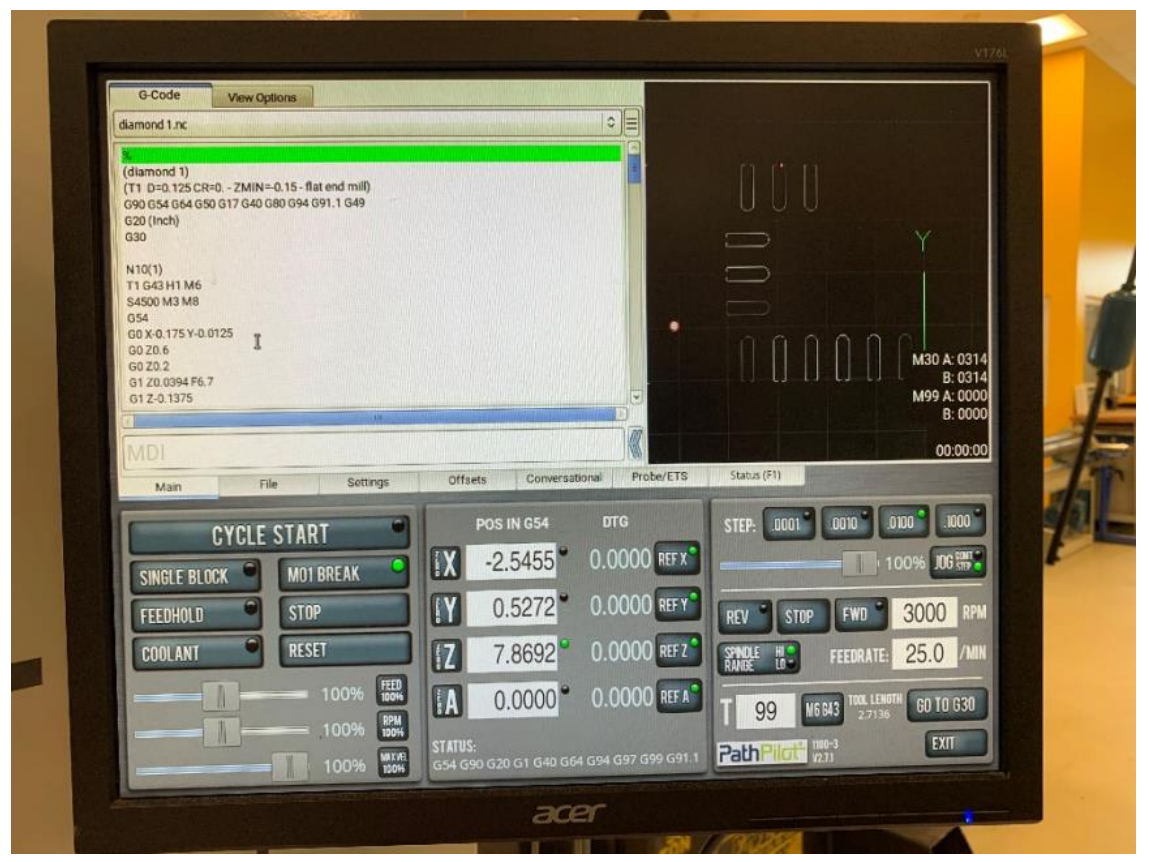




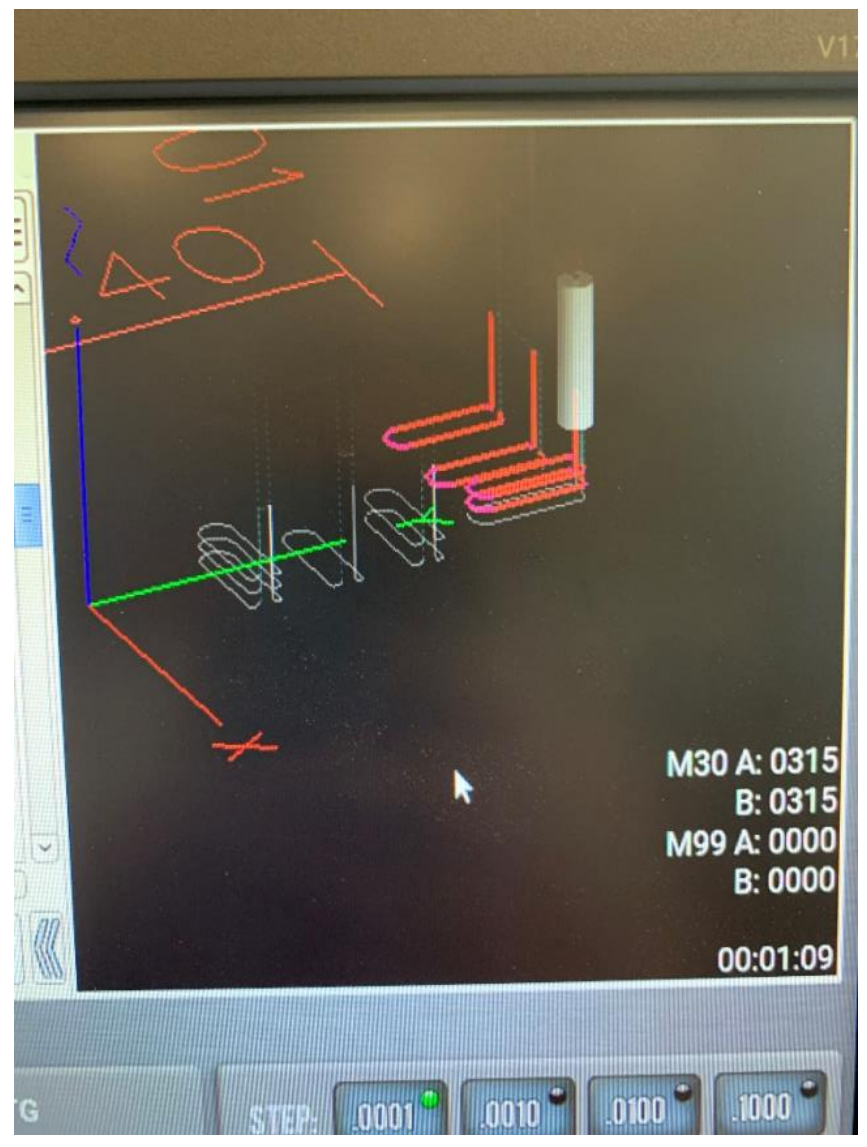

Figure A.10: Work Area with Stock

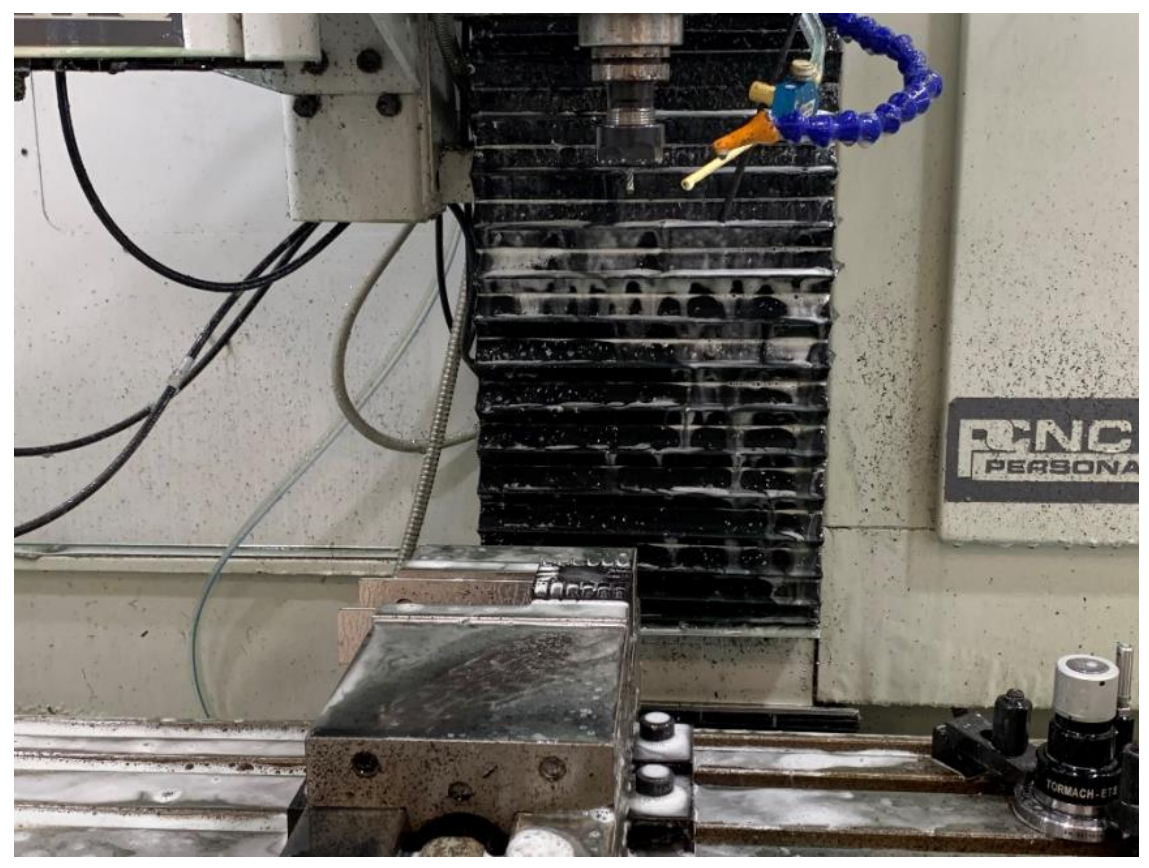


Appendix B: Dektak XT Stylus Profilometer Software and Equipment

Figure B.1: Dektak XT Stylus Profilometer

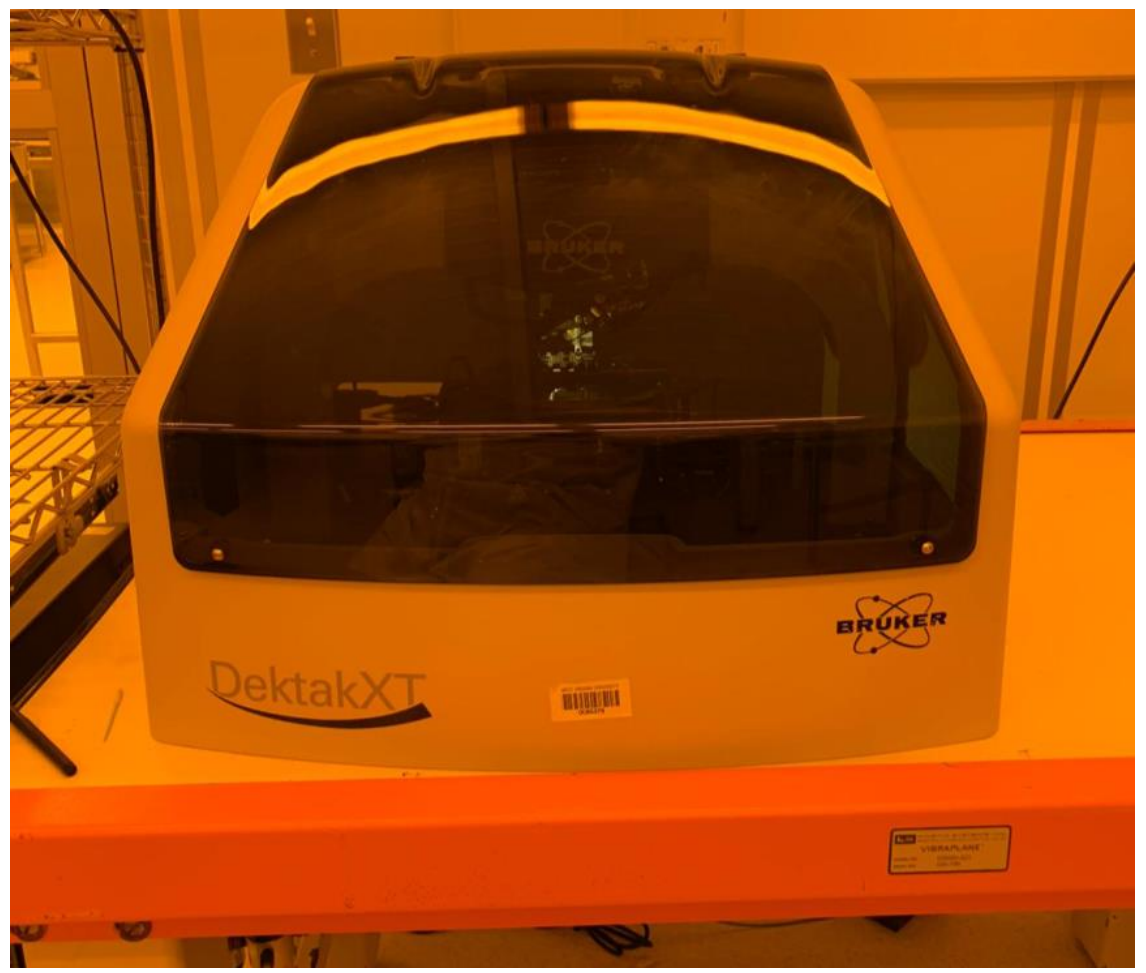

Figure B.2: Workpiece

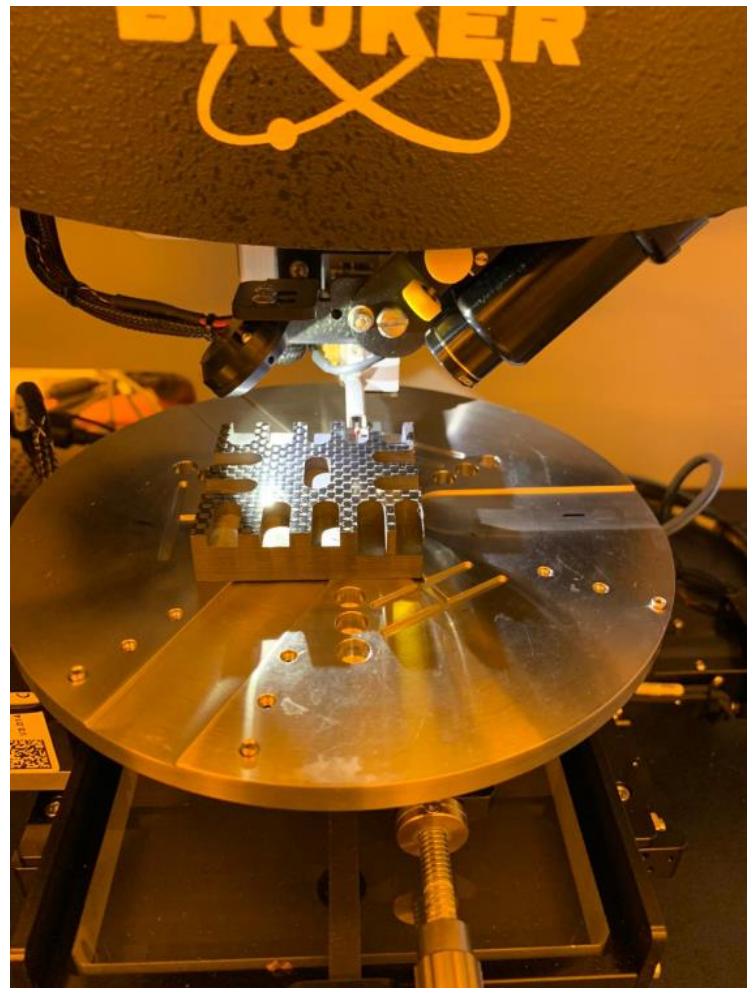


Figure B.3: Machine Settings

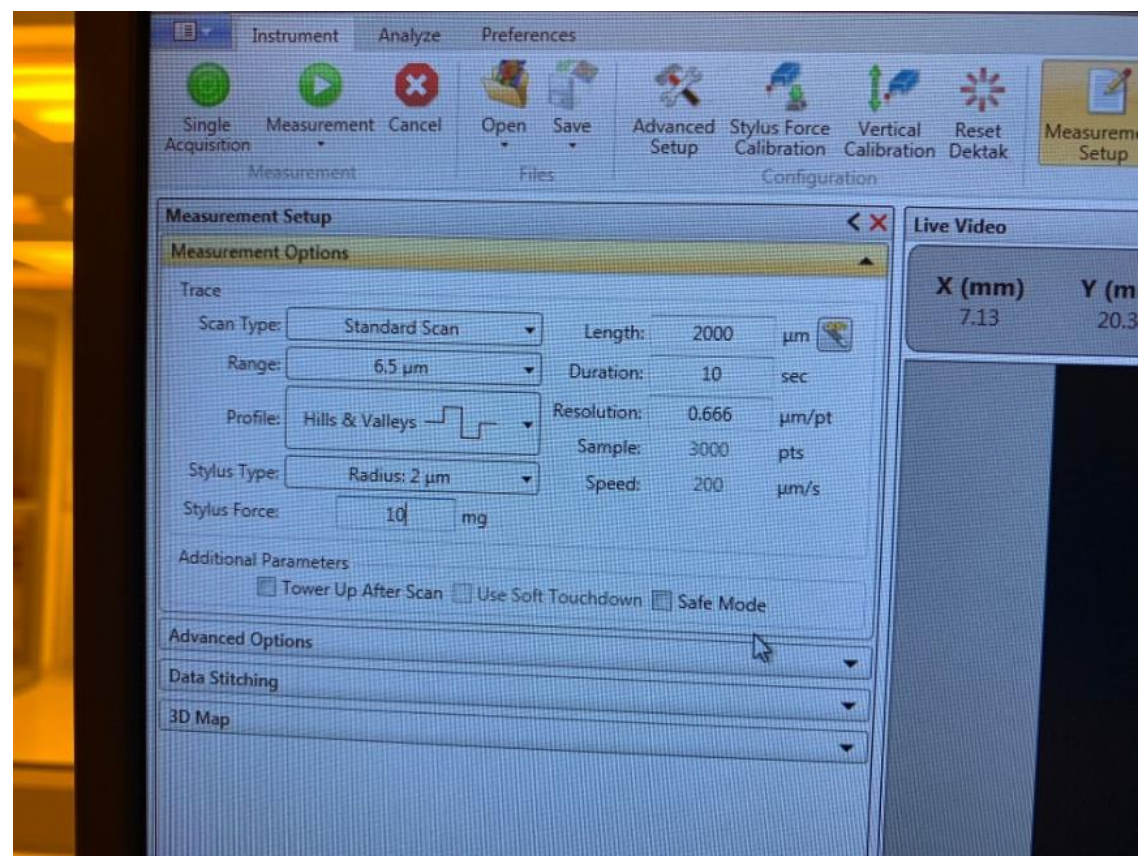

Figure B.4: Surface Roughness Measurment

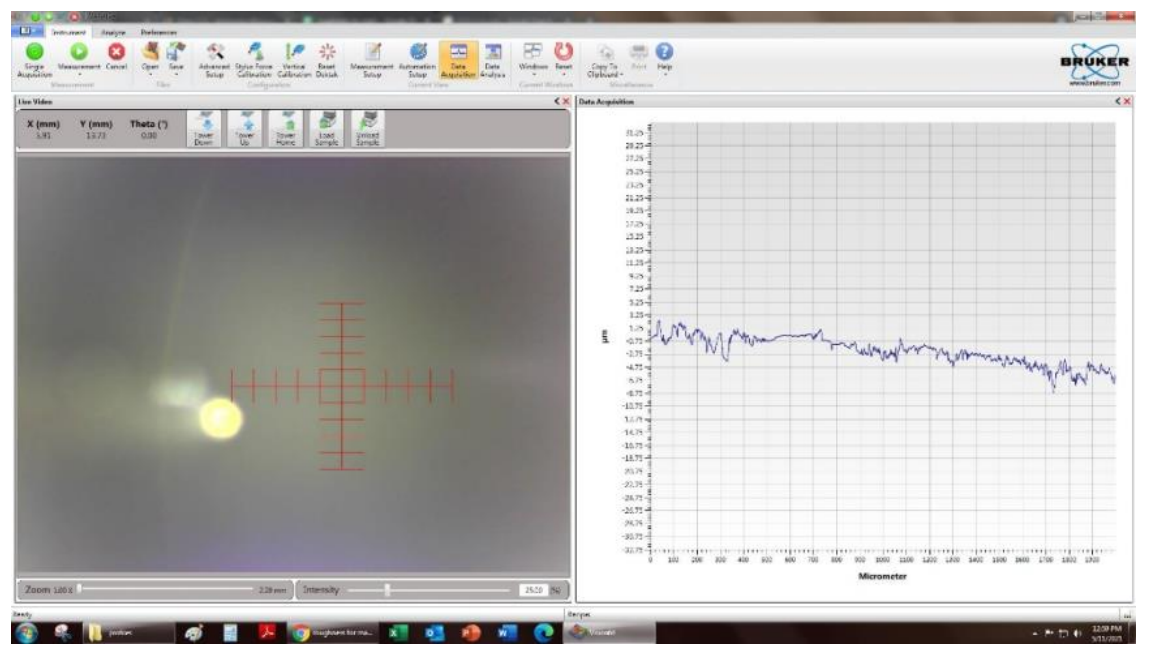


Figure B.5: Surface Image

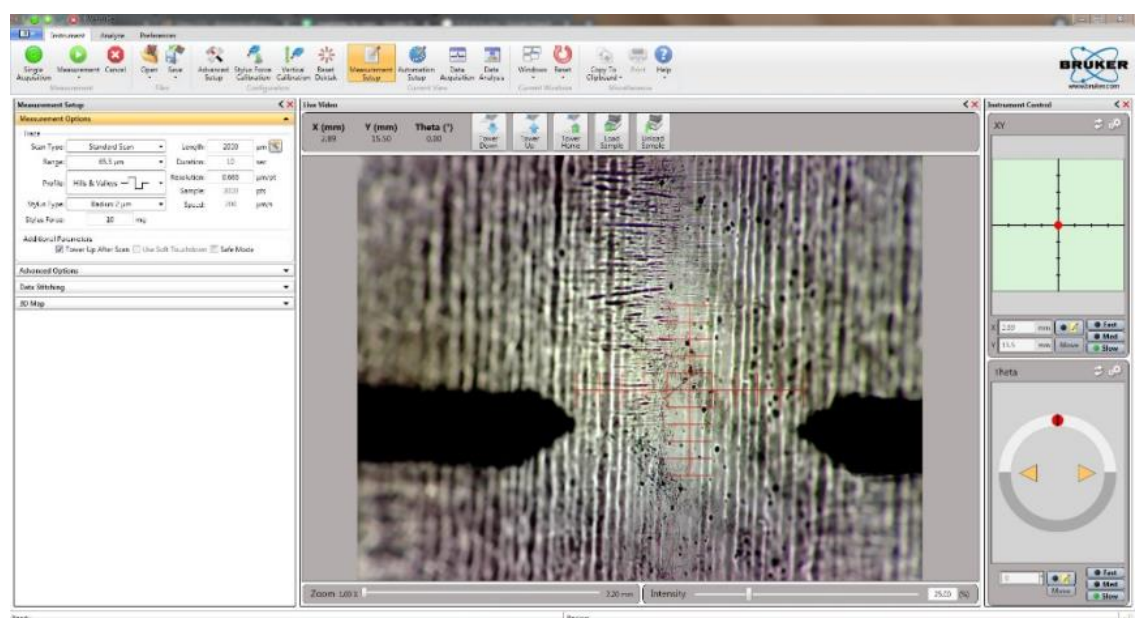

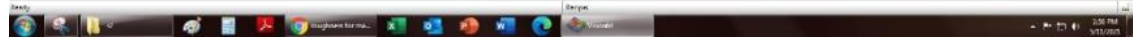

Figure B.6: Measurement Output

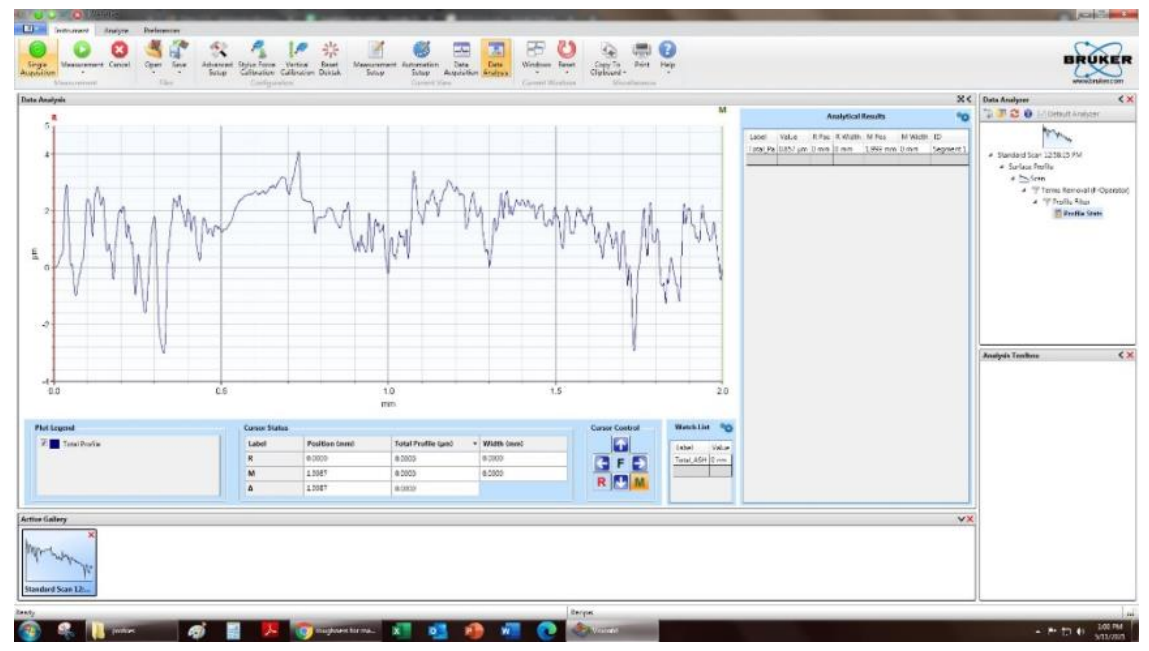




\section{Appendix C: Data Tables}

Table C.1: Factor combinations for the Factor Level Determination.

\begin{tabular}{|c|c|c|c|c|c|c|c|}
\hline $\begin{array}{c}\text { Slot } \\
\text { Number }\end{array}$ & Pattern & $\begin{array}{l}\text { Feedrate } \\
(\mathrm{mm} / \mathrm{rev})\end{array}$ & Tool Coating & $\begin{array}{l}\text { Depth of Cut } \\
\text { (in) }\end{array}$ & $\begin{array}{l}\begin{array}{l}\text { Width } \\
(\mathrm{mm})\end{array} \\
\end{array}$ & $\begin{array}{c}\text { Length } \\
(\mathrm{mm})\end{array}$ & $\begin{array}{c}\begin{array}{c}\text { Height } \\
(\mathbf{m m})\end{array} \\
\end{array}$ \\
\hline 1 & 111 & 0.03 & Diamond & 0.15 & 6.20 & 12.04 & 3.78 \\
\hline 2 & 112 & 0.03 & Diamond & 0.05 & 6.21 & 12.10 & 3.69 \\
\hline 3 & 112 & 0.03 & Diamond & 0.05 & 6.25 & 12.12 & 3.71 \\
\hline 4 & 113 & 0.03 & Diamond & 0.075 & 6.18 & 11.96 & 3.82 \\
\hline 5 & 113 & 0.03 & Diamond & 0.075 & 6.20 & 11.79 & 3.81 \\
\hline 6 & 211 & 0.15 & Diamond & 0.15 & 5.91 & 11.81 & 3.83 \\
\hline 7 & 211 & 0.15 & Diamond & 0.15 & 5.98 & 11.85 & 3.72 \\
\hline 8 & 212 & 0.15 & Diamond & 0.05 & 6.07 & 11.91 & 3.98 \\
\hline 9 & 212 & 0.15 & Diamond & 0.05 & 6.11 & 11.79 & 3.83 \\
\hline 10 & 312 & 0.5 & Diamond & 0.05 & 5.87 & 12.64 & 3.79 \\
\hline 11 & 313 & 0.5 & Diamond & 0.075 & 5.64 & 12.92 & 3.69 \\
\hline 12 & 313 & 0.5 & Diamond & 0.075 & 5.63 & 12.59 & 3.97 \\
\hline 13 & 111 & 0.03 & Diamond & 0.15 & 6.08 & 12.76 & 3.82 \\
\hline 14 & 111 & 0.03 & Diamond & 0.15 & 6.16 & 12.54 & 3.81 \\
\hline 15 & 112 & 0.03 & Diamond & 0.05 & 6.14 & 12.71 & 3.76 \\
\hline 16 & 113 & 0.03 & Diamond & 0.075 & 6.12 & 12.30 & 3.72 \\
\hline 17 & 211 & 0.15 & Diamond & 0.15 & 6.02 & 12.08 & 3.80 \\
\hline 18 & 212 & 0.15 & Diamond & 0.05 & 6.15 & 12.19 & 3.73 \\
\hline 19 & 213 & 0.15 & Diamond & 0.075 & 6.06 & 9.32 & 3.98 \\
\hline 20 & 213 & 0.15 & Diamond & 0.075 & 6.02 & 9.59 & 4.01 \\
\hline 21 & 213 & 0.15 & Diamond & 0.075 & 6.07 & 9.54 & 3.87 \\
\hline 22 & 311 & 0.1 & Diamond & 0.15 & 6.00 & 11.79 & 3.69 \\
\hline 23 & 311 & 0.1 & Diamond & 0.15 & 6.03 & 11.83 & 3.68 \\
\hline 24 & 312 & 0.1 & Diamond & 0.05 & 6.19 & 11.94 & 3.77 \\
\hline 25 & 111 & 0.03 & Diamond & 0.15 & 5.98 & 12.21 & 3.81 \\
\hline 26 & 112 & 0.03 & Diamond & 0.05 & 6.21 & 12.20 & 3.78 \\
\hline 27 & 113 & 0.03 & Diamond & 0.075 & 6.20 & 12.06 & 3.88 \\
\hline 28 & 211 & 0.15 & Diamond & 0.15 & 6.02 & 12.30 & 3.71 \\
\hline 29 & 212 & 0.15 & Diamond & 0.05 & 6.11 & 12.42 & 3.69 \\
\hline 30 & 213 & 0.15 & Diamond & 0.075 & 6.04 & 12.32 & 3.68 \\
\hline 31 & 311 & 0.1 & Diamond & 0.15 & 6.01 & 12.16 & 3.71 \\
\hline 32 & 311 & 0.1 & Diamond & 0.15 & 6.05 & 12.35 & 3.70 \\
\hline 33 & 312 & 0.1 & Diamond & 0.05 & 6.14 & 12.34 & 3.69 \\
\hline 34 & 312 & 0.1 & Diamond & 0.05 & 6.04 & 12.22 & 3.73 \\
\hline 35 & 313 & 0.1 & Diamond & 0.075 & 6.09 & 12.19 & 3.67 \\
\hline 36 & 313 & 0.1 & Diamond & 0.075 & 6.10 & 12.12 & 3.67 \\
\hline 37 & 131 & 0.03 & DLC & 0.15 & 6.03 & 11.95 & 3.65 \\
\hline 38 & 131 & 0.03 & DLC & 0.15 & 6.07 & 12.10 & 3.64 \\
\hline 39 & 133 & 0.03 & DLC & 0.075 & 6.12 & 11.90 & 3.73 \\
\hline 40 & 232 & 0.15 & DLC & 0.05 & 6.09 & 12.07 & 3.67 \\
\hline 41 & 232 & 0.15 & DLC & 0.05 & 6.12 & 11.87 & 3.68 \\
\hline 42 & 233 & 0.15 & DLC & 0.075 & 6.10 & 11.87 & 3.69 \\
\hline 43 & 233 & 0.15 & DLC & 0.075 & 6.04 & 12.17 & 3.87 \\
\hline
\end{tabular}




\begin{tabular}{|c|c|c|c|c|c|c|c|}
\hline 44 & 332 & 0.1 & DLC & 0.05 & 6.10 & 12.34 & 3.85 \\
\hline 45 & 332 & 0.1 & DLC & 0.05 & 6.12 & 12.11 & 3.86 \\
\hline 46 & 332 & 0.1 & DLC & 0.05 & 6.12 & 12.62 & 3.72 \\
\hline 47 & 333 & 0.1 & DLC & 0.075 & 6.07 & 12.53 & 3.73 \\
\hline 48 & 333 & 0.1 & DLC & 0.075 & 6.08 & 12.63 & 3.83 \\
\hline 49 & 131 & 0.03 & DLC & 0.15 & 6.16 & 12.34 & 3.77 \\
\hline 50 & 132 & 0.03 & DLC & 0.05 & 6.26 & 12.54 & 3.76 \\
\hline 51 & 132 & 0.03 & DLC & 0.05 & 6.32 & 12.23 & 3.91 \\
\hline 52 & 133 & 0.03 & DLC & 0.075 & 6.18 & 12.21 & 3.80 \\
\hline 53 & 133 & 0.03 & DLC & 0.075 & 6.30 & 12.18 & 3.76 \\
\hline 54 & 231 & 0.15 & DLC & 0.15 & 5.99 & 11.91 & 3.67 \\
\hline 55 & 231 & 0.15 & DLC & 0.15 & 5.97 & 12.05 & 3.65 \\
\hline 56 & 231 & 0.15 & DLC & 0.15 & 5.98 & 11.80 & 3.69 \\
\hline 57 & 331 & 0.1 & DLC & 0.15 & 6.06 & 11.88 & 3.75 \\
\hline 58 & 331 & 0.1 & DLC & 0.15 & 6.01 & 11.78 & 3.67 \\
\hline 59 & 331 & 0.1 & DLC & 0.15 & 6.06 & 11.79 & 3.86 \\
\hline 60 & 333 & 0.1 & DLC & 0.075 & 6.18 & 12.08 & 3.70 \\
\hline 61 & 131 & 0.03 & DLC & 0.15 & 6.10 & 11.85 & 3.80 \\
\hline 62 & 132 & 0.03 & DLC & 0.05 & 6.17 & 11.94 & 3.73 \\
\hline 63 & 132 & 0.03 & DLC & 0.05 & 6.16 & 11.93 & 3.73 \\
\hline 64 & 133 & 0.03 & DLC & 0.075 & 6.09 & 12.39 & 3.73 \\
\hline 65 & 231 & 0.15 & DLC & 0.15 & 5.93 & 12.36 & 3.71 \\
\hline 66 & 232 & 0.15 & DLC & 0.05 & 6.17 & 12.24 & 3.86 \\
\hline 67 & 232 & 0.15 & DLC & 0.05 & 6.15 & 12.07 & 3.72 \\
\hline 68 & 233 & 0.15 & DLC & 0.075 & 6.11 & 12.04 & 3.73 \\
\hline 69 & 233 & 0.15 & DLC & 0.075 & 6.11 & 12.16 & 3.84 \\
\hline 70 & 331 & 0.1 & DLC & 0.15 & 6.05 & 12.19 & 3.68 \\
\hline 71 & 332 & 0.1 & DLC & 0.05 & 6.18 & 12.40 & 3.71 \\
\hline 72 & 333 & 0.1 & DLC & 0.075 & 6.14 & 12.44 & 3.68 \\
\hline 73 & 121 & 0.03 & TiCN & 0.15 & 6.07 & 11.95 & 3.66 \\
\hline 74 & 123 & 0.03 & TiCN & 0.075 & 6.13 & 11.85 & 3.88 \\
\hline 75 & 123 & 0.03 & TiCN & 0.075 & 6.16 & 11.90 & 3.75 \\
\hline 76 & 221 & 0.15 & TiCN & 0.15 & 5.98 & 11.88 & 3.88 \\
\hline 77 & 222 & 0.15 & TiCN & 0.05 & 6.14 & 11.80 & 3.76 \\
\hline 78 & 222 & 0.15 & TiCN & 0.05 & 6.17 & 11.55 & 3.80 \\
\hline 79 & 222 & 0.15 & TiCN & 0.05 & 6.08 & 11.71 & 3.84 \\
\hline 80 & 223 & 0.15 & TiCN & 0.075 & 6.05 & 11.82 & 3.79 \\
\hline 81 & 321 & 0.1 & TiCN & 0.15 & 6.02 & 11.85 & 3.84 \\
\hline 82 & 322 & 0.1 & TiCN & 0.05 & 6.09 & 12.27 & 3.76 \\
\hline 83 & 322 & 0.1 & TiCN & 0.05 & 6.10 & 12.14 & 3.70 \\
\hline 84 & 323 & 0.1 & TiCN & 0.075 & 6.10 & 12.48 & 3.74 \\
\hline 85 & 121 & 0.03 & TiCN & 0.15 & 6.13 & 12.28 & 3.68 \\
\hline 86 & 121 & 0.03 & TiCN & 0.15 & 6.16 & 12.33 & 3.65 \\
\hline 87 & 122 & 0.03 & TiCN & 0.05 & 6.27 & 12.36 & 3.71 \\
\hline 88 & 123 & 0.03 & TiCN & 0.075 & 6.11 & 12.36 & 3.78 \\
\hline 89 & 123 & 0.03 & TiCN & 0.075 & 6.18 & 12.37 & 3.74 \\
\hline 90 & 221 & 0.15 & TiCN & 0.15 & 5.99 & 12.36 & 3.70 \\
\hline 91 & 222 & 0.15 & TiCN & 0.05 & 6.24 & 12.80 & 3.74 \\
\hline 92 & 223 & 0.15 & TiCN & 0.075 & 6.17 & 12.78 & 3.82 \\
\hline
\end{tabular}




\begin{tabular}{|c|c|c|c|c|c|c|c|}
\hline 93 & 321 & 0.1 & TiCN & 0.15 & 6.04 & 12.70 & 3.74 \\
\hline 94 & 322 & 0.1 & TiCN & 0.05 & 6.22 & 12.82 & 3.80 \\
\hline 95 & 323 & 0.1 & TiCN & 0.075 & 6.16 & 12.74 & 3.78 \\
\hline 96 & 323 & 0.1 & TiCN & 0.075 & 6.15 & 12.66 & 3.88 \\
\hline 97 & 121 & 0.03 & TiCN & 0.15 & 6.13 & 11.74 & 3.88 \\
\hline 98 & 122 & 0.03 & TiCN & 0.05 & 6.12 & 11.80 & 3.84 \\
\hline 99 & 122 & 0.03 & TiCN & 0.05 & 6.14 & 11.82 & 3.86 \\
\hline 100 & 122 & 0.03 & $\mathrm{TiCN}$ & 0.05 & 6.14 & 12.22 & 3.81 \\
\hline 101 & 221 & 0.15 & TiCN & 0.15 & 6.01 & 12.25 & 3.87 \\
\hline 102 & 221 & 0.15 & TiCN & 0.15 & 5.97 & 12.38 & 3.81 \\
\hline 103 & 223 & 0.15 & TiCN & 0.075 & 6.04 & 12.44 & 3.80 \\
\hline 104 & 223 & 0.15 & TiCN & 0.075 & 6.03 & 12.38 & 3.97 \\
\hline 105 & 321 & 0.1 & TiCN & 0.15 & 5.98 & 12.16 & 3.86 \\
\hline 106 & 321 & 0.1 & TiCN & 0.15 & 5.90 & 12.27 & 3.77 \\
\hline 107 & 322 & 0.1 & $\mathrm{TiCN}$ & 0.05 & 6.07 & 12.21 & 3.75 \\
\hline 108 & 323 & 0.1 & TiCN & 0.075 & 6.07 & 12.32 & 3.81 \\
\hline 109 & 141 & 0.03 & TiN and TiAlN & 0.15 & 6.03 & 11.57 & 3.90 \\
\hline 110 & 142 & 0.03 & TiN and TiAlN & 0.05 & 6.17 & 11.74 & 3.79 \\
\hline 111 & 143 & 0.03 & TiN and TiAlN & 0.075 & 6.10 & 11.68 & 3.75 \\
\hline 112 & 143 & 0.03 & TiN and TiAlN & 0.075 & 6.11 & 11.74 & 3.81 \\
\hline 113 & 143 & 0.03 & TiN and TiAlN & 0.075 & 6.17 & 11.40 & 3.91 \\
\hline 114 & 241 & 0.15 & TiN and TiAlN & 0.15 & 6.00 & 11.50 & 3.88 \\
\hline 115 & 341 & 0.1 & TiN and TiAlN & 0.15 & 6.03 & 11.97 & 3.84 \\
\hline 116 & 341 & 0.1 & TiN and TiAlN & 0.15 & 6.00 & 11.89 & 3.99 \\
\hline 117 & 342 & 0.1 & TiN and TiAlN & 0.05 & 6.14 & 11.91 & 3.80 \\
\hline 118 & 343 & 0.1 & TiN and TiAlN & 0.075 & 6.09 & 12.16 & 3.94 \\
\hline 119 & 343 & 0.1 & TiN and TiAlN & 0.075 & 6.13 & 12.47 & 3.96 \\
\hline 120 & 343 & 0.1 & TiN and TiAlN & 0.075 & 6.10 & 12.49 & 3.81 \\
\hline 121 & 141 & 0.03 & TiN and TiAlN & 0.15 & 6.13 & 12.48 & 3.82 \\
\hline 122 & 141 & 0.03 & TiN and TiAlN & 0.15 & 6.12 & 11.74 & 3.72 \\
\hline 123 & 142 & 0.03 & TiN and TiAlN & 0.05 & 6.27 & 11.57 & 3.81 \\
\hline 124 & 142 & 0.03 & TiN and TiAlN & 0.05 & 6.26 & 12.01 & 3.86 \\
\hline 125 & 241 & 0.15 & TiN and TiAlN & 0.15 & 6.08 & 12.04 & 3.91 \\
\hline 126 & 242 & 0.15 & TiN and TiAlN & 0.05 & 6.16 & 12.01 & 3.74 \\
\hline 127 & 243 & 0.15 & TiN and TiAlN & 0.075 & 6.10 & 11.26 & 3.81 \\
\hline 128 & 243 & 0.15 & TiN and TiAlN & 0.075 & 6.10 & 11.42 & 3.78 \\
\hline 129 & 243 & 0.15 & TiN and TiAlN & 0.075 & 6.14 & 11.30 & 3.76 \\
\hline 130 & 341 & 0.1 & TiN and TiAlN & 0.15 & 6.12 & 11.38 & 3.84 \\
\hline 131 & 342 & 0.1 & TiN and TiAlN & 0.05 & 6.18 & 11.18 & 3.77 \\
\hline 132 & 342 & 0.1 & TiN and TiAlN & 0.05 & 6.13 & 11.26 & 3.77 \\
\hline 133 & 141 & 0.03 & TiN and TiAlN & 0.15 & 6.08 & 11.55 & 3.82 \\
\hline 134 & 142 & 0.03 & TiN and TiAlN & 0.05 & 6.12 & 11.75 & 3.93 \\
\hline 135 & 143 & 0.03 & TiN and TiAlN & 0.075 & 6.16 & 11.69 & 3.91 \\
\hline 136 & 241 & 0.15 & TiN and TiAlN & 0.15 & 5.97 & 12.63 & 3.95 \\
\hline 137 & 241 & 0.15 & TiN and TiAlN & 0.15 & 5.95 & 12.64 & 3.82 \\
\hline 138 & 242 & 0.15 & TiN and TiAlN & 0.05 & 6.11 & 12.46 & 3.88 \\
\hline 139 & 242 & 0.15 & TiN and TiAlN & 0.05 & 6.10 & 12.66 & 3.88 \\
\hline 140 & 242 & 0.15 & TiN and TiAlN & 0.05 & 6.09 & 12.66 & 3.77 \\
\hline 141 & 243 & 0.15 & TiN and TiAlN & 0.075 & 6.03 & 12.60 & 3.82 \\
\hline
\end{tabular}




\begin{tabular}{|l|l|l|l|l|l|l|l|}
\hline 142 & 341 & 0.1 & TiN and TiAlN & 0.15 & 6.09 & 12.27 & 3.90 \\
\hline 143 & 342 & 0.1 & TiN and TiAlN & 0.05 & 6.14 & 12.46 & 3.92 \\
\hline 144 & 343 & 0.1 & TiN and TiAlN & 0.075 & 6.10 & 12.30 & 3.92 \\
\hline
\end{tabular}




\section{Appendix D: Toolpath Determination JMP Output Response RMS}

Figure D.1: Actual by Predicted Plot

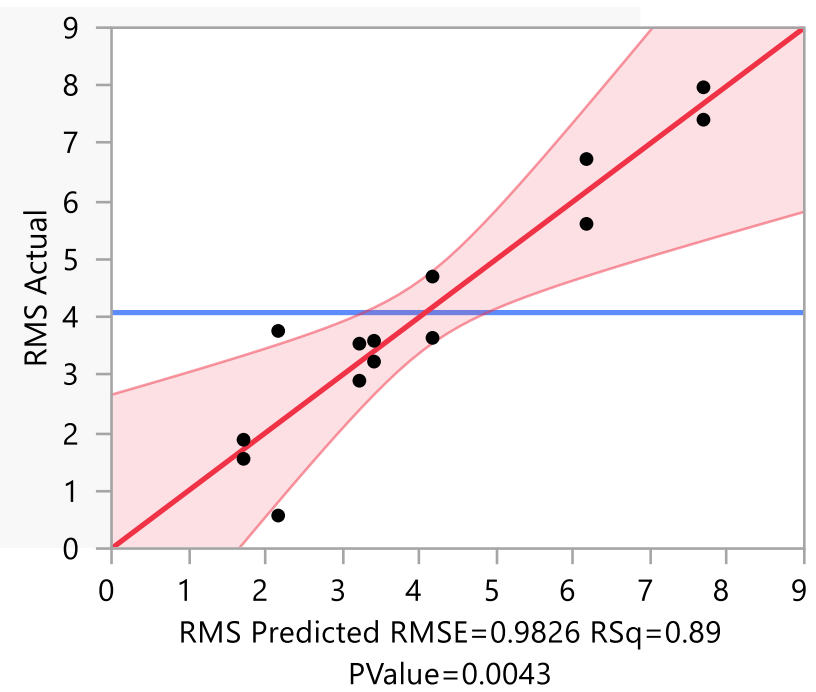

Figure D.2: Residual by Predicted Plot

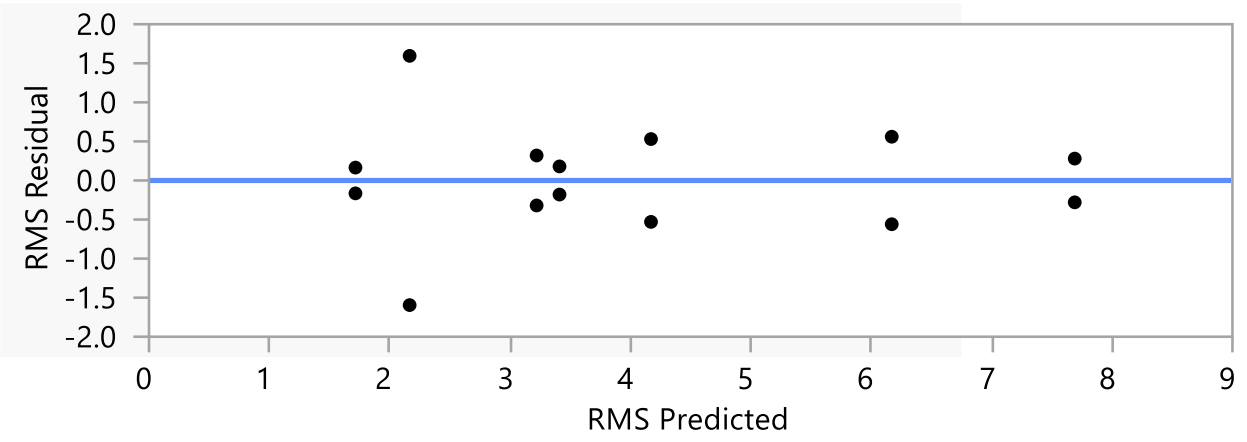

Figure D.3: Studentized Residuals

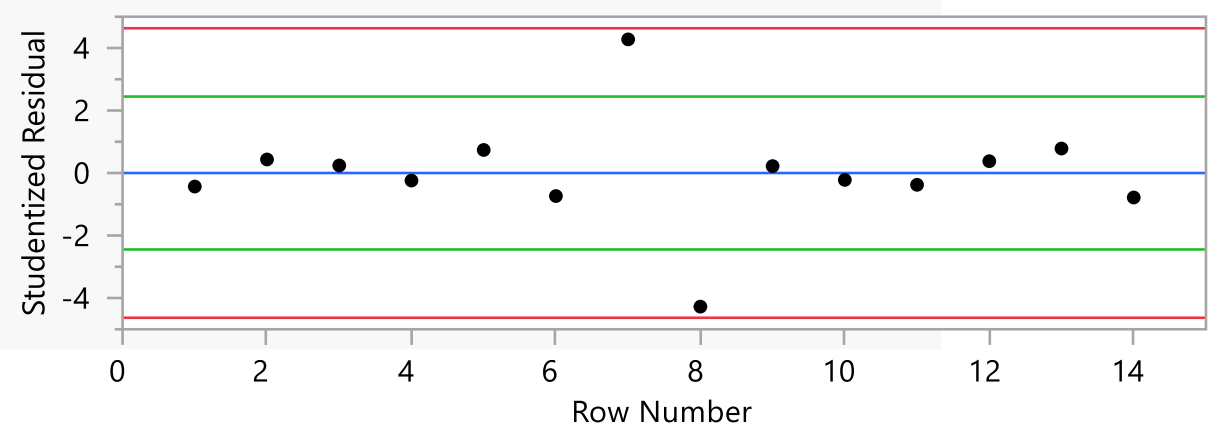


Table D.1: Summary of Fit

\begin{tabular}{|l|l|}
\hline RSquare & 0.891826 \\
\hline RSquare Adj & 0.799105 \\
\hline Root Mean Square Error & 0.982555 \\
\hline Mean of Response & 4.077143 \\
\hline Observations (or Sum Wgts) & 14 \\
\hline
\end{tabular}

Table D.2: Analysis of Variance

$\begin{array}{lllll}\text { Source } & \text { DF } & \text { Sum of Squares } & \text { Mean Square } & \text { F Ratio } \\ \text { Model } & 6 & 55.714386 & 9.28573 & 9.6184 \\ \text { Error } & 7 & 6.757900 & 0.96541 & \text { Prob > F } \\ \text { C. Total } & 13 & 62.472286 & & 0.0043 *\end{array}$

Table D.3: Parameter Estimates

$\begin{array}{llll}\text { Term } & \text { t Ratio } & \text { Prob>|t| } & \text { AdjPower0.05 } \\ \text { Intercept } & 15.53 & <.0001^{*} & 1.0000 \\ \text { Toolpath[2D Adaptive] } & -1.33 & 0.2244 & 0.0736 \\ \text { Toolpath[2D Contour] } & -1.04 & 0.3342 & 0.0500 \\ \text { Toolpath[2D Pocket] } & 0.14 & 0.8893 & 0.0500 \\ \text { Toolpath[3D Adaptive] } & 5.62 & 0.0008^{*} & 0.9764 \\ \text { Toolpath[3D Contour] } & -3.67 & 0.0079 * & 0.7131 \\ \text { Toolpath[3D Pencil] } & -2.97 & 0.0207 * & 0.5106\end{array}$

Table D.4: Effect Tests

$\begin{array}{llllll}\text { Source } & \text { Nparm } & \text { DF } & \text { Sum of Squares } & \text { F Ratio } & \text { Prob > F } \\ \text { Toolpath } & 6 & 6 & 55.714386 & 9.6184 & 0.0043^{*}\end{array}$

Figure D.4: Residual by Row Plot

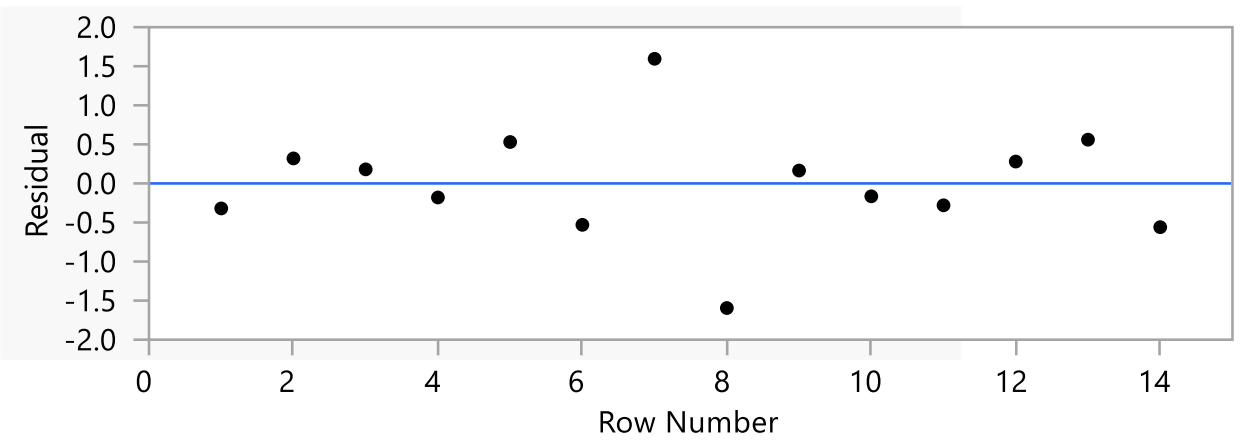


Figure D.5: Residual Normal Quantile Plot

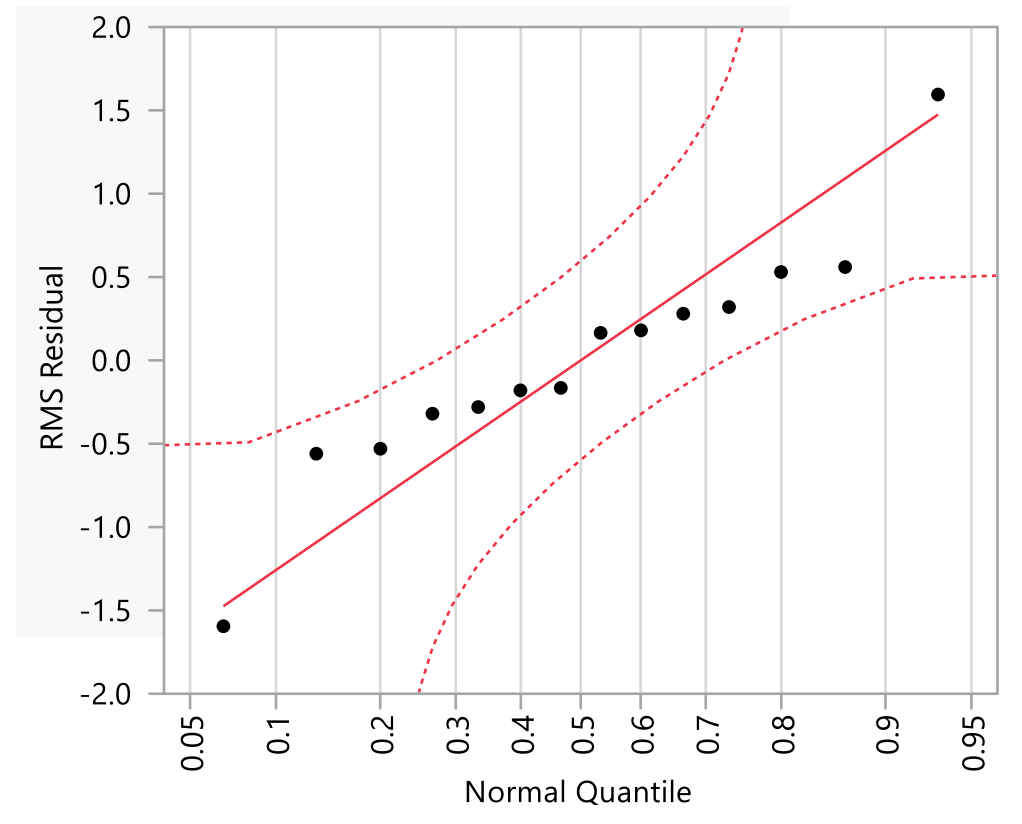

Table D.5: Parameter Estimate Population

$\begin{array}{llllll}\text { Term } & \text { Estimate } & \mathbf{t} \text { Ratio } & \text { Orthog Coded } & \text { Orthog t-Ratio } & \text { Prob>|t| } \\ \text { Intercept } & 4.07714 & 15.5261 & 4.07714 & 15.5261 & <.0001^{*} \\ \text { Toolpath[2D Adaptive] } & -0.85714 & -1.3326 & -0.78842 & -3.0024 & 0.0199^{*} \\ \text { Toolpath[2D Contour] } & -0.66714 & -1.0372 & -0.39656 & -1.5101 & 0.1748 \\ \text { Toolpath[2D Pocket] } & 0.09286 & 0.1444 & -0.03164 & -0.1205 & 0.9075 \\ \text { Toolpath[3D Adaptive] } & 3.61286 & 5.6167 & 1.16547 & 4.4382 & 0.0030^{*} \\ \text { Toolpath[3D Contour] } & -2.36214 & -3.6723 & -1.10997 & -4.2269 & 0.0039^{*} \\ \text { Toolpath[3D Pencil] } & -1.91214 & -2.9727 & -0.78063 & -2.9727 & 0.0207^{*}\end{array}$

Table D.6: Correlations of Estimates

$\begin{array}{llllllll}\text { Intercept } & 1.0000 & 0.0000 & 0.0000 & 0.0000 & 0.0000 & 0.0000 & 0.0000 \\ \text { Toolpath[2D Adaptive] } & 0.0000 & 1.0000 & -0.1667 & -0.1667 & -0.1667 & -0.1667 & -0.1667 \\ \text { Toolpath[2D Contour] } & 0.0000 & -0.1667 & 1.0000 & -0.1667 & -0.1667 & -0.1667 & -0.1667 \\ \text { Toolpath[2D Pocket] } & 0.0000 & -0.1667 & -0.1667 & 1.0000 & -0.1667 & -0.1667 & -0.1667 \\ \text { Toolpath[3D Adaptive] } & 0.0000 & -0.1667 & -0.1667 & -0.1667 & 1.0000 & -0.1667 & -0.1667 \\ \text { Toolpath[3D Contour] } & 0.0000 & -0.1667 & -0.1667 & -0.1667 & -0.1667 & 1.0000 & -0.1667 \\ \text { Toolpath[3D Pencil] } & 0.0000 & -0.1667 & -0.1667 & -0.1667 & -0.1667 & -0.1667 & 1.0000\end{array}$


Table D.7: Transformation to make uncorrelated

\begin{tabular}{|c|c|c|c|c|c|c|c|}
\hline Intercept & 3.80809 & 0 & 0 & 0 & 0 & 0 & 0 \\
\hline $\begin{array}{l}\text { Toolpath[2D } \\
\text { Adaptive] }\end{array}$ & 0 & 2.03551 & 1.01775 & 1.01775 & 1.01775 & 1.01775 & 1.01775 \\
\hline $\begin{array}{l}\text { Toolpath[2D } \\
\text { Contour] }\end{array}$ & 0 & 0 & 1.7628 & 0.5876 & 0.5876 & 0.5876 & .5876 \\
\hline Toolpath[2D Pocket] & 0 & 0 & 0 & 1.66199 & 0.4155 & 0.4155 & 0.4155 \\
\hline $\begin{array}{l}\text { Toolpath[3D } \\
\text { Adaptive] }\end{array}$ & 0 & 0 & 0 & 0 & 1.60921 & 0.32184 & 0.32184 \\
\hline $\begin{array}{l}\text { Toolpath[3D } \\
\text { Contour] }\end{array}$ & 0 & 0 & 0 & 0 & 0 & 1.5767 & 0.262 \\
\hline Toolpath[3D Pencil] & 0 & 0 & 0 & 0 & 0 & 0 & 1.55465 \\
\hline
\end{tabular}

Figure D.6: Normal Plot

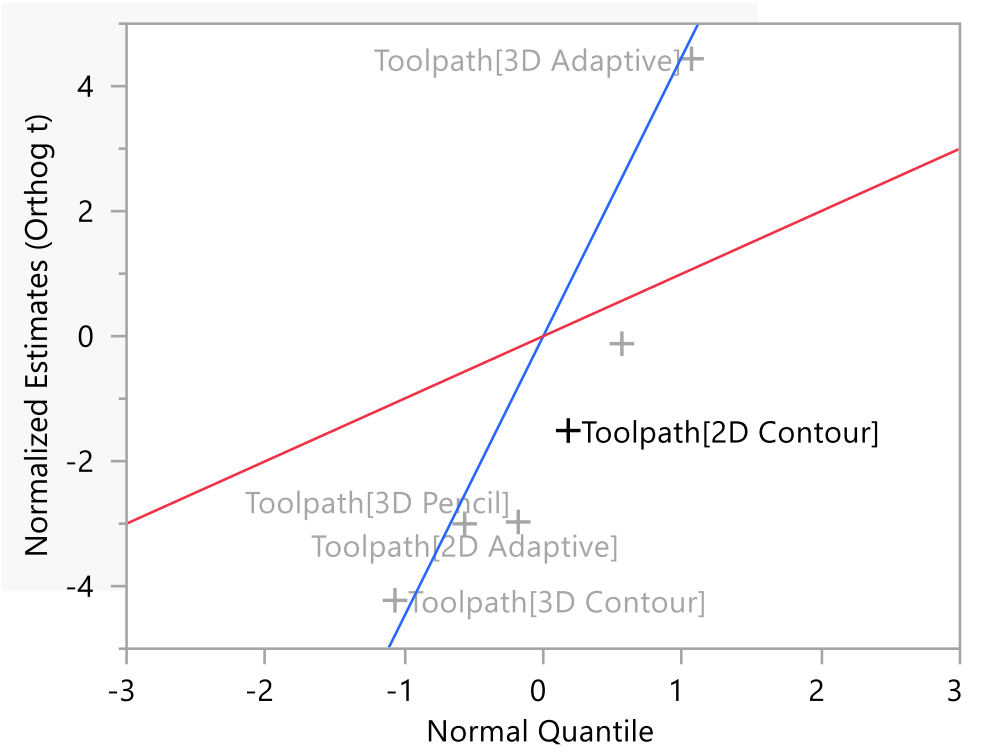




\section{Response Surface Roughness}

Figure D.7: Actual by Predicted Plot

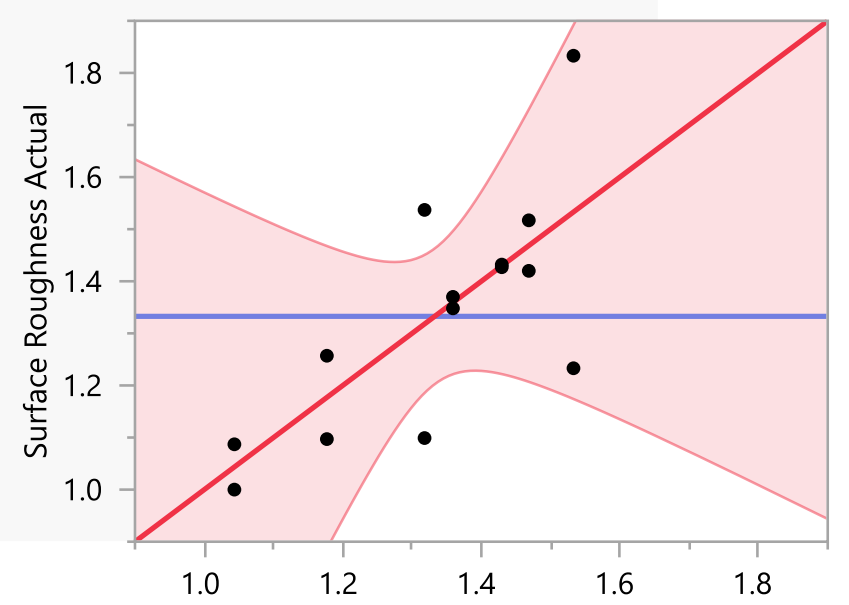

Surface Roughness Predicted RMSE $=0.2061$

$\mathrm{RSq}=0.54$ PValue $=0.3370$

Figure D.8: Residual by Predicted Plot

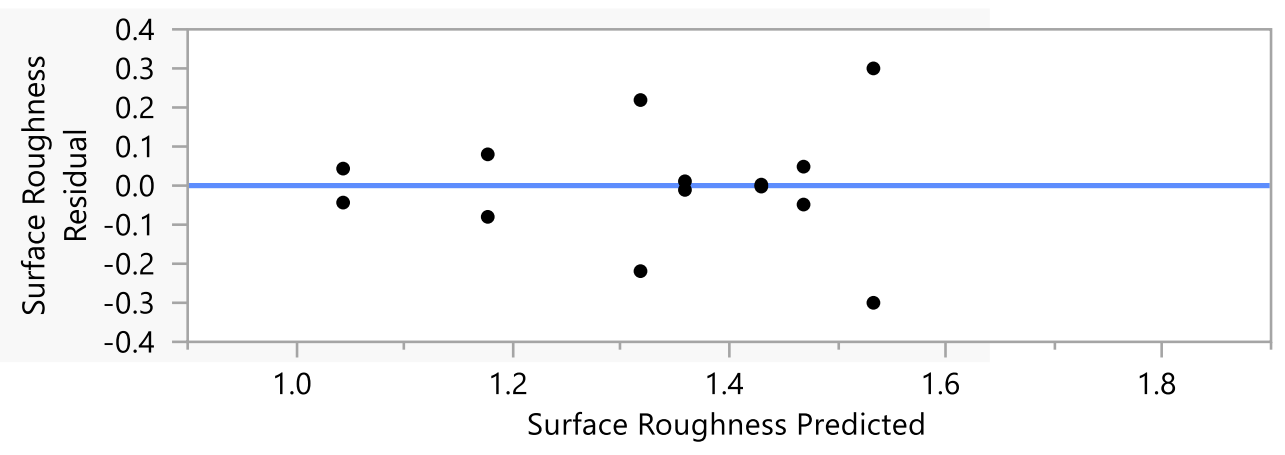

Figure D.9: Studentized Residuals

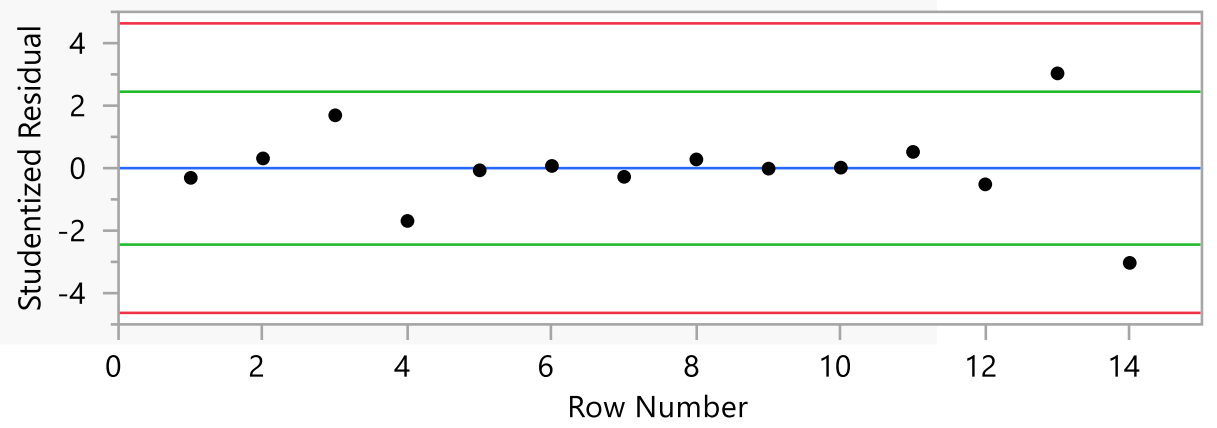


Table D.8: Summary of Fit

\begin{tabular}{|l|l|}
\hline RSquare & 0.542996 \\
\hline RSquare Adj & 0.151278 \\
\hline Root Mean Square Error & 0.206143 \\
\hline Mean of Response & 1.332643 \\
\hline Observations (or Sum Wgts) & 14 \\
\hline
\end{tabular}

Table D.9: Analysis of Variance

$\begin{array}{lllll}\text { Source } & \text { DF } & \text { Sum of Squares } & \text { Mean Square } & \text { F Ratio } \\ \text { Model } & 6 & 0.35343771 & 0.058906 & 1.3862 \\ \text { Error } & 7 & 0.29746550 & 0.042495 & \text { Prob > F } \\ \text { C. Total } & 13 & 0.65090321 & & 0.3370\end{array}$

Table D.10: Parameter Estimates

$\begin{array}{llll}\text { Term } & \text { t Ratio } & \text { Prob }>|\mathbf{t}| & \text { AdjPower0.05 } \\ \text { Intercept } & 24.19 & <.0001^{*} & 1.0000 \\ \text { Toolpath[2D Adaptive] } & 1.01 & 0.3476 & 0.0500 \\ \text { Toolpath[2D Contour] } & -0.11 & 0.9166 & 0.0500 \\ \text { Toolpath[2D Pocket] } & 0.20 & 0.8507 & 0.0500 \\ \text { Toolpath[3D Adaptive] } & -1.15 & 0.2866 & 0.0500 \\ \text { Toolpath[3D Contour] } & 0.72 & 0.4962 & 0.0500 \\ \text { Toolpath[3D Pencil] } & -2.14 & 0.0694 & 0.2576\end{array}$

Table D.11: Effect Tests

\section{Source Nparm DF Sum of Squares F Ratio Prob > F \\ $\begin{array}{llllll}\text { Toolpath } & 6 & 6 & 0.35343771 & 1.3862 & 0.3370\end{array}$}

Figure D.10: Residual by Row Plot

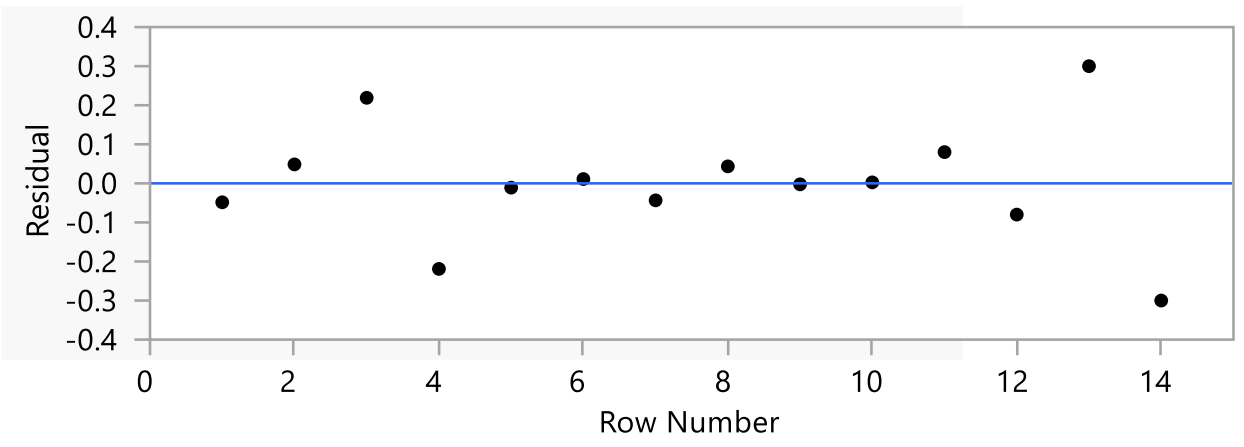


Figure D.11: Residual Normal Quantile Plot

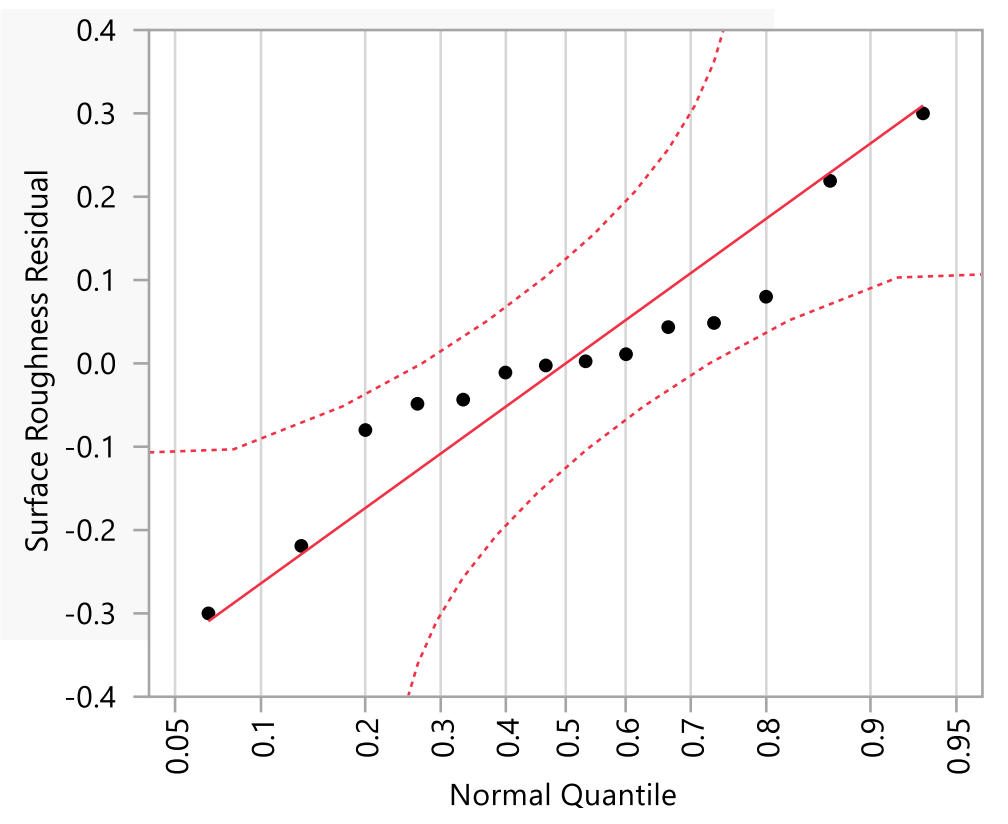

Table D.12: Parameter Estimate Population

\begin{tabular}{|c|c|c|c|c|c|}
\hline Term & Estimate & t Ratio & $\begin{array}{l}\text { Orthog } \\
\text { Coded }\end{array}$ & $\begin{array}{l}\text { Orthog } \\
\text { t-Ratio }\end{array}$ & Prob $>|t|$ \\
\hline Intercept & 1.33264 & 24.1885 & 1.33264 & 24.1885 & $<.0001 *$ \\
\hline $\begin{array}{l}\text { Toolpath[2D } \\
\text { Adaptive] }\end{array}$ & 0.13586 & 1.0067 & -0.01724 & -0.3129 & 0.7635 \\
\hline $\begin{array}{l}\text { Toolpath[2D } \\
\text { Contour] }\end{array}$ & -0.01464 & -0.1085 & -0.05640 & -1.0237 & 0.3401 \\
\hline $\begin{array}{l}\text { Toolpath[2D } \\
\text { Pocket] }\end{array}$ & 0.02636 & 0.1953 & -0.02646 & -0.4802 & 0.6457 \\
\hline $\begin{array}{l}\text { Toolpath[3D } \\
\text { Adaptive] }\end{array}$ & -0.15564 & -1.1533 & -0.08202 & -1.4888 & 0.1802 \\
\hline $\begin{array}{l}\text { Toolpath[3D } \\
\text { Contour] }\end{array}$ & 0.09686 & 0.7177 & 0.02015 & 0.3657 & 0.7254 \\
\hline $\begin{array}{l}\text { Toolpath[3D } \\
\text { Pencil] }\end{array}$ & -0.28914 & -2.1426 & -0.11804 & -2.1426 & 0.0694 \\
\hline
\end{tabular}


Table D.13: Correlations of Estimates

\begin{tabular}{|c|c|c|c|c|c|c|c|}
\hline Intercept & 1.0000 & 0.0000 & 0.0000 & 0.0000 & 0.0000 & 0.0000 & 0.0000 \\
\hline Toolpath[2D & 0.0000 & 1.0000 & -0.1667 & -0.1667 & -0.1667 & -0.1667 & -0.1667 \\
\hline Adaptive] & & & & & & & \\
\hline Toolpath[2D & 0.0000 & -0.1667 & 1.0000 & -0.1667 & -0.1667 & -0.1667 & -0.1667 \\
\hline Contour] & & & & & & & \\
\hline $\begin{array}{l}\text { Toolpath[2D } \\
\text { Pocket] }\end{array}$ & 0.0000 & -0.1667 & -0.1667 & 1.0000 & -0.1667 & -0.1667 & -0.1667 \\
\hline $\begin{array}{l}\text { Toolpath[3D } \\
\text { Adaptive] }\end{array}$ & 0.0000 & -0.1667 & -0.1667 & -0.1667 & 1.0000 & -0.1667 & -0.1667 \\
\hline $\begin{array}{l}\text { Toolpath[3D } \\
\text { Contour] }\end{array}$ & 0.0000 & -0.1667 & -0.1667 & -0.1667 & -0.1667 & 1.0000 & -0.1667 \\
\hline $\begin{array}{l}\text { Toolpath[3D } \\
\text { Pencil] }\end{array}$ & 0.0000 & -0.1667 & -0.1667 & -0.1667 & -0.1667 & -0.1667 & 1.0000 \\
\hline
\end{tabular}

Table D.14: Transformation to make uncorrelated

\begin{tabular}{|c|c|c|c|c|c|c|c|}
\hline Intercept & 18.1508 & 0 & 0 & 0 & 0 & 0 & 0 \\
\hline Toolpath[2D & 0 & 9.70199 & 4.85099 & 4.85099 & 4.85099 & 4.85099 & 4.85099 \\
\hline Adaptive] & & & & & & & \\
\hline $\begin{array}{l}\text { Toolpath[2D } \\
\text { Contour] }\end{array}$ & 0 & 0 & 8.40217 & 2.80072 & 2.80072 & 2.80072 & 2.80072 \\
\hline $\begin{array}{l}\text { Toolpath[2D } \\
\text { Pocket] }\end{array}$ & 0 & 0 & 0 & 7.92164 & 1.98041 & 1.98041 & 1.98041 \\
\hline $\begin{array}{l}\text { Toolpath[3D } \\
\text { Adaptive] }\end{array}$ & 0 & 0 & 0 & 0 & 7.67009 & 1.53402 & 1.53402 \\
\hline $\begin{array}{l}\text { Toolpath[3D } \\
\text { Contour] }\end{array}$ & 0 & 0 & 0 & 0 & 0 & 7.51513 & 1.25252 \\
\hline $\begin{array}{l}\text { Toolpath[3D } \\
\text { Pencil] }\end{array}$ & 0 & 0 & 0 & 0 & 0 & 0 & 7.41002 \\
\hline
\end{tabular}


Figure D.12: Normal Plot

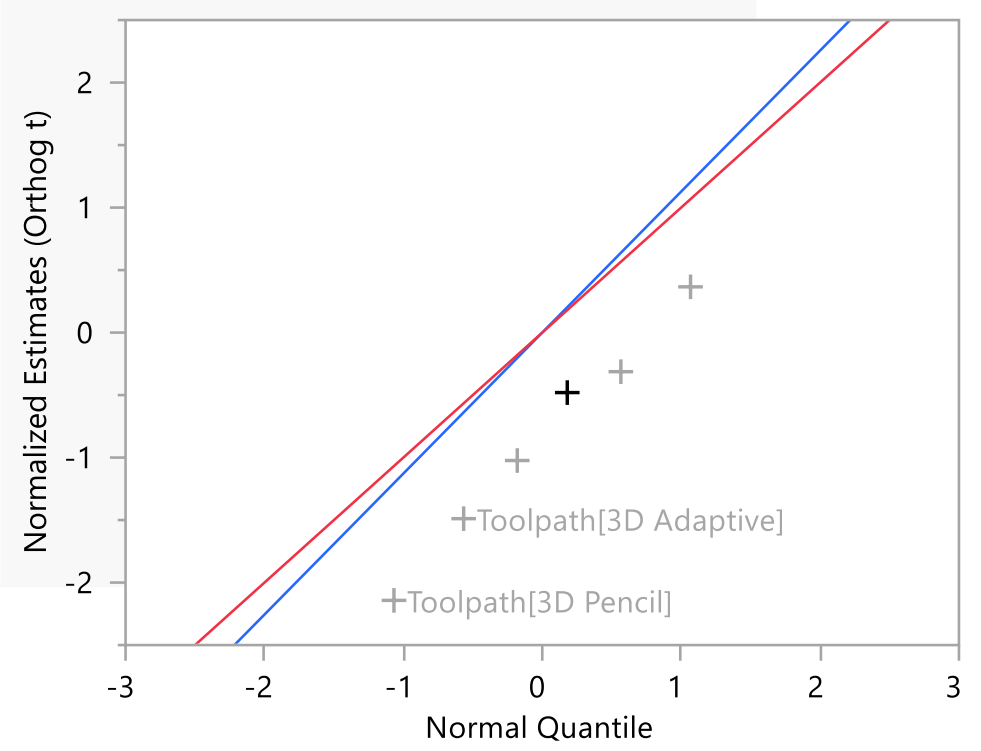

Figure D.13: Prediction Profiler
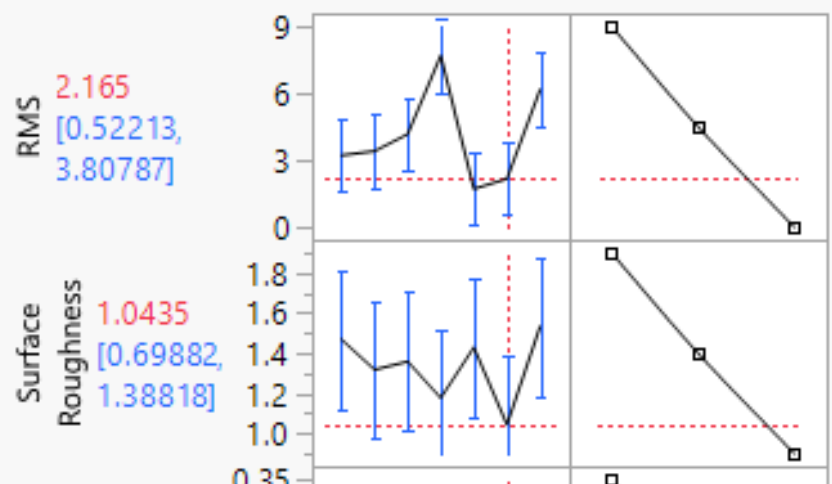

蒙 $\begin{aligned} & 0.01 \\ & {[0.01} \\ & 0.011\end{aligned}$
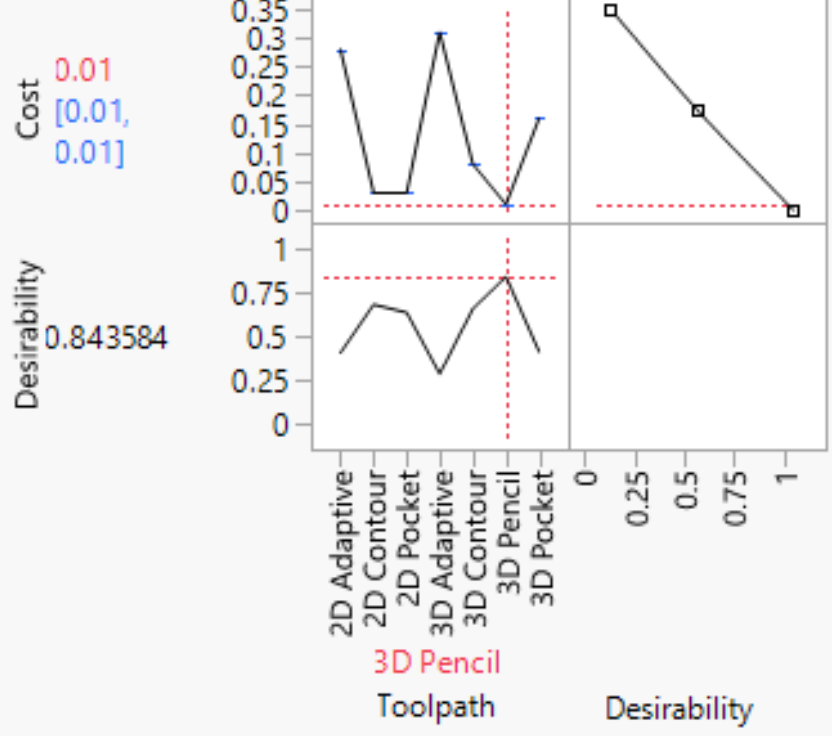


\section{Appendix E: Factor Level Determination JMP Output}

Table E.1: Effect Summary

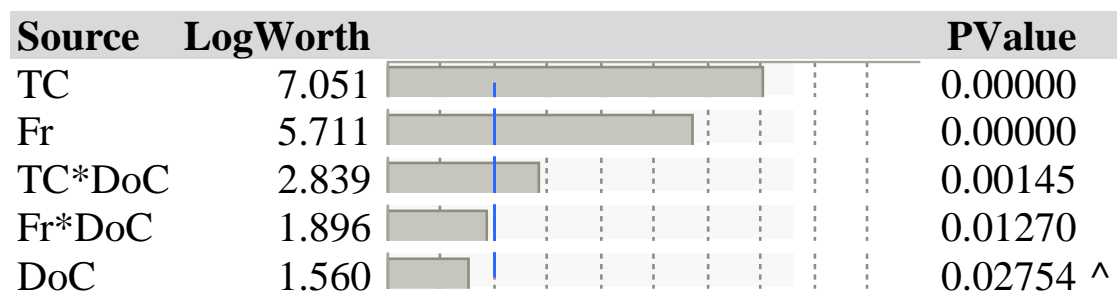

Table E.2: Singularity Details

\section{Term Details}

Intercept $=\operatorname{Fr}[0.03]+\operatorname{Fr}[0.15]-3 * \operatorname{Fr}[0.5]+\operatorname{DoC}[0.05]+\operatorname{DoC}[0.075]-\operatorname{Fr}[0.03] * \operatorname{DoC}[0.05]-$ $\operatorname{Fr}[0.03] * \operatorname{DoC}[0.075]-\operatorname{Fr}[0.15] * \operatorname{DoC}[0.05]-\operatorname{Fr}[0.15] * \operatorname{DoC}[0.075]+$ $3 * \operatorname{Fr}[0.5] * \operatorname{DoC}[0.05]+3 * \operatorname{Fr}[0.5] * \operatorname{DoC}[0.075]$

\section{Response Surface Roughness}

Figure E.1: Actual by Predicted Plot

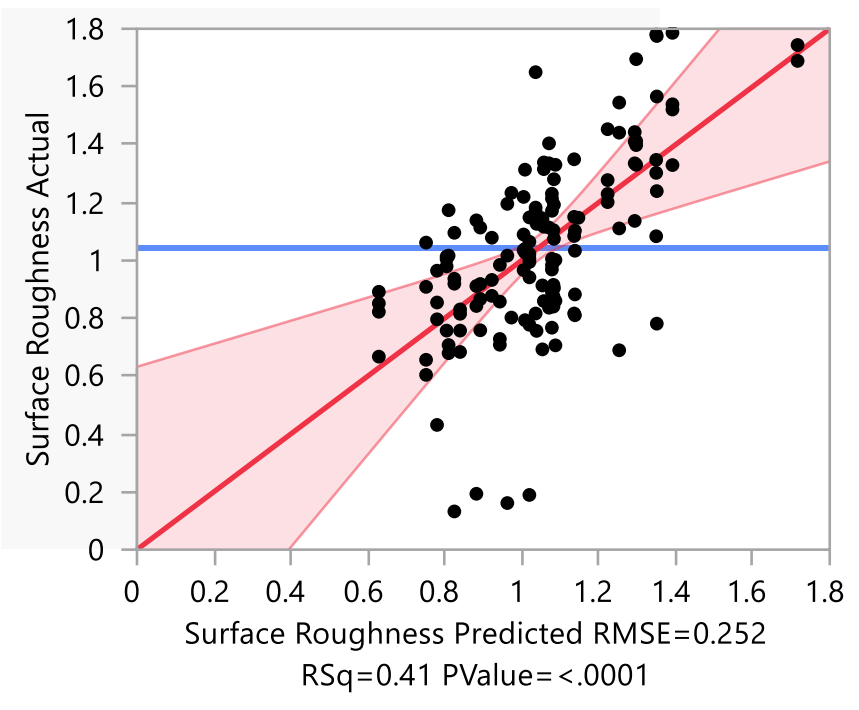

Table E.3: Lack Of Fit

\begin{tabular}{lrrrr|} 
Source & DF & Sum of Squares & Mean Square & F Ratio \\
\hline Lack Of Fit & 18 & 1.4687683 & 0.081598 & 1.3503 \\
Pure Error & 106 & 6.4056039 & 0.060430 & Prob > F \\
Total Error & 124 & 7.8743722 & & 0.1728 \\
& & & & Max RSq \\
& & & & 0.5218
\end{tabular}


Figure E.2: Residual by Predicted Plot

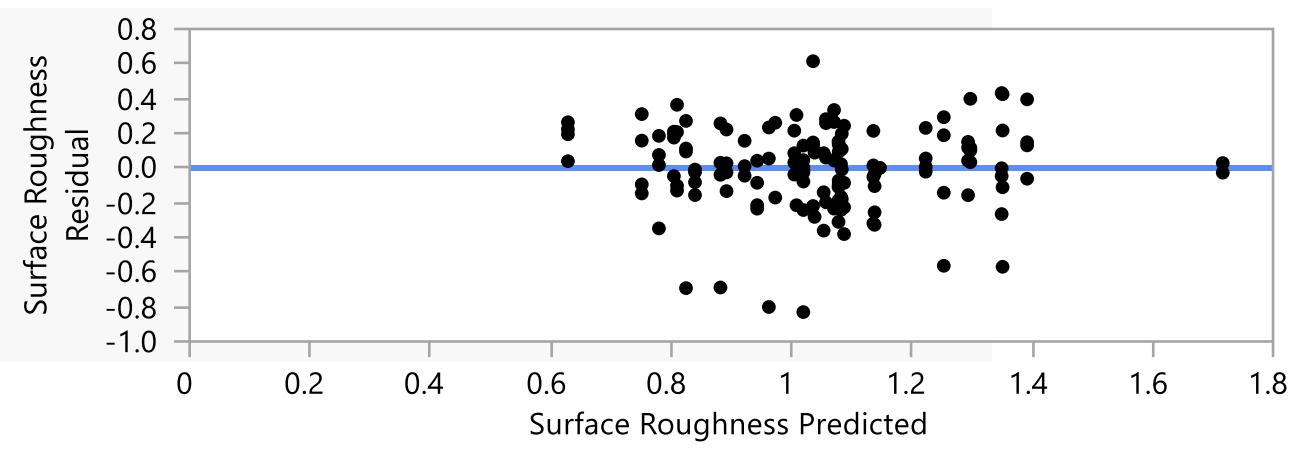

Figure E.3: Studentized Residuals

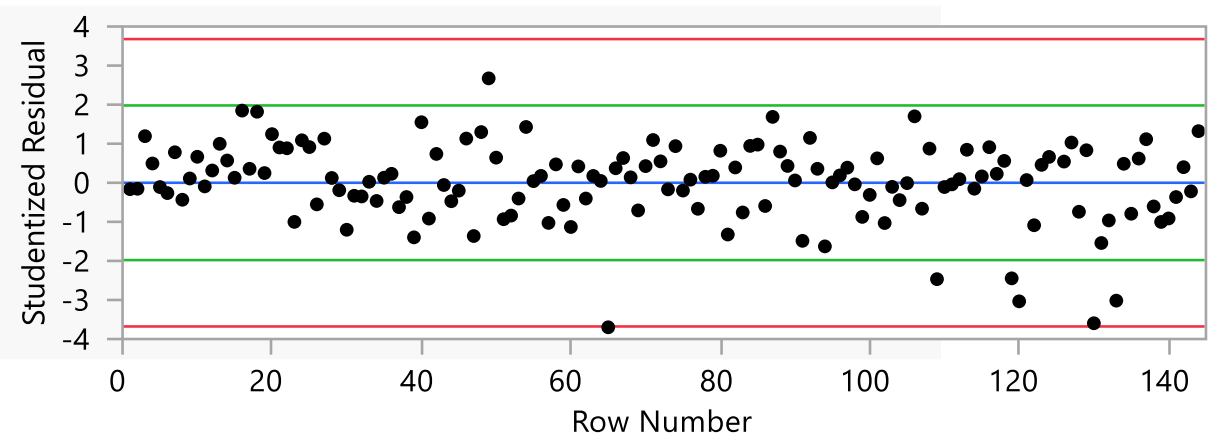

Table E.4: Summary of Fit

\begin{tabular}{|l|r|}
\hline RSquare & 0.412204 \\
\hline RSquare Adj & 0.322139 \\
\hline Root Mean Square Error & 0.251998 \\
\hline Mean of Response & 1.043833 \\
\hline Observations (or Sum Wgts) & 144 \\
\hline
\end{tabular}

Table E.5: Analysis of Variance

$\begin{array}{lrrrr}\text { Source } & \text { DF } & \text { Sum of Squares } & \text { Mean Square } & \text { F Ratio } \\ \text { Model } & 19 & 5.522072 & 0.290635 & 4.5767 \\ \text { Error } & 124 & 7.874372 & 0.063503 & \text { Prob > F } \\ \text { C. Total } & 143 & 13.396444 & & <.0001 *\end{array}$


Table E.6: Parameter Estimates

\begin{tabular}{|c|c|c|c|c|}
\hline Term & $\begin{array}{r}\text { Scaled } \\
\text { Estimate }\end{array}$ & $\operatorname{Prob}>|t|$ & $\begin{array}{r}\text { Lower } \\
95 \%\end{array}$ & $\begin{array}{r}\text { Upper } \\
95 \%\end{array}$ \\
\hline Intercept & $1.2124759 \square: \begin{array}{l:l} & \end{array}$ & $<.0001 *$ & 1.1120994 & 1.312852 \\
\hline $\operatorname{Fr}[0.03]$ & -0.310663 & $<.0001 *$ & -0.423211 & -0.19811 \\
\hline $\operatorname{Fr}[0.15]$ & -0.09108 & 0.1118 & -0.203627 & 0.021467 \\
\hline $\operatorname{Fr}[0.5]$ & 0.5407569 & $0.0003 *$ & 0.2505482 & 0.830965 \\
\hline $\operatorname{Fr}[0.1]$ & $\begin{array}{l}-0.139013 \mid \\
\end{array}$ & $0.0189 *$ & -0.254685 & -0.02334 \\
\hline TC[Diamond] & -0.077246 & $0.0431 *$ & -0.15204 & -0.00245 \\
\hline $\mathrm{TC}[\mathrm{TiCN}]$ & $-0.020946 \mid: \vdots$ & 0.5675 & -0.093254 & 0.051362 \\
\hline $\mathrm{TC}[\mathrm{DLC}]$ & 0.2249986 & $<.0001 *$ & 0.15269 & 0.297307 \\
\hline TC[TiN and TiAlN] & -0.126807 & $0.0007 *$ & -0.199116 & $-0.0544 \mathrm{C}-\mathrm{s}$ \\
\hline $\mathrm{DoC}[0.05]$ & -0.161809|: & 0.0532 & -0.325881 & 0.002262 \\
\hline $\mathrm{DoC}[0.075]$ & 0.0368783 & 259 & -0.023096 & 0.096852 \\
\hline DoC $[0.15]$ & 0.124931 & 0.1555 & -0.04809 & 0.297951 \\
\hline $\operatorname{Fr}[0.03] * \operatorname{DoC}[0.05]$ & 0.0955592 & 0.2996 & -0.086007 & 0.277125 \\
\hline ]*DoC[0.075] & 0.0778092 & 691 & -0.006168 & 0.161786 \\
\hline $\operatorname{Fr}[\mathrm{C}$ & -0.173368 & 528 & -0.356102 & 0.00936 \\
\hline $\operatorname{Fr}[0.15] * \operatorname{DoC}[0.05]$ & 0.1294134 & 0.1608 & -0.052153 & 0.310979 \\
\hline $\operatorname{Fr}[0.15] * \operatorname{DoC}[0.075]$ & -0.014024 & 0.7416 & -0.098001 & 0.069952 \\
\hline $\operatorname{Fr}[0.15] * \operatorname{DoC}[0.15]$ & $\begin{array}{ll:l:}-0.115389 & & \square\end{array}$ & 137 & -0.298122 & 0.067343 \\
\hline .05$]$ & |-0.360026 & 0.1457 & -0.846781 & 0.126727 \\
\hline $\mathrm{oC}[0.075]$ & ! & 1.0000 & 0 & \\
\hline $\operatorname{Fr}[0.5] * \operatorname{DoC}[0.15]$ & 0.3600263 & 0.1457 & -0.126728 & 0.846780 \\
\hline $\operatorname{Fr}[0.1] * \operatorname{DoC}[0.05]$ & 0.1350536 & 0.1514 & -0.050139 & 0.320246 \\
\hline $\operatorname{Fr}[($ & $-0.063785 \mid$ & 68 & -0.150256 & 0.022685 \\
\hline $\operatorname{Fr}[0.1] * \operatorname{DoC}[0.15]$ & -0.071268 & 0.4403 & -0.253476 & 0.110938 \\
\hline TC[Diamond]*DoC[0.05 & -0.007151 & 0.8936 & -0.112732 & 0.098428 \\
\hline TC[Diamond]*DoC[0.075] & 0.0036348 & 0.9469 & -0.104258 & 0.111527 \\
\hline TC[Diams & 0.0035167 & 467 & -0.100296 & 0.107329 \\
\hline TC[TiC & 0.0100227 & 0.8465 & -0.092215 & 0.112260 \\
\hline $\mathrm{TC}[\mathrm{TiCN}] * \operatorname{DoC}[0.075]$ & 0.0126773 & 0.8070 & -0.089828 & 0.115182 \\
\hline $\mathrm{TC}[\mathrm{TiCN}] * \operatorname{DoC}[0.15]$ & -0.0227 & 0.6605 & -0.124736 & 0.079336 \\
\hline $\mathrm{TC}[\mathrm{DLC}] * \operatorname{DoC}[0.05]$ & $0.0774116: \mid$ & 0.1365 & -0.024826 & $0.17964 \mathrm{C}$ \\
\hline $\mathrm{TC}[\mathrm{DLC}] * \mathrm{DoC}[0.075]$ & -0.0186 & 0.7201 & -0.121106 & 0.083904 \\
\hline $\mathrm{TC}[\mathrm{DLC}] * \operatorname{DoC}[0.15]$ & 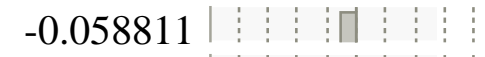 & 0.2561 & -0.160847 & 0.04322 \\
\hline $\begin{array}{l}\text { TC[TiN and } \\
\text { TiAlN] }{ }^{*} \text { DoC }[0.05]\end{array}$ & $\begin{array}{ll:l:l} & -0.080283 \\
\end{array}$ & 0.1227 & -0.18252 & 0.02195 \\
\hline $\begin{array}{l}\text { TC }[\mathrm{TiN} \text { and } \\
\text { TiAlN] } * \text { DoC }[0.0\end{array}$ & 288 & 9648 & -0.100217 & 0.10 \\
\hline $\begin{array}{l}\text { TC[TiN and } \\
\text { TiAlN] }{ }^{*} \text { DoC }[0.15]\end{array}$ & 0.0779944 & 0.1328 & -0.024042 & 0.180030 \\
\hline
\end{tabular}


Table E.7: Effect Tests

\begin{tabular}{lcccccc} 
Source & \multicolumn{1}{c}{ Nparm DF Sum of Squares F Ratio Prob $>$ F } & \\
Fr & 3 & 2 & 1.2734975 & 10.0271 & $<.0001^{*}$ & LostDFs \\
TC & 3 & 3 & 2.6109013 & 13.7049 & $<.0001^{*}$ & \\
DoC & 2 & 1 & 0.3158138 & 4.9732 & $0.0275^{*}$ & LostDFs \\
Fr*DoC & 6 & 5 & 0.3815797 & 1.2018 & 0.3123 & LostDFs \\
TC*DoC & 6 & 6 & 0.2781252 & 0.7300 & 0.6263 &
\end{tabular}

Figure E.4: Residual by Row Plot

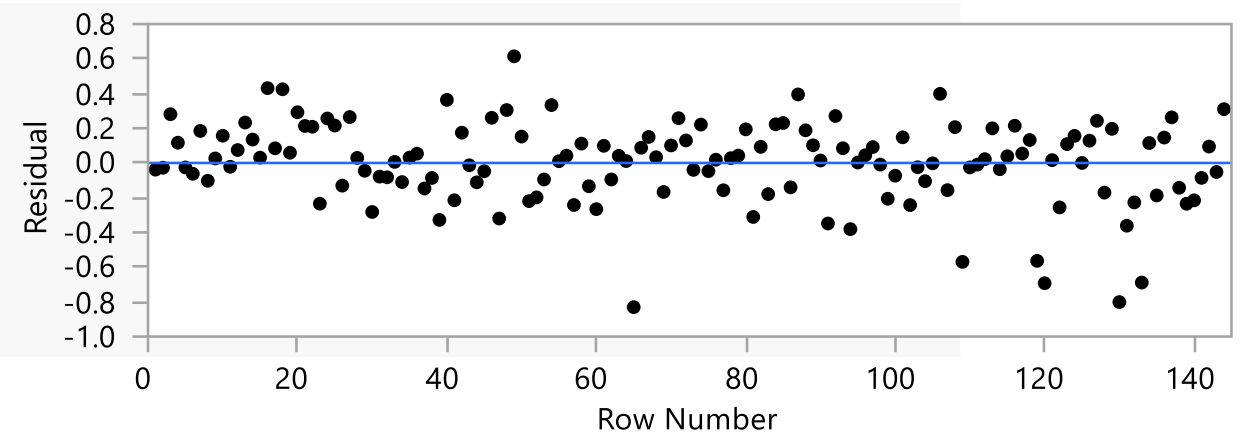

Figure E.5: Residual Normal Quantile Plot

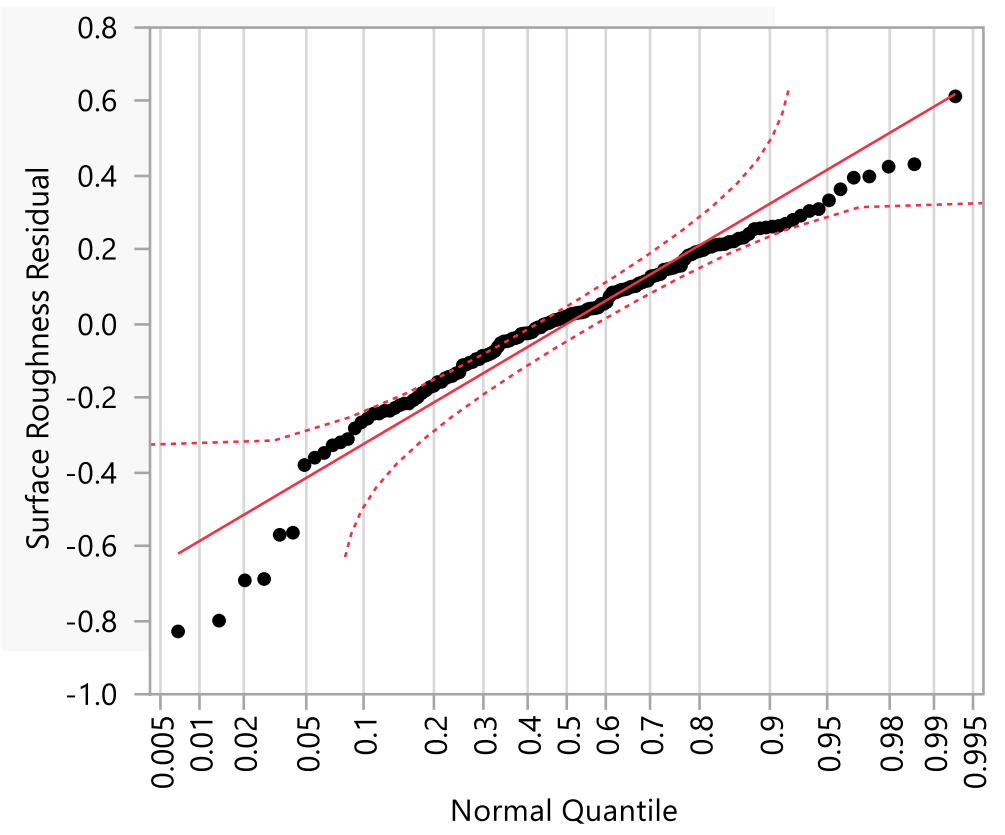


Figure E.6: Normal Plot

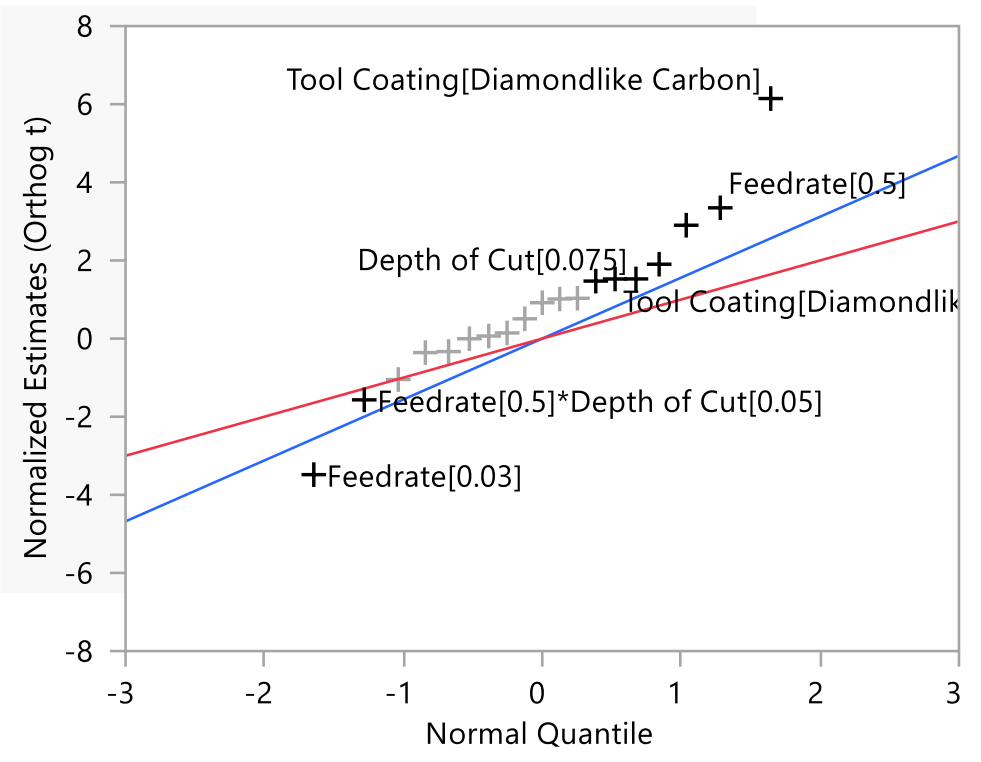




\section{Response RMS}

Figure E.7: Actual by Predicted Plot

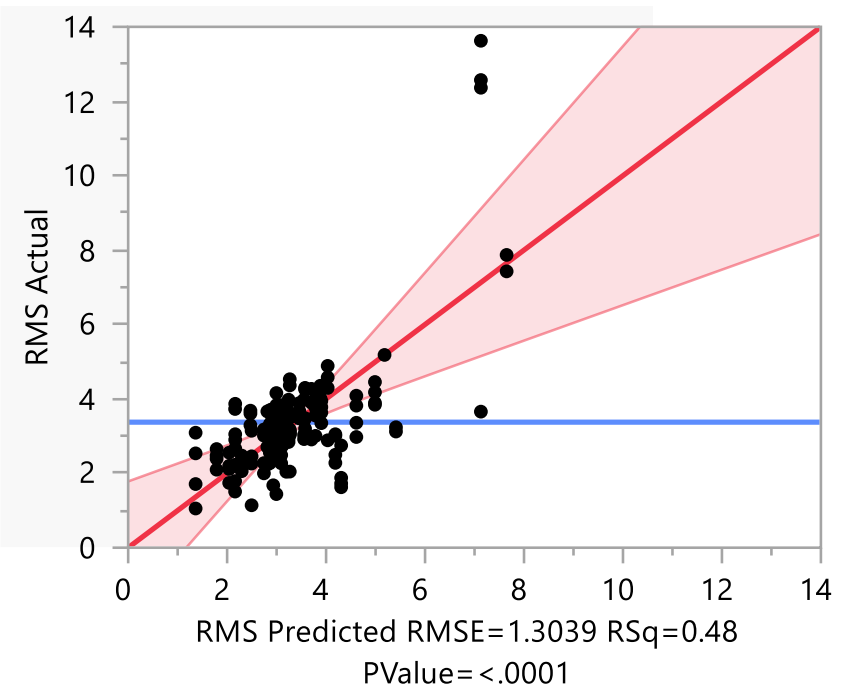

Table E.8: Lack Of Fit

\section{Source DF Sum of Squares Mean Square F Ratio

$\begin{array}{lllll}\text { Lack Of Fit } 18 & 107.39336 & 5.96630 & 6.1151\end{array}$ \\ Pure Error $106 \quad 103.42082 \quad 0.97567$ Prob > F \\ Total Error $124 \quad 210.81419<.0001 *$ \\ Max RSq \\ 0.7460}

Figure E.8: Residual by Predicted Plot

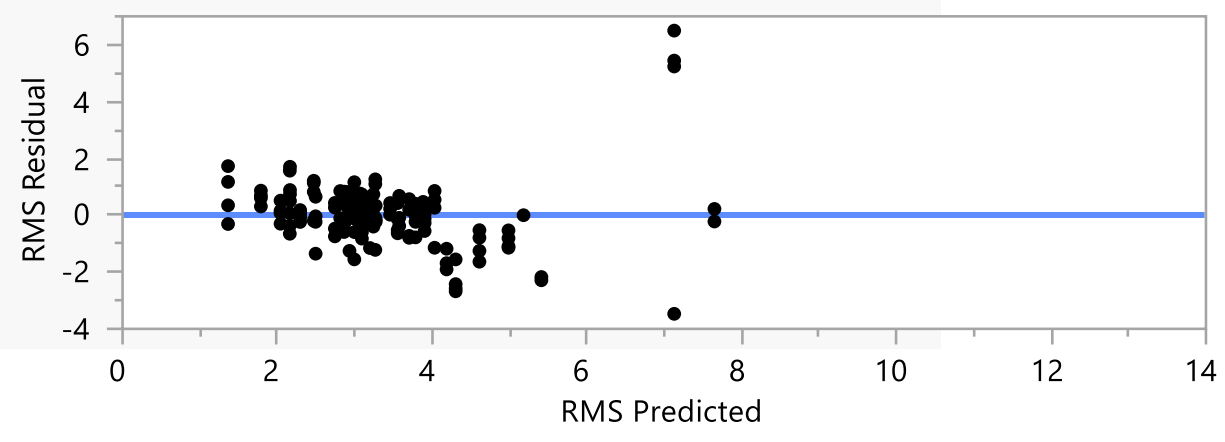




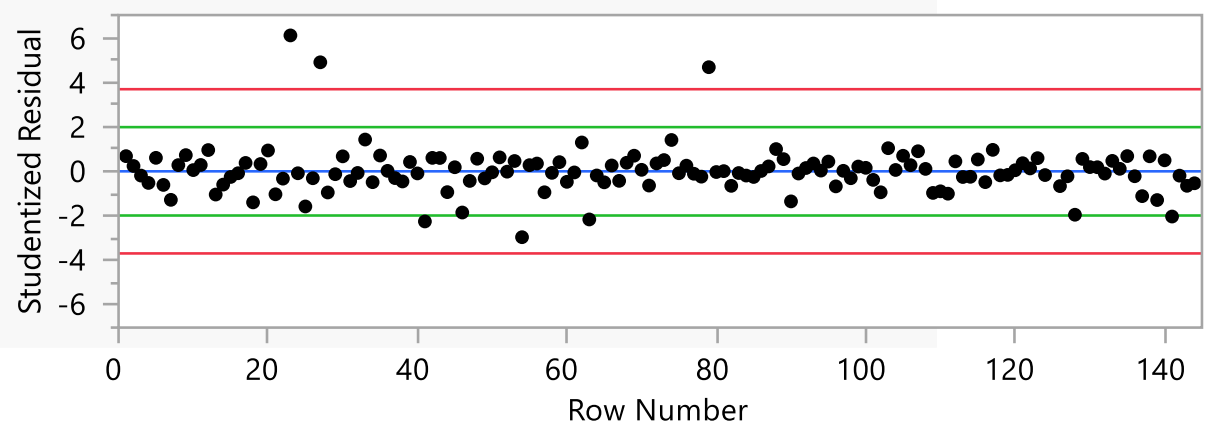

Table E.9: Summary of Fit

\begin{tabular}{|l|r|}
\hline RSquare & 0.482268 \\
\hline RSquare Adj & 0.402938 \\
\hline Root Mean Square Error & 1.303884 \\
\hline Mean of Response & 3.374174 \\
\hline Observations (or Sum Wgts) & 144 \\
\hline
\end{tabular}

Table E.10: Analysis of Variance

$\begin{array}{lrrrr}\text { Source } & \text { DF Sum of Squares } & \text { Mean Square } & \text { F Ratio } \\ \text { Model } & 19 & 196.37334 & 10.3354 & 6.0793 \\ \text { Error } & 124 & 210.81419 & 1.7001 & \text { Prob > F } \\ \text { C. Total } & 143 & 407.18753 & & <.0001^{*}\end{array}$


Table E.11: Parameter Estimates

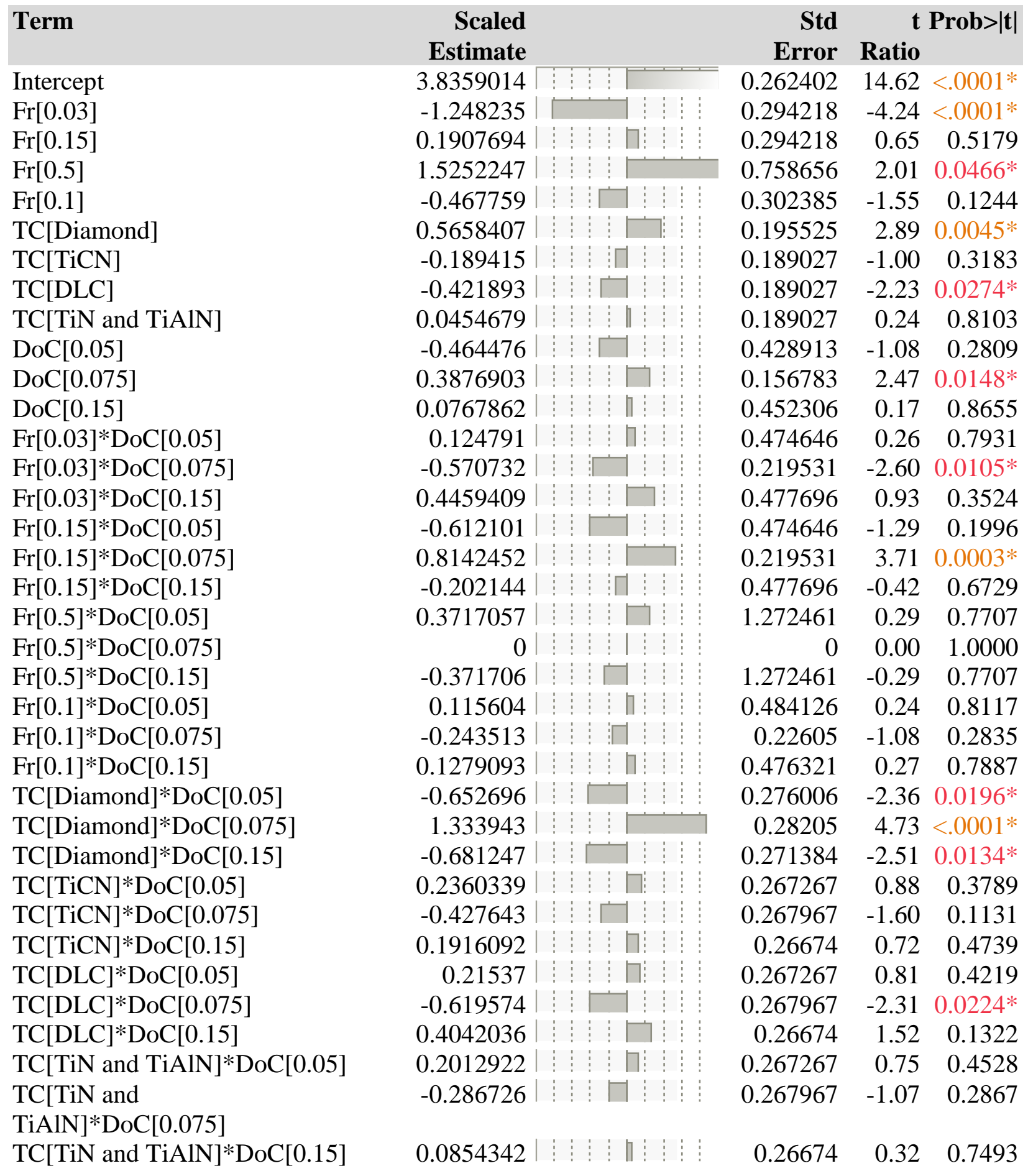




$\begin{array}{lrrrrrr}\text { Source } & \text { Nparm DF Sum of Squares F Ratio Prob }>\text { F } & \\ \text { Fr } & 3 & 2 & 49.810581 & 14.6492 & <.0001^{*} & \text { LostDFs } \\ \text { TC } & 3 & 3 & 18.170111 & 3.5625 & 0.0162^{*} & \\ \text { DoC } & 2 & 1 & 5.809504 & 3.4171 & 0.0669 & \text { LostDFs } \\ \text { Fr*DoC } & 6 & 5 & 25.833172 & 3.0390 & 0.0127 * & \text { LostDFs } \\ \text { TC*DoC } & 6 & 6 & 39.376198 & 3.8602 & 0.0014 * & \end{array}$

Figure E.10: Residual by Row Plot

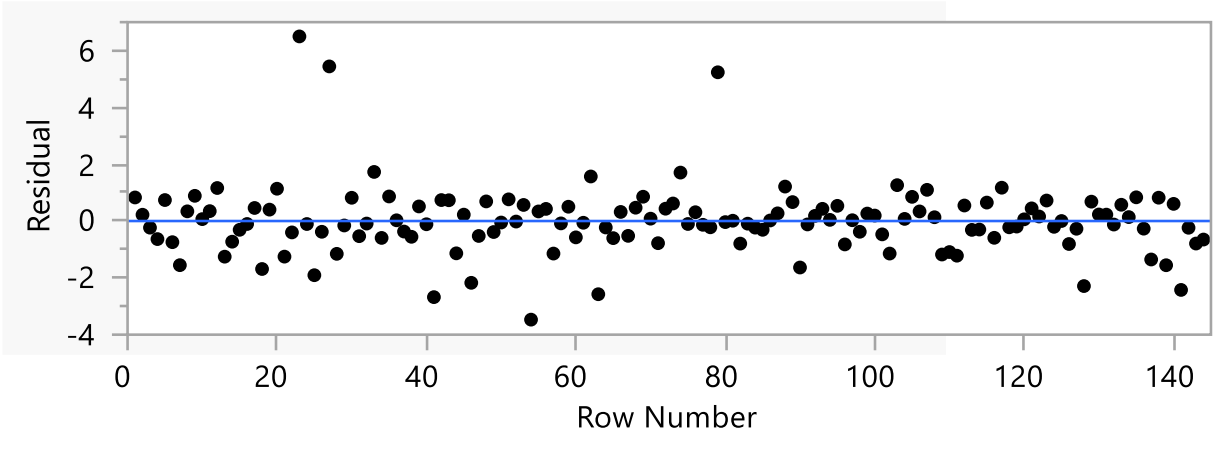

Figure E.11: Residual Normal Quantile Plot

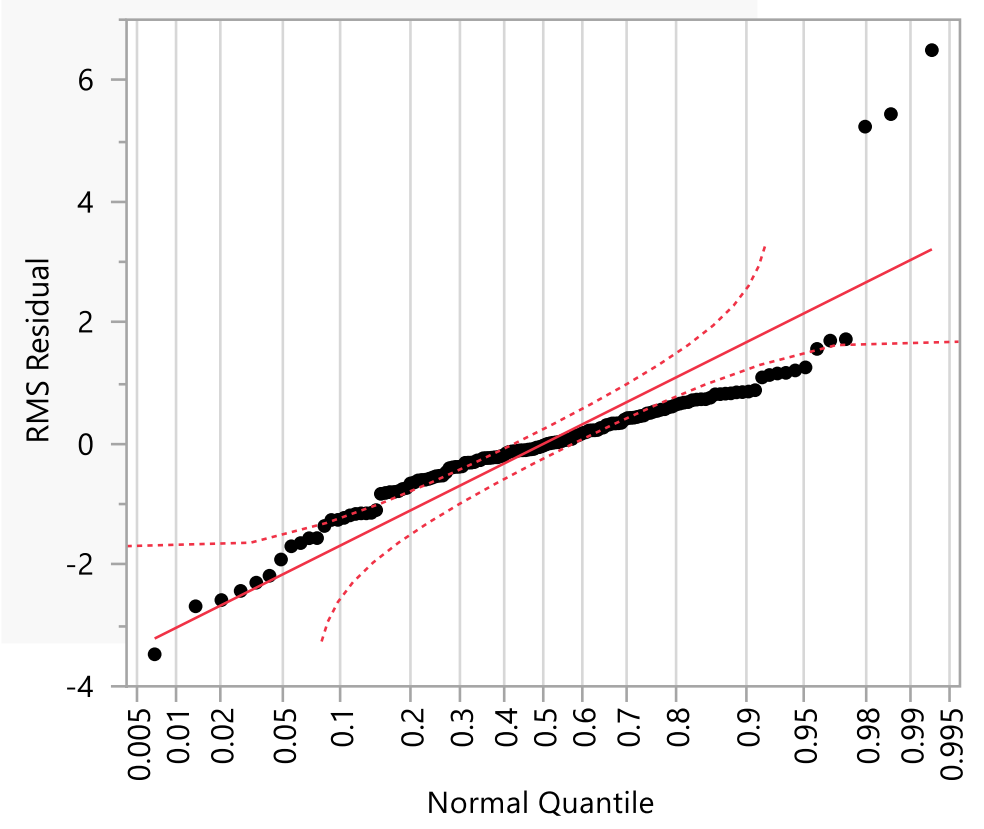


Figure E.12: Normal Plot

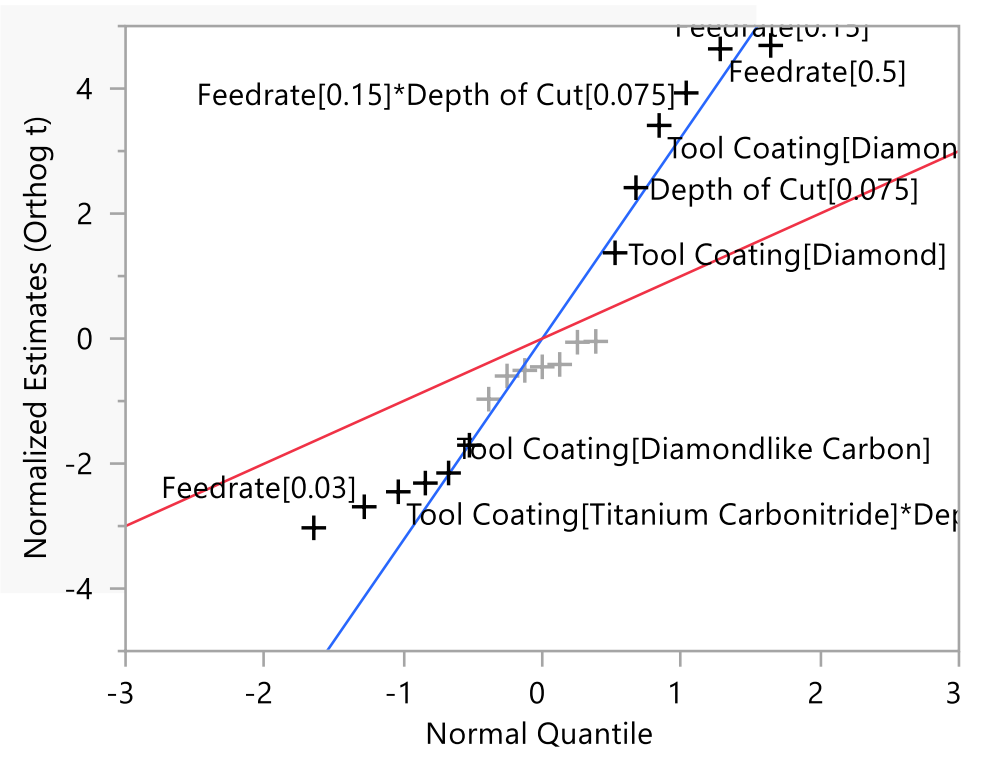


Figure E.13: Prediction Profiler

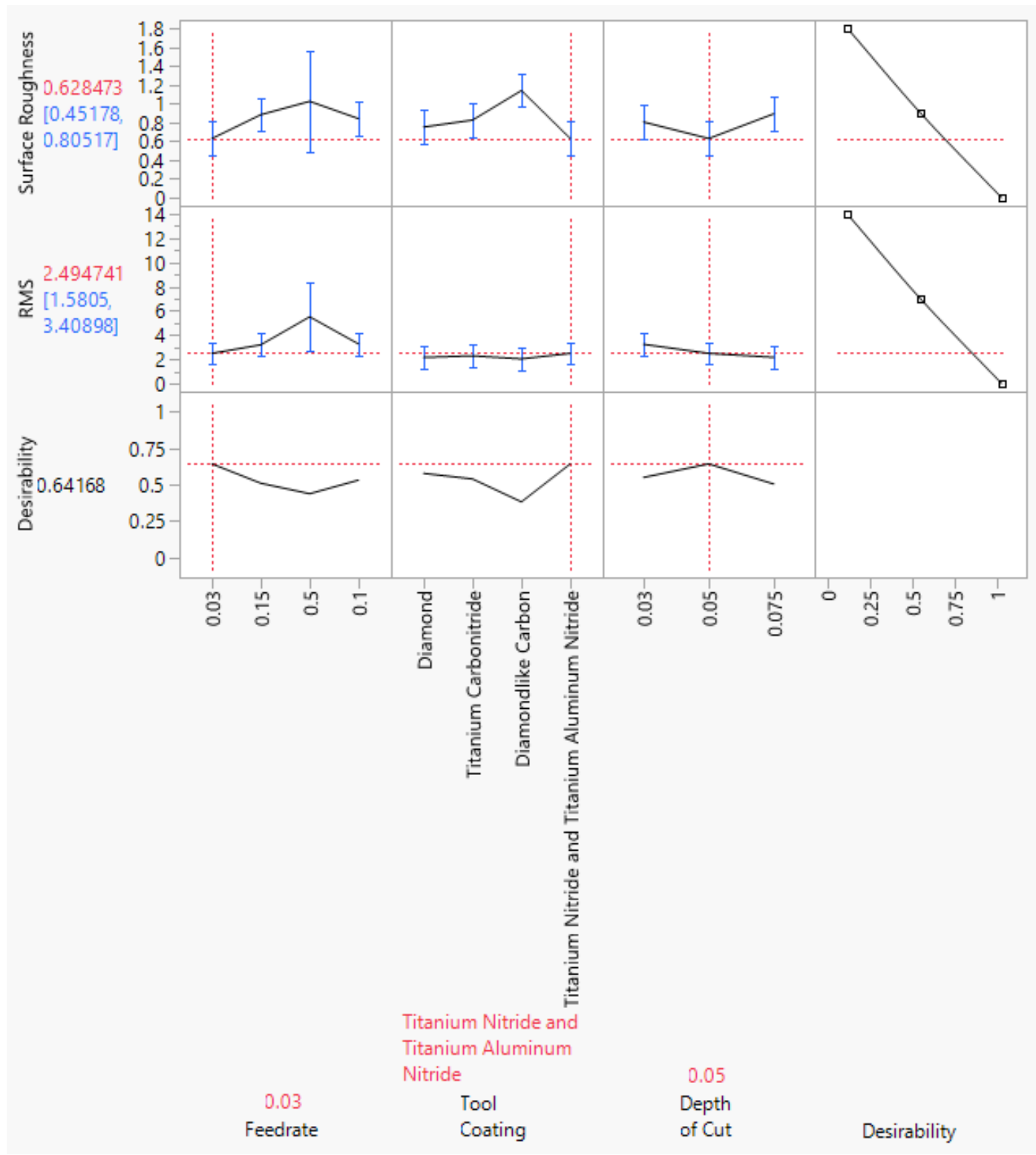


Figure E.14: Prediction Profiler when Cost is included

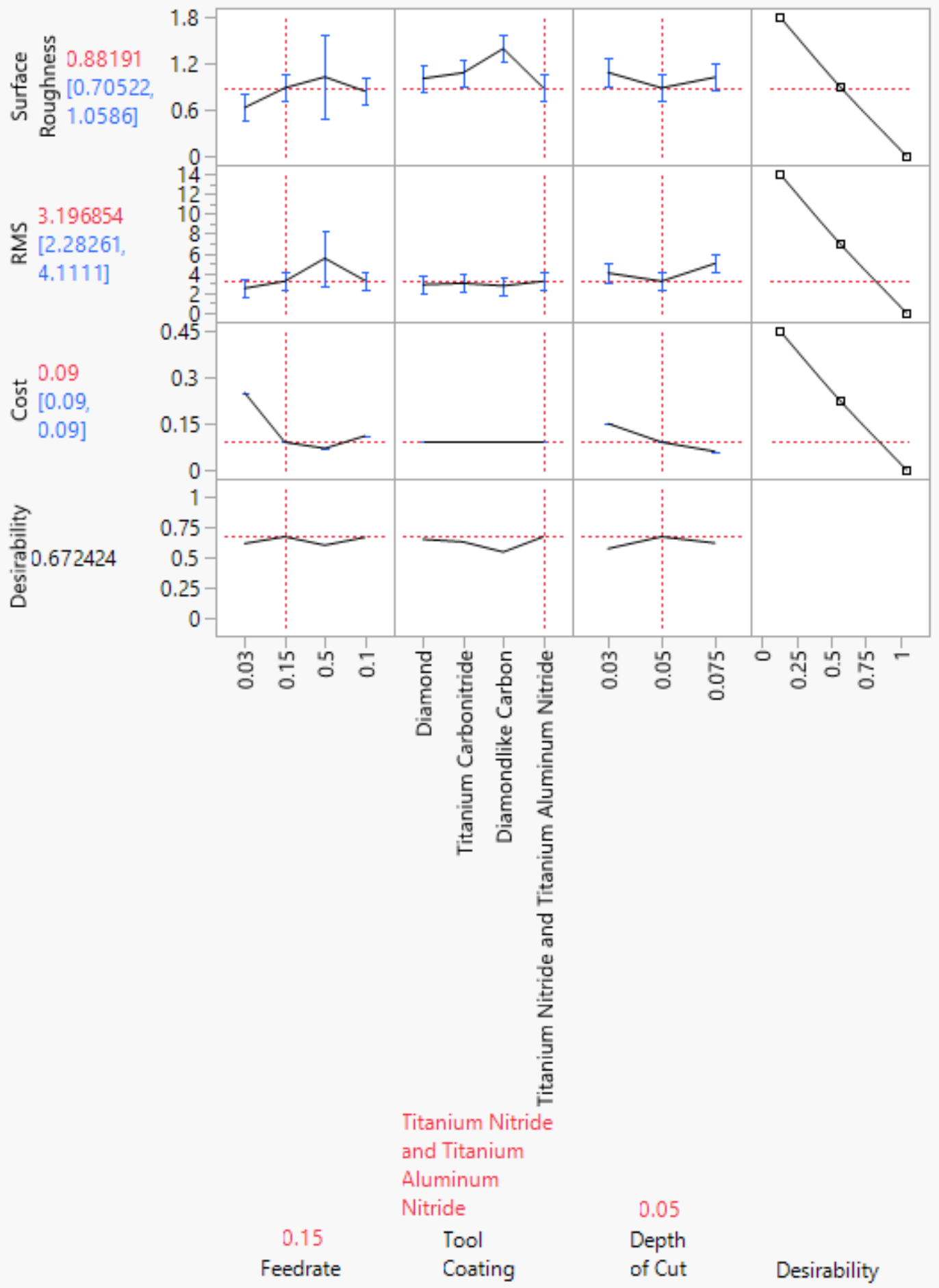

